\title{
Cellulose-Based Bio- and Nanocomposites: A Review
}

\author{
Susheel Kalia, ${ }^{1}$ Alain Dufresne, ${ }^{2}$ Bibin Mathew Cherian, ${ }^{3}$ B. S. Kaith, ${ }^{4}$ Luc Averous, ${ }^{5}$ \\ James Njuguna, ${ }^{6}$ and Elias Nassiopoulos ${ }^{6}$
}

${ }^{1}$ Department of Chemistry, Shoolini University of Biotechnology and Management Sciences, Bajhol-173 229, District Solan (Himachal Pradesh), India

${ }^{2}$ Grenoble Institute of Technology, The International School of Paper, Print Media and Biomaterials (Pagora), Grenoble Institute of Technology, BP 65-38402 Saint Martin d'Hères, Grenolde, France

${ }^{3}$ Department of Natural Resources, Sao Paulo State University (UNESP), Botucatu 18610-307, SP, Brazil

${ }^{4}$ Department of Chemistry, Dr. B.R. Ambedkar National Institute of Technology, Punjab, Jalandhar 144011, India

${ }^{5}$ LIPHT-ECPM, EAC (CNRS) 4375, University of Strasbourg, 25 rue Becquerel, 67087 Strasbourg Cedex 2, France

${ }^{6}$ School of Applied Sciences, Cranfield University, Bedfordshire MK43 OAL, UK

Correspondence should be addressed to Susheel Kalia, susheel_kalia@yahoo.com

Received 16 June 2011; Accepted 1 August 2011

Academic Editor: Jose Ramon Leiza

Copyright (C) 2011 Susheel Kalia et al. This is an open access article distributed under the Creative Commons Attribution License, which permits unrestricted use, distribution, and reproduction in any medium, provided the original work is properly cited.

Cellulose macro- and nanofibers have gained increasing attention due to the high strength and stiffness, biodegradability and renewability, and their production and application in development of composites. Application of cellulose nanofibers for the development of composites is a relatively new research area. Cellulose macro- and nanofibers can be used as reinforcement in composite materials because of enhanced mechanical, thermal, and biodegradation properties of composites. Cellulose fibers are hydrophilic in nature, so it becomes necessary to increase their surface roughness for the development of composites with enhanced properties. In the present paper, we have reviewed the surface modification of cellulose fibers by various methods. Processing methods, properties, and various applications of nanocellulose and cellulosic composites are also discussed in this paper.

\section{Introduction}

Cellulose-fiber-reinforced polymer composites have received much attention because of their low density, nonabrasive, combustible, nontoxic, low cost, and biodegradable properties. A lot of research works have been performed all over the world on the use of cellulose fibers as a reinforcing material for the preparation of various types of composites. However, lack of good interfacial adhesion, low melting point, and water sensitivity make the use of cellulose-fiberreinforced composites less attractive. Pretreatments of the cellulose fibers can modify the fiber surface, such as chemical functionalization stop the moisture absorption process and increase the surface roughness [1].

The production of nanoscale cellulose fibers and their application in composite materials have gained increasing attention due to their high strength and stiffness combined with low weight, biodegradability, and renewability. Application of cellulose nanofibers in polymer reinforcement is a relatively new research field [2]. The main reason to utilize cellulose nanofibers in composite materials is because one can potentially exploit the high stiffness of the cellulose crystal for reinforcement. This can be done by breaking down the hierarchical structure of the plant into individualized nanofibers of high crystallinity, with a reduction of amorphous parts [3].

In this paper we describe various approaches to the synthesis of nanofibers from plant resources. Potential use of macro- and nanofibers as reinforcing material for the development of polymers composites with enhanced properties and application of these composites in various fields are also discussed.

\section{Cellulose Fibers}

Cellulose fibers are being used as potential reinforcing materials because of so many advantages such as abundantly available, low weight, biodegradable, cheaper, renewable, low abrasive nature, interesting specific properties, since these are waste biomass, and exhibit good mechanical properties 
[4-6]. Cellulose fibers also have some disadvantages such as moisture absorption, quality variations, low thermal stability, and poor compatibility with the hydrophobic polymer matrix $[7,8]$.

2.1. Chemistry of Cellulose. Cellulose is the most abundant form of living terrestrial biomass [9] and finds applications in many spheres of modern industry. Existence of cellulose as the common material of plant cell walls was first recognized by Anselm Payen in 1838 [10]. Cellulose has been shown to be a long-chain polymer with repeating units of $\mathrm{D}$ glucose, a simple sugar. It occurs in almost pure form in cotton fiber. However, in wood, plant leaves and stalks, it is found in combination with other materials, such as lignin and hemicelluloses. Although, generally considered a plant material, but some bacteria are also found to produce cellulose.

Cellulose is a natural polymer, a long chain made by the linking of smaller molecules. The links in the cellulose chain consist of sugar, $\beta$-D-glucose [11]. The sugar units are linked when water is eliminated by combining the $\mathrm{H}$ and $-\mathrm{OH}$ group. Linking just two of these sugars produces a disaccharide called cellobiose [12]. In the cellulose chain, the glucose units are in 6-membered rings, called pyranoses. They are joined by single oxygen atoms (acetal linkages) between the $\mathrm{C}-1$ of one pyranose ring and the C- 4 of the next ring. Since a molecule of water is lost due to the reaction of an alcohol and a hemiacetal to form an acetal, the glucose units in the cellulose polymer are referred to as anhydroglucose units.

The spatial arrangement or stereochemistries of these acetal linkages is very important. The pyranose rings of the cellulose molecule have all the groups larger than hydrogen sticking-out from the periphery of the rings (equitorial positions). The stereochemistry at carbons 2, 3, 4 and 5 of the glucose molecule are fixed, but in pyranose form, the hydroxyl at C-4 can approach the carbonyl at C-1 from either side, resulting in two different stereochemistry at $\mathrm{C}-1$. When the hydroxyl group at $\mathrm{C}-1$ is on the same side of the ring as the C- 6 carbon, it is said to be in the $\alpha$ configuration. In cellulose, the $\mathrm{C}-1$ oxygen is in the opposite or $\beta$ configuration (i.e., cellulose is poly $[\beta-1,4-\mathrm{D}$-anhydroglucopyranose $]$ ). This $\beta$ configuration, with all functional groups in equatorial positions, causes the molecular chain of cellulose to extend in a more or less straight line, making it a good fiber-forming polymer [13].

Because of the equatorial positions of the hydroxyls on the cellulose chain, they protrude laterally along the extended molecule and are readily available for hydrogen bonding. These hydrogen bonds cause the chains to group together in a highly ordered structure. Since the chains are usually longer than the crystalline regions, they are thought to pass through several different crystalline regions, with areas of disorder in between ("fringed-micelle" model) [14]. The interchain hydrogen bonds in the crystalline regions are strong, giving the resultant fiber good strength and insolubility in most solvents. They also prevent cellulose from melting (nonthermoplastic). In the less-ordered regions, the chains are further apart and more available for hydrogen bonding with other molecules, such as water. Most cellulose structures can absorb large quantities of water (hygroscopic). Thus, cellulose swells but does not dissolve in water [13].

The cellulose molecule contains three different kinds of anhydroglucose units, the reducing end with a free hemiacetal (or aldehyde) group at C-1, the nonreducing end with a free hydroxyl at C-4 and the internal rings joined at C1 and C-4. But because of long-chain length, the chemistry of the alcohol groups of the internal units predominates, so long as the chains are not cleaved by the reaction conditions. However, unlike simple alcohols, cellulose reactions are usually controlled by steric factors than would be expected on the basis of the inherent reactivity of the different hydroxyl groups. C-2, C-3, and C-6 hydroxyls and C-H groups are active sites in cellulose for the incorporation of polymeric chains through grafting. In grafting, it has been reported that the reactivity of hydroxyl group at C-6 is far less than those at C-2 and C-3 [13].

2.2. Chemical Composition, Structure, and Properties of Cellulose Fibers. Cellulose fibers can be classified according to their origin and grouped into leaf: abaca, cantala, curaua, date palm, henequen, pineapple, sisal, banana; seed: cotton; bast: flax, hemp, jute, ramie; fruit: coir, kapok, oil palm; grass: alfa, bagasse, bamboo; stalk: straw (cereal). The bast and leaf (the hard fibers) types are the most commonly used in composite applications $[15,16]$. Commonly used plant fibers are cotton, jute, hemp, flax, ramie, sisal, coir, henequen, and kapok. The largest producers of sisal in the world are Tanzania and Brazil. Henequen is produced in Mexico whereas abaca and hemp in Philippines. The largest producers of jute are India, China, and Bangladesh [1].

Plant fibers are constitutes of cellulose fibers, consisting of helically wound cellulose microfibrils, bound together by an amorphous lignin matrix. Lignin keeps the water in fibers, acts as a protection against biological attack and as a stiffener to give stem its resistance against gravity forces and wind. Hemicellulose found in the natural fibers is believed to be a compatibilizer between cellulose and lignin [1]. The cell wall in a fiber is not a homogenous membrane (Figure 1) [17]. Each fiber has a complex, layered structure consisting of a thin primary wall which is the first layer deposited during cell growth encircling a secondary wall. The secondary wall is made up of three layers and the thick middle layer determines the mechanical properties of the fiber. The middle layer consists of a series of helically wound cellular microfibrils formed from long-chain cellulose molecules. The angle between the fiber axis and the microfibrils is called the microfibrillar angle. The characteristic value of microfibrillar angle varies from one fiber to another. These microfibrils have typically a diameter of about 10-30 nm and are made up of 30-100 cellulose molecules in extended chain conformation and provide mechanical strength to the fiber.

The properties of cellulose fibers are affected by many factors such as variety, climate, harvest, maturity, retting degree, decortications, disintegration (mechanical, steam explosion treatment), fiber modification, textile, and technical processes (spinning and carding) [18]. In order to understand the properties of natural fiber-reinforced composite materials, it becomes necessary to know the mechanical, 


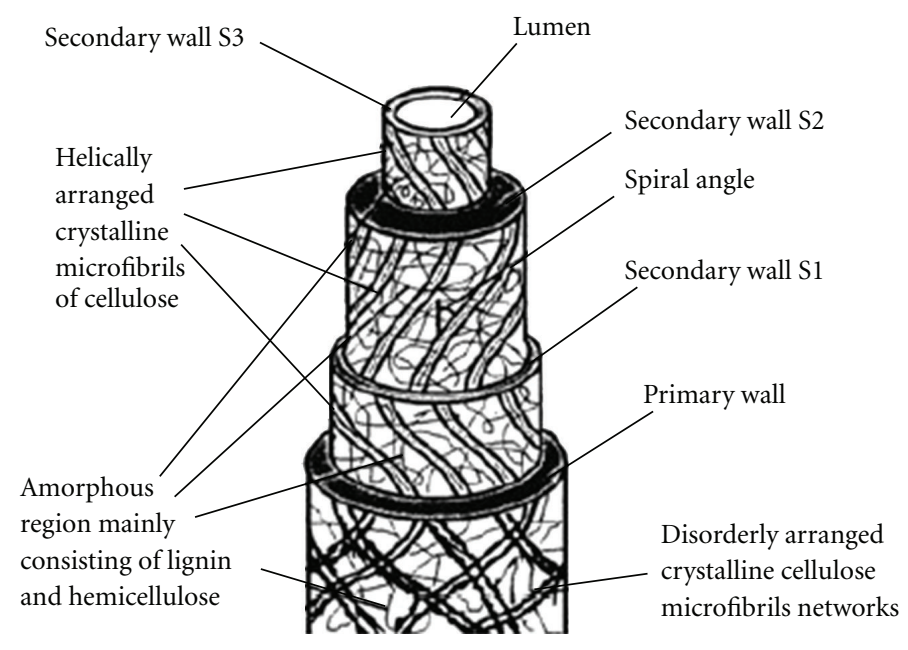

FIgURE 1: Structural constitution of natural fiber cell [17].

physical, and chemical properties of natural fibers. Flax fibers are relatively strong fibers as compared to other natural fibers. The tensile strength of elementary fibers is in the region of $1500 \mathrm{MPa}$ and for technical fibers a value of circa $800 \mathrm{MPa}$ was observed at $3 \mathrm{~mm}$ clamp length [19]. Baley [20] and Lamy and Baley [21] investigated the modulus of flax fibers. The modulus of elementary fibers is dependent on the diameter of fiber and it ranges from $39 \mathrm{GPa}$ for fibers having diameter approximately $35 \mu \mathrm{m}$ to $78 \mathrm{GPa}$ for fibers having $5 \mu \mathrm{m}$ diameter. This variation is related to the variation in relative lumen size between fibers having different diameter. An average Young's modulus of $54 \mathrm{GPa}$ was observed after numerous tensile tests on single flax fibers and the results are within the range of moduli measured on technical fibers. The mechanical, chemical, and physical properties of plant fibers are strongly harvest dependent, influenced by climate, location, weather conditions, and soil characteristics. These properties are also affected during the processing of fiber such as retting, scotching, bleaching, and spinning [22].

Cellulose fibers have relatively high strength, high stiffness, and low density [23]. The characteristic value for soft-wood-Kraft-fibers and flax has been found close to the value for E-glass fibers. Different mechanical properties can be incorporated in natural fibers during processing period. The fiber properties and structure are influenced by several conditions and varies with area of growth, its climate and age of the plant [24]. Technical digestion of the fiber is another important factor which determines the structure as well as characteristic value of fiber. The elastic modulus of the bulk natural fibers such as wood is about $10 \mathrm{GPa}$. Cellulose fibers with moduli up to $40 \mathrm{GPa}$ can be separated from wood by chemical-pulping process. Such fibers can be further subdivided into microfibrils within elastic modulus of $70 \mathrm{GPa}$. Theoretical calculations of elastic moduli of cellulose chain have been given values up to $250 \mathrm{GPa}$. However, no technology is available to separate these from microfibrils [25]. The tensile strength of natural fibers depends upon the test length of the specimen which is of main importance with respect to reinforcing efficiency.
Mieck et al. [26] and Mukherjee and Satyanarayana [27] reported that tensile strength of flax fiber is significantly more dependent on the length of the fiber. In comparison to this, the tensile strength of pineapple fiber is less dependent on the length, while the scatter of the measured values for both is located mainly in the range of the standard deviation. The properties of flax fiber are controlled by the molecular fine structure of the fiber which is affected by growing conditions and the fiber processing techniques used. Flax fibers possess moderately high-specific strength and stiffness.

Quality and other properties of fibers depend on factors such as size, maturity, and processing methods adopted for the extraction of fibers. Properties such as density, electrical resistivity, ultimate tensile strength, and initial modulus are related to the internal structure and chemical composition of fibers [23]. Desirable properties for fibers include excellent tensile strength and modulus, high durability, low bulk density, good moldability, and recyclability.

\section{Cellulose Nanofibers}

Cellulose nanofibers have a high potential to be used in many different area particularly as reinforcement in development of nanocomposites. Many studies have been done on isolation and characterization of cellulose nanofibers from various sources. Cellulose nanofibers can be extracted from the cell walls by simple mechanical methods or a combination of both chemical and mechanical methods.

3.1. Synthesis of Cellulose Nanofibers. Alemdar and Sain [28] have extracted cellulose nanofibers from wheat straw by a chemical treatment, resulting to purified cellulose. To individualize the nanofibers from the cell walls a mechanical treatment (cryocrushing, disintegration, and defibrillation steps) was applied to the chemically treated fibers. Cellulose nanofibers were extracted from the agricultural residues, wheat straw and soy hulls, by a chemomechanical technique [29]. The wheat straw nanofibers were determined to have diameters in the range of $10-80 \mathrm{~nm}$ and lengths of a few 


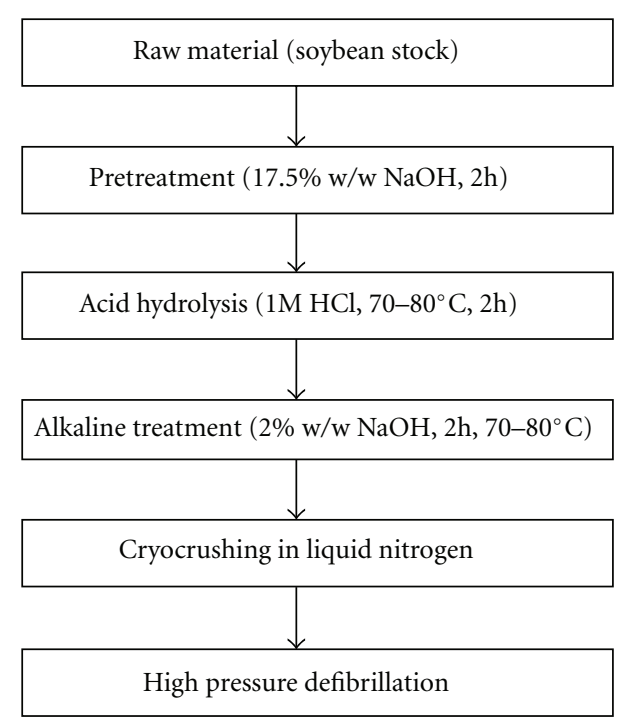

FIGURE 2: Isolation of nanofibers by chemomechanical treatment [31].

thousand nanometers. By comparison, the soy hull nanofibers had diameter $20-120 \mathrm{~nm}$ and shorter lengths than the wheat straw nanofibers. Zimmermann et al. [30] separated nanofibrillated cellulose (NFC) at the greatest possible lengths and diameters below $100 \mathrm{~nm}$ from different starting cellulose materials by mechanical dispersion and high pressure (up to 1500 bar) homogenization processes. The treatment resulted in nanoscaled fibril networks. Two commercial fibrous celluloses showed bigger cellulose aggregates with micrometer dimensions and a less homogeneous network structure.

The cellulose nanofibers were extracted by Wang and Sain [31] from soybean stock by chemomechanical treatments (Figure 2). These are bundles of cellulose nanofibers with a diameter ranging between 50 and $100 \mathrm{~nm}$ and lengths of thousands of nanometers.

The cellulose nanofibrils were extracted from wheat straw using steam explosion, acidic treatment, and high shear mechanical treatment. Alkaline-treated pulp was soaked in $8 \%$ solution of $\mathrm{H}_{2} \mathrm{O}_{2}(\mathrm{v} / \mathrm{v})$ overnight. Bleached pulp was then rinsed with abundant distilled water. Bleached pulp was then treated with $10 \% \mathrm{HCl}(1 \mathrm{~N})$ solution and mixed using ultrasonicator at temperature around $60 \pm 1^{\circ} \mathrm{C}$ for $5 \mathrm{~h}$. Finally, the fibers were taken out and washed several times with distilled water in order to neutralize the final $\mathrm{pH}$ and then dried. Fibers were suspended in water and continuously stirred with a high shear homogenizer for $15 \mathrm{~min}$. Highshearing action breaks down the fiber agglomerates and result in nanofibrils [32].

3.2. Structure and Properties of Cellulose Nanofibers. Transmission electron microscopy (TEM), scanning electron microscopy (SEM), field-emission scanning electron microscopy (FE-SEM), atomic force microscopy (AFM), wide-angle Xray scattering (WAXS), and NMR spectroscopy have been used to study the structure of cellulose nanofibers [33]. A combination of microscopic techniques with image analysis can provide information about widths of cellulose nanofiber but it is very difficult to find out the lengths of nanofiber because of entanglements and difficulties in identifying both ends of individual nanofibers. It is often reported that MFC suspensions are not homogeneous and that they consist of cellulose nanofibers and nanofiber bundles [2].

Teixeira et al. [34] obtained the suspensions of white and colored nanofibers by the acid hydrolysis of white and naturally colored cotton fibers. Possible differences among them in morphology and other characteristics were investigated. Morphological study of cotton nanofibers showed a length of $85-225 \mathrm{~nm}$ and diameter of $6-18 \mathrm{~nm}$. It was found that there were no significant morphological differences among the nanostructures from different cotton fibers. The main differences found were the slightly higher yield, sulfonation effectiveness, and thermal stability under dynamic temperature conditions of the white nanofiber. On the other hand, the colored nanofibers showed a better thermal stability than the white in isothermal conditions at $180^{\circ} \mathrm{C}$.

The structure of the cellulose nanofibers from agricultural residues was investigated by Alemdar and Sain [29]. FTIR spectroscopic analysis demonstrated that chemical treatment also led to partial removal of hemicelluloses and lignin from the structure of the fibers. PXRD results revealed that this resulted in improved crystallinity of the fibers. Thermal properties of the nanofibers were studied by the TGA technique and were found to increase dramatically.

Stelte and Sanadi [35] have studied the mechanical fibrillation process for the preparation of cellulose nanofibers from two commercial hard- and softwood cellulose pulps. The degree of fibrillation was studied using light microscopy (LM), scanning electron microscopy (SEM), and atomic force microscopy (AFM). LM and SEM images (Figure 3) of hard- and softwood fibers showed that the hardwood fibers that were fibrillated only on the surface during the refining step are now disintegrated into a network of small fibers. AFM images (Figure 4) of the final products after highpressure homogenization showed that the size distribution of the hard- and softwood nanofibers is in the range of 10$25 \mathrm{~nm}$ in diameter.

Wang and Sain [31] synthesized soybean stock-based nanofibers having a diameter in the range $50-100 \mathrm{~nm}$ by chemomechanical isolation. X-ray crystallography (Figure 5) was carried out to investigate the percentage crystallinity after various stages of the chemomechanical treatment. It has been found that crystallinity of the samples increased after each stage of nanofiber development.

Figure 6 shows the network of cellulose nanofibers. The nanofiber suspension obtained after the high pressure defibrillation was analyzed to determine diameters using AFM. The AFM image (Figure 6) shows the surface of airdried soybean stock nanofiber. It is seen that the fibers are indeed nanosized and the diameter of nanofibers is within the range $50-100 \mathrm{~nm}$.

\section{Surface Modification of Cellulose Fibers}

In order to develop composites with better mechanical properties and environmental performance, it becomes necessary 

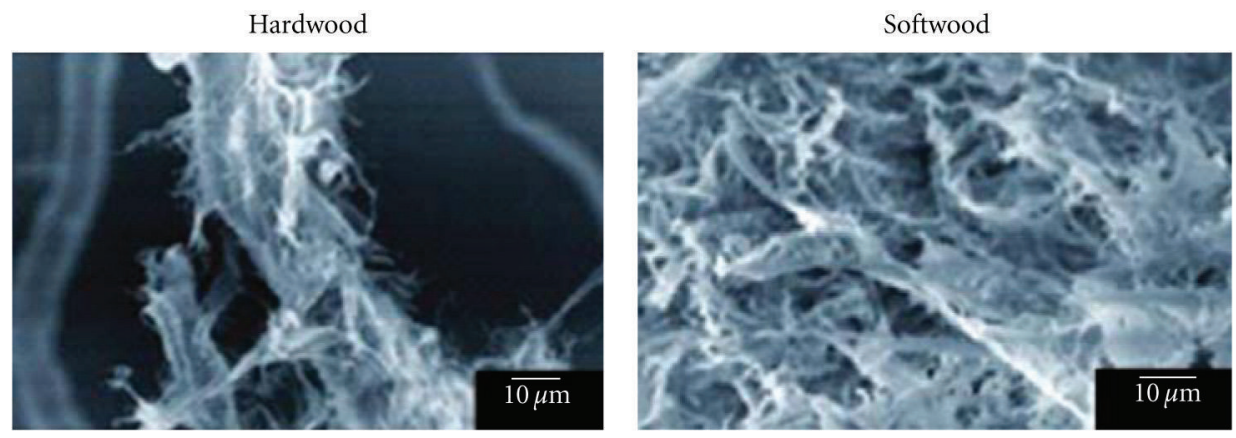

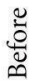
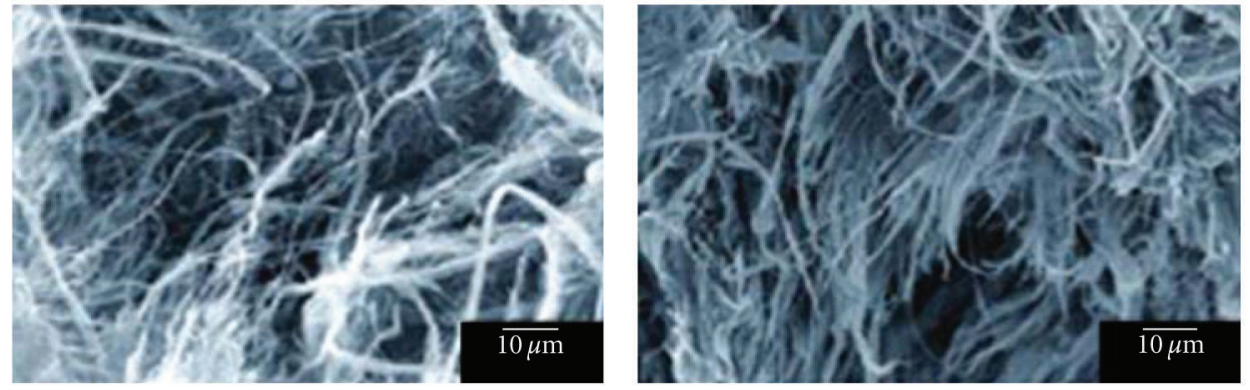

危

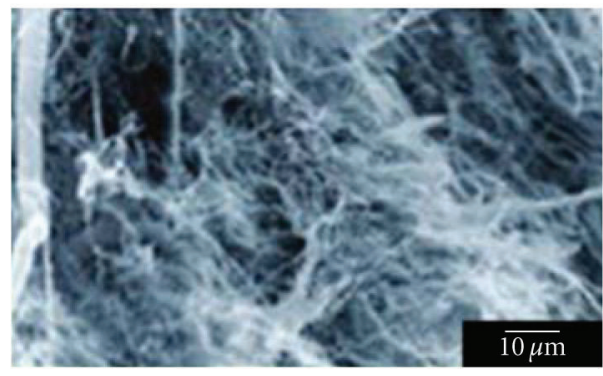

Figure 3: Scanning electron micrographs of hard- and softwood cellulose fibers, before and after 10 passes through the homogenizer [35].

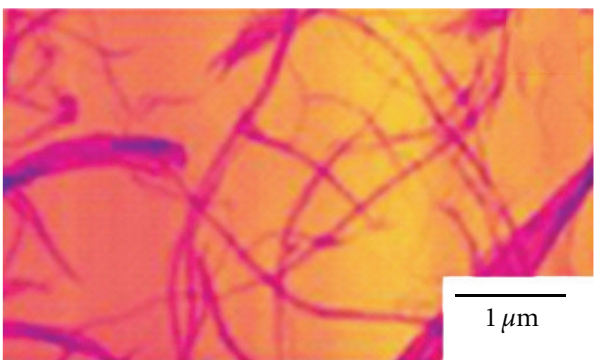

(a)

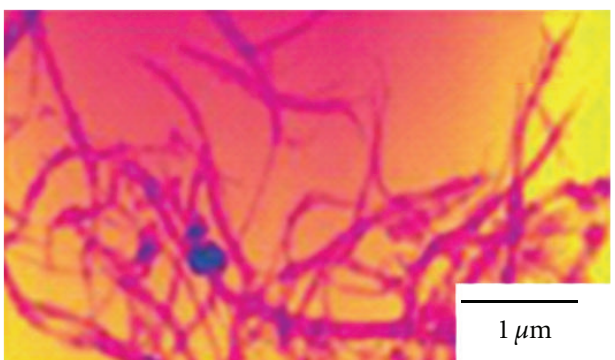

(b)

FIgURE 4: AFM images (a) hard- and (b) softwood cellulose nanofibers at process equilibrium [35].

to increase the hydrophobicity of the cellulose fibers and to improve the interface between matrix and fibers. Lack of good interfacial adhesion, low melting point, and poor resistance towards moisture make the use of plant cellulose fiberreinforced composites less attractive. Pretreatments of the cellulose fiber can clean the fiber surface, chemically modify the surface, stop the moisture absorption process, and increase the surface roughness $[1,36]$. Among the various pretreatment techniques, silylation, mercerization, peroxide, benzoylation, graft copolymerization, and bacterial cellulose treatment are the best methods for surface modification of natural fibers.

4.1. Silylation, Mercerization, and Other Surface Chemical Modifications. Silane-coupling agents usually improve the degree of cross-linking in the interface region and offer a perfect bonding. Among the various coupling agents, silanecoupling agents were found to be effective in modifying the natural fiber-matrix interface. Efficiency of silane treatment was high for the alkaline-treated fiber than for the untreated 


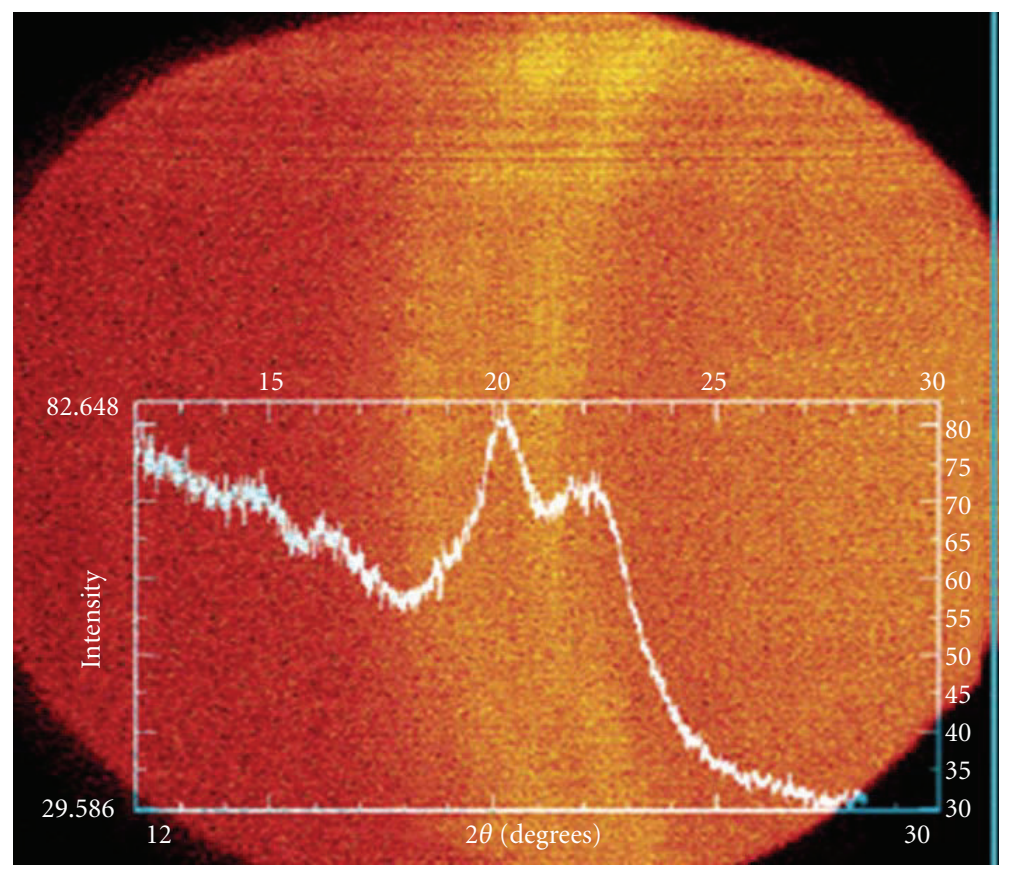

FIgURE 5: X-ray pattern to demonstrate the crystallinity of soybean stock nanofibers [31].

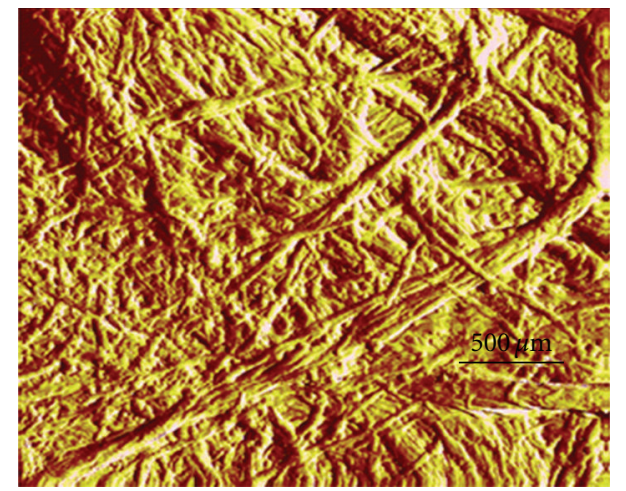

FIGURE 6: Atomic force micrograph of soybean stock nanofibers [31].

fiber because more reactive site can be generated for silane reaction. Therefore, fibers were pretreated with $\mathrm{NaOH}$ for about half an hour prior to its coupling with silane. Fibers were then washed many times in distilled water and finally dried. Silane-coupling agents may reduce the number of cellulose hydroxyl groups in the fiber-matrix interface. In the presence of moisture, hydrolyzable alkoxy group leads to the formation of silanols. The silanol then reacts with the hydroxyl group of the fiber, forming stable covalent bonds to the cell wall that are chemisorbed onto the fiber surface [37]. Therefore, the hydrocarbon chains provided by the application of silane restrain the swelling of the fiber by creating a crosslinked network due to covalent bonding between the matrix and the fiber [1].

Silanes were effective in improving the interface properties [38-41]. Alkoxy silanes are able to form bonds with hydroxyl groups. Fiber treatment with toluene dissocyanate and triethoxyvinyl silane could improve the interfacial properties. Silanes after hydrolysis undergo condensation and bond formation stage and can form polysiloxane structures by reaction with hydroxyl group of the fibers. The reactions are given in Schemes 1 and $2[1,42]$.

In the presence of moisture, hydrolysable alkoxy group leads to the formation of silanols. Hydrogen and covalentbonding mechanisms could be found in the natural fibersilane system. It is understood that the hydrocarbon chains provided by the silane application influenced the wetability of the fibers, thus improving the chemical affinity to polyethylene. $1 \%$ solution of three aminopropyl trimethoxy silane in a solution of acetone and water (50/50 by volume) for $2 \mathrm{~h}$ was reportedly used to modify the flax surface [43]. Rong et al. [17] soaked sisal fiber in a solution of $2 \%$ aminosilane in $95 \%$ alcohol for $5 \mathrm{~min}$ at a $\mathrm{pH}$ value of 4.5-5.5 followed by $30 \mathrm{~min}$ air drying for hydrolyzing the coupling agent. Silane solution in water and ethanol mixture with concentration of $0.033 \%$ and $1 \%$ was also carried by ValadezGonzalez et al. [44] and Agrawal et al. [37] to treat henequen and oil-palm fibers. They modified the short henequén fibers with a silane coupling agent in order to find out its deposition mechanism on the fiber surface and the influence of this chemical treatment on the mechanical properties of the composite. It was shown that the partial removal of lignin and other alkali soluble compounds from the fiber surface increases the adsorption of the silane coupling-agent whereas the formation of polysiloxanes inhibits this process.

Mercerization is the common method to produce highquality fibers [45]. Scheme 3 shows the probable mechanism of mercerization of cellulose fibers. Mercerization leads to fibrillation which causes the breaking down of the composite fiber bundle into smaller fibers. Mercerization reduces fiber 


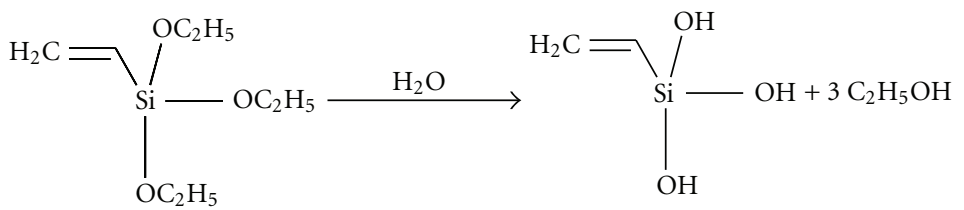

SCHEMe 1
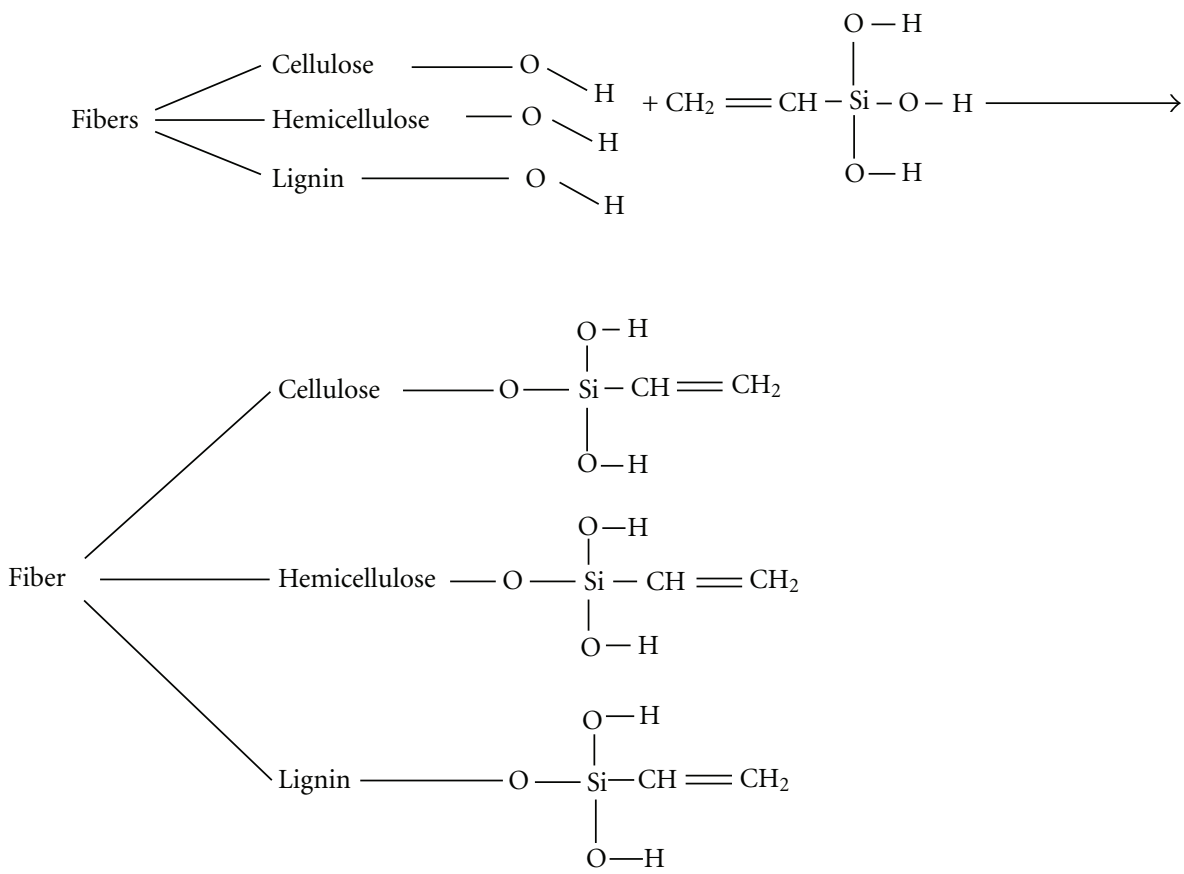

Scheme 2

diameter, thereby increases the aspect ratio which leads to the development of a rough surface topography that results in better fiber-matrix interface adhesion and an increase in mechanical properties [46]. Moreover, mercerization increases the number of possible reactive sites and allows better fiber wetting. Mercerization has an effect on the chemical composition of the flax fibers, degree of polymerization, and molecular orientation of the cellulose crystallites due to cementing substances like lignin and hemicellulose which were removed during the mercerization process. As a result, mercerization had a long-lasting effect on the mechanical properties of flax fibers, mainly on fiber strength and stiffness [47]. Sreekala et al. [42] indicated that a $10-30 \%$ sodium hydroxide solution produced the best effects on natural fiber properties. Flax fibers were soaked into 2.5, 5, 10, 13, $15,18,20,25$, or $30 \% \mathrm{NaOH}$ solutions, and it was found that $5 \%, 18 \%$, or $10 \%$ of sodium hydroxide solution was the appropriate concentration for mercerization. Jute fibers were treated with $5 \%$ alkali solution for $0,2,4,6$, and 8 $\mathrm{h}$ at $30^{\circ} \mathrm{C}$ by Ray et al. [45]. The fibers were then dried at room temperature for $48 \mathrm{~h}$ followed by oven drying at $100^{\circ} \mathrm{C}$ for $6 \mathrm{~h}$. It has been reported by Garcia-Jaldon et al. [48] that $2 \%$ alkali solution at $200^{\circ} \mathrm{C}$ and $1.5 \mathrm{MPa}$ pressure for $90 \mathrm{~s}$ was suitable for degumming and defibrillation to individual fibers. Several workers have carried out work on alkali treatment and reported that mercerization leads to an increase in the amount of amorphous cellulose at the cost of crystalline cellulose and the removal of hydrogen bonding in the network structure $[42,46]$. The jute fibers were washed with detergent $(2$ vol.\% in aqueous solution, $15 \%$ active matter) and then immersed in beakers with a solution of $5 \mathrm{wt}$. \% NaOH for $24 \mathrm{~h}$ at room temperature. After that, the fibers were washed thoroughly with distilled water to remove the excess of $\mathrm{NaOH}$ and dried at $70^{\circ} \mathrm{C}$ for $24 \mathrm{~h}$ under vacuum [49]. The banana fibers were cleaned and refluxed in $0.25 \%$ solution of $\mathrm{NaOH}$ for $1 \mathrm{~h}$ and then washed in very dilute acid to remove the nonreacted alkali. Washing was continued until the fibers were alkali free. The washed fibers were then dried in an oven at $70^{\circ} \mathrm{C}$ for $3 \mathrm{~h}$ [50].

Peroxide treatment of cellulose fiber has attracted the attention of various researchers due to easy processability and improvement in mechanical properties. Organic peroxides tend to decompose easily to free radicals (RO), which further react with the hydrogen group of the matrix and cellulose fibers. Schemes 4 and 5 show the peroxide treatment reaction onto cellulose fibers [42].

In peroxide treatment, fibers are treated with $6 \%$ benzoyl peroxide or dicumyl peroxide in acetone solution for about 30 min after alkali pretreatment [42, 51, 52]. Flax fibers were coated with dicumyl peroxide from acetone solution 


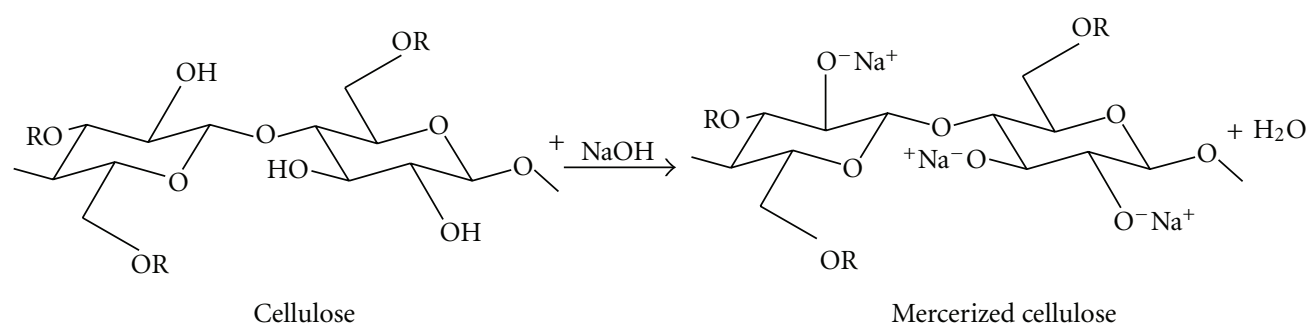

Scheme 3<smiles>O=C([O-])c1ccccc1</smiles>

Benzoyl peroxide

SCHEME 4

after alkali pretreatments. Saturated solution of the peroxide in acetone was used. Soaking of the fibers in the solution was conducted at a temperature of $70^{\circ} \mathrm{C}$ for $30 \mathrm{~min}$. High temperatures were favored for decomposition with the peroxide. The chemically treated fibers were washed with distilled water and placed in an oven at $80^{\circ} \mathrm{C}$ for $24 \mathrm{~h} \mathrm{[53].}$

In benzoylation treatment, benzoyl chloride is most often used in fiber pretreatment and inclusion of benzoyl $\left(\mathrm{C}_{6} \mathrm{H}_{5} \mathrm{C}=\mathrm{O}\right)$ group in the fiber is responsible for the decreased hydrophilic nature of the treated fiber [46]. A known amount of washed fibers (35 g) were soaked in $18 \%$ $\mathrm{NaOH}$ solution for 30 minutes followed by filtration and washing with water. The treated fiber was suspended in $10 \%$ $\mathrm{NaOH}$ solution and agitated with $50 \mathrm{~mL}$ benzoyl chloride. The reaction between the cellulosic-OH group of sisal fiber and benzoyl chloride is shown in Scheme 6 [46, 54].

Joseph et al. [46] and Kalia et al. [54] used $\mathrm{NaOH}$ and benzoyl chloride $\left(\mathrm{C}_{6} \mathrm{H}_{5} \mathrm{COCl}\right)$ solution for surface treatment of sisal fibers. The fiber was initially alkaline pretreated in order to activate the hydroxyl groups of the cellulose and lignin in the fiber; then the fiber was suspended in $10 \%$ $\mathrm{NaOH}$ and benzoyl chloride solution for $15 \mathrm{~min}$. The isolated fibers were then soaked in ethanol for $1 \mathrm{~h}$ to remove the benzoyl chloride and finally was washed with water and dried in the oven at $80^{\circ} \mathrm{C}$ for $24 \mathrm{~h} \mathrm{[55].}$

4.2. Polymer Grafting. Desirable and targeted properties can be imparted to the cellulose fibers through graft copolymerization in order to meet out the requirement of specialized applications. Graft copolymerization is one of the best methods for modifying the properties of cellulose fibers. Different binary vinyl monomers and their mixtures have been graftcopolymerized onto cellulosic material for modifying the properties of numerous polymer backbones $[1,56]$.

During last decades, several methods have been suggested for the preparation of graft copolymers by conventional chemical techniques. Creation of an active site on the preexisting polymeric backbone is the common feature of most methods for the synthesis of graft copolymers. The active site may be either a free-radical or a chemical group which may get involved in an ionic polymerization or in a condensation process. Polymerization of an appropriate monomer onto this activated backbone polymer leads to the formation of a graft copolymer. Ionic polymerization has to be carried-out in presence of anhydrous medium and/or in the presence of considerable quantity of alkali metal hydroxide. Another disadvantage with the ionic grafting is that low molecular weight graft copolymers are obtained while in case of free radical grafting high molecular weight polymers can be prepared. $\mathrm{C}_{2}, \mathrm{C}_{3}$, and $\mathrm{C}_{6}$ hydroxyls and $\mathrm{C}-\mathrm{H}$ groups are the active cites for grafting in cellulosics (Figure 7) [57].

The conventional technique of grafting and chemical modification of natural fibers requires significant time and energy. The use of MWR technique to modify the properties of natural fibers within the textile industry, although somewhat slow and still rather limited, is finding its way into numerous uses in production plants. Microwave radiation technique reduces the extent of physicochemical stresses to which the fibers are exposed during the conventional techniques. Microwave technology uses electromagnetic waves, which passes through material and causes its molecules to oscillate. Microwave energy is not observed by nonpolar materials to any degree while polar water molecules held within a polymer matrix do absorb energy very proficiently, thus becoming heated $[58,59]$.

Graft copolymerization of methyl methacrylate onto flax fiber was carried out under three different reaction methods, in air, under pressure, and under the influence of microwave radiations. Grafting through microwave-radiation technique is an effective method in terms of time consumption and cost effectiveness. Maximum percentage grafting has been observed in case of grafting carried out in air followed by grafting under pressure and under the influence 


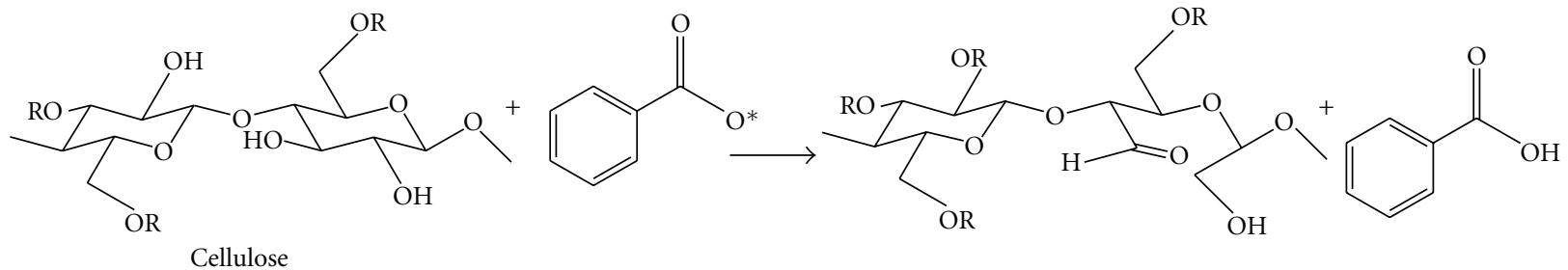

Scheme 5
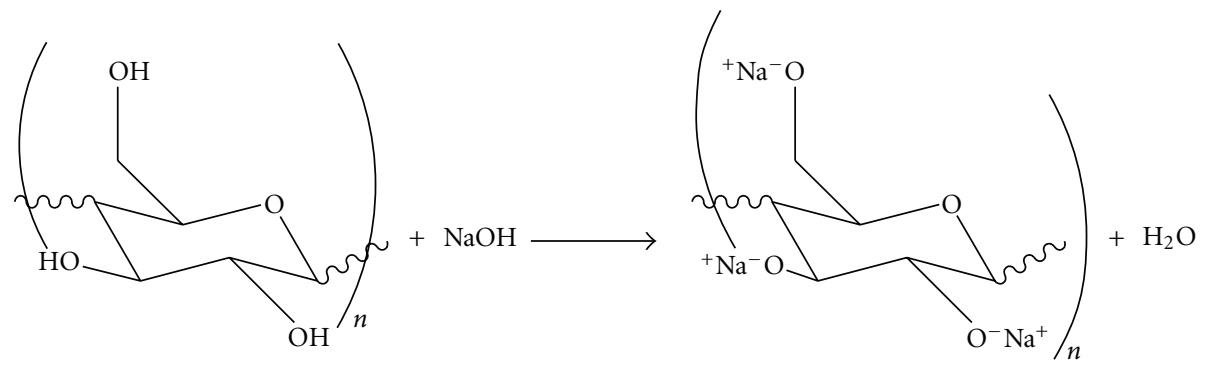

Cellulose fiber

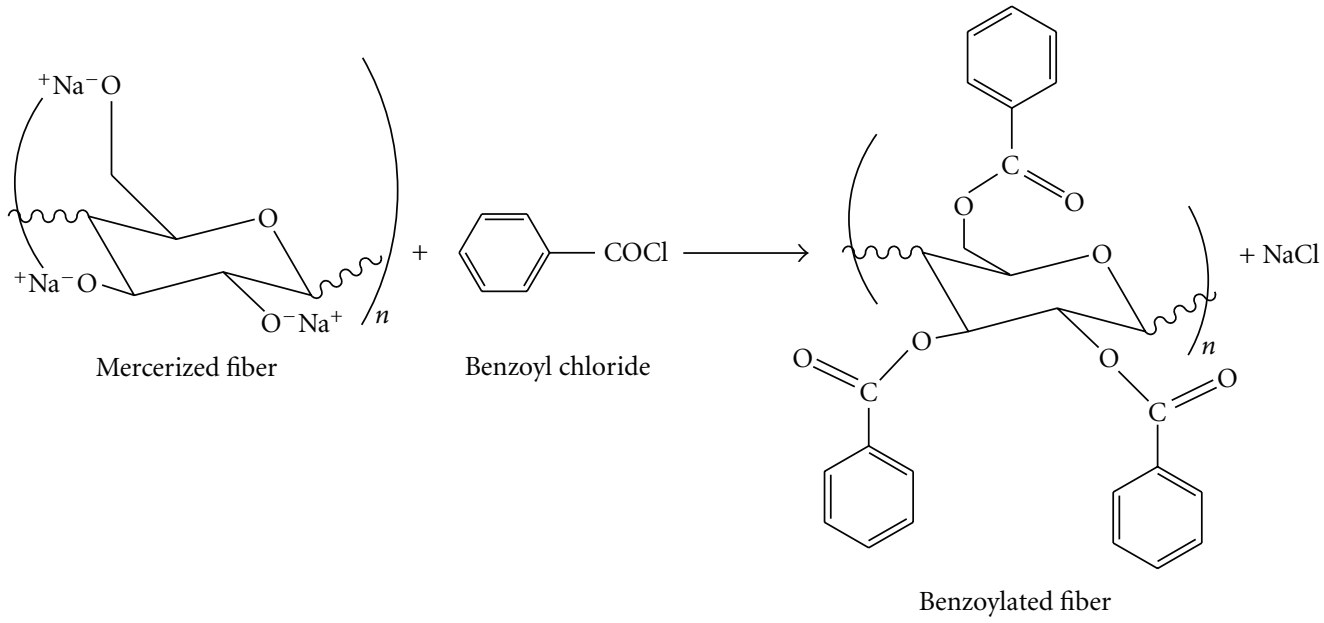

SCHeme 6

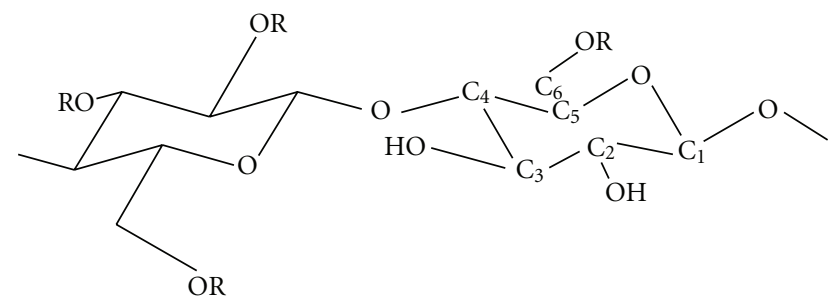

Figure 7: Structure of cellulose [57].

of microwave radiations. Flax fiber faces less surface deformations during grafting process under the influence of microwave radiations as compared to grafting in air and under pressure, thereby retaining better crystalline structure. Morphological and thermal studies showed that surface of sunn hemp fibers becomes rough through graft copolymer- ization and thermal stability has been found to be increased. Microwave radiation-induced grafting showed a diminutive effect on the crystalline behavior of the sunn hemp fibers as optimum time to get maximum grafting is very less (40 minutes) in comparison to conventional grafting [60].

4.3. Bacterial Modification. The coating of bacterial cellulose onto cellulose fibers provides new means of controlling the interaction between fibers and polymer matrices. Coating of fibers with bacterial cellulose does not only facilitate good distribution of bacterial cellulose within the matrix, but also results in an improved interfacial adhesion between the fibers and the matrix. This enhances the interaction between the fibers and the polymer matrix through mechanical interlocking [3, 61]. Surface modification of cellulose fibers using bacterial cellulose is one of the best methods for greener surface treatment of fibers. Bacterial Cellulose has 
gained attention in the research area for the encouraging properties it possesses; such as its significant mechanical properties in both dry and wet states, porosity, water absorbency, moldability, biodegradability, and excellent biological affinity [62]. Because of these properties, $\mathrm{BC}$ has a wide range of potential applications.

Acetobacter xylinum (or Gluconacetobacter xylinus) is the most efficient producer of bacterial cellulose. BC is secreted as a ribbon-shaped fibril, less than $100 \mathrm{~nm}$ wide, which is composed of much finer 2-4 nm nanofibrils. In comparison to the methods for obtaining nanocellulose through mechanical or chemomechanical processes, it is produced by bacteria through cellulose biosynthesis and the building up of bundles of microfibrils [63-65].

The cultivation of the cellulose producing bacteria in the presence of natural fibers, such as sisal and hemp, results in the coating of natural fiber surfaces by bacterial nanocellulose (Figure 8) [61]. Strong and highly crystalline nanocellulosic fibrils preferentially attached to the surface of natural fibers thereby creating "hairy fibers" (Figure 9), leading to a nanostructured natural fiber surface. Simply weighing the fibers before and after the $\mathrm{BC}$ fermentation process confirmed that between 5 and $6 \mathrm{wt} \%$ of bacterial cellulose adhered to the fibers after the surface modification. The strength of attachment of the nanocellulose coating to the fibers can be attributed to strong hydrogen bonding between the hydroxyl groups present in bacterial cellulose and the lignocellulose in natural fibers [66]. The modification process did not affect the mechanical properties of sisal fibers but it significantly reduced the mechanical properties of hemp fibers. Figure 10 shows the coating of bacterial nanocellulose onto hemp fibers [61].

To improve the compatibility between natural fibers and hydrophobic polymer matrices, various greener methods have been explored such as fungi, enzymes and bacterial treatments. Kalia and Sheoran [67] have reported cellulase enzyme assisted biopolishing of ramie fibers using bacteria Streptomyces albaduncus. Biopolishing of ramie fibers by utilizing cellulase from bacteria Streptomyces albaduncus was observed for 5 days, at the $\mathrm{pH} 7.4$ and $2.0 \mathrm{~g}$ glucose, which results in enhanced brightness due to the removal of gum materials and small fibrils protruding from the fiber surface. Bacterial treatment has diminutive effect on thermal stability and crystalline structure of ramie fibers.

\section{Cellulose-Fiber-Reinforced Biocomposites}

5.1. Processing Method. Natural fiber composites are prepared using various composites manufacturing methods such as compression molding, injection molding, resin transfer molding (RTM), and vacuum bagging. The preforms are mostly fibers, fabrics, or nonwovens. Prepregs are also widely used to prepare composites [68]. Equation (1) is commonly used in the preparation of composites

$$
V_{f}=\frac{W_{f} / \rho_{f}}{\left(W_{f} / \rho_{f}\right)+\left(W_{m} / \rho_{m}\right)}
$$

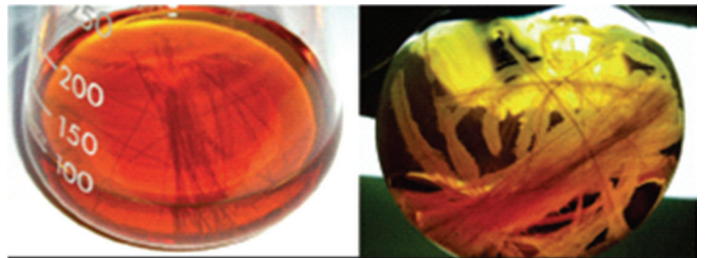

Figure 8: Photographs of sisal fibers before and after bacterial culture [61].

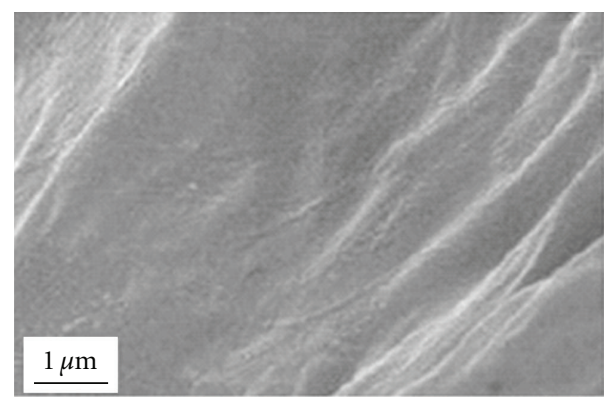

(a)

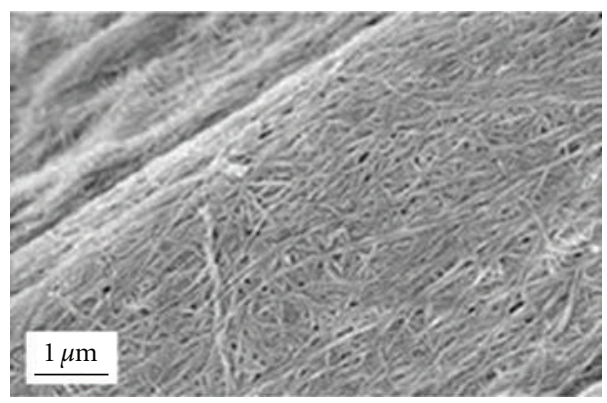

(b)

Figure 9: SEM micrographs (a) sisal fiber and (b) bacterial cellulose-coated sisal fiber [61].

where $V_{f}$ is the fiber-volume fraction, $W_{f}$ is the weight of fiber, and $W_{m}$ is the weight of matrix. $r_{f}$ and $r_{m}$ are the densities of the fiber and matrix, respectively.

The production of the composites is optimized in relation to temperature, pressure, and molding time. It is often necessary to preheat the natural fibers to reduce the moisture before processing the composites. High temperatures degrade the cellulose; thus, negatively affecting the mechanical properties of the composites. Inefficient fiber dispersion in the matrix causes fiber agglomeration which decreases the tensile strength [68]. Most of the previous research on natural fiber composites has focused on reinforcements such as flax, hemp, sisal and jute, and thermoplastic and thermoset matrices. Some of these composites have been produced using matrices made of derivatives from cellulose, starch, and lactic acid to develop fully biodegradable composites or biocomposites [69]. The emerging diversity of applications of natural fiber composites has seen the production of sandwich structures based on natural-fiber composite skins. In some cases, these sandwich composites have been produced from paper honeycomb and natural fiber-reinforced thermoplastic or thermoset skins, depending on the applications. 


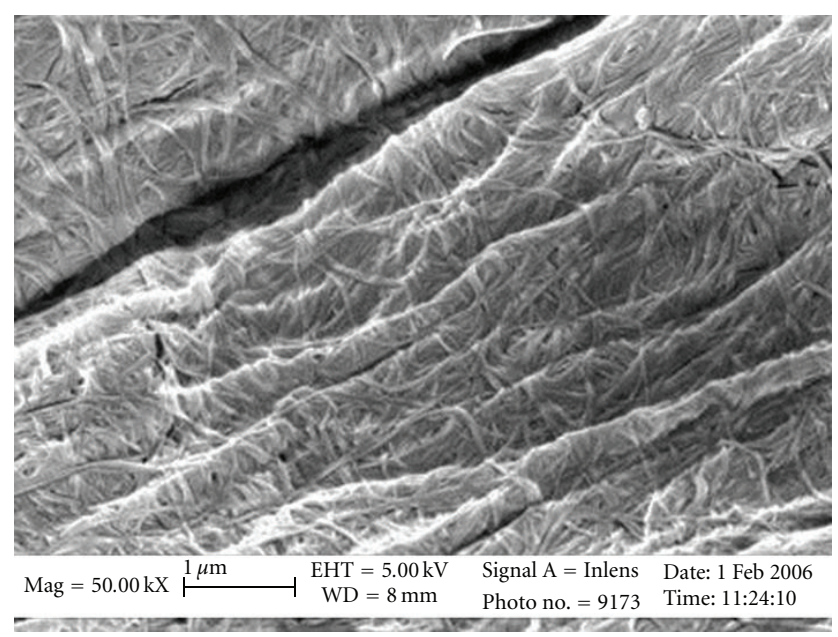

FIgURE 10: Hemp fiber after bacterial cellulose modification [61].

The main criteria for the selection of the appropriate process technology for natural-fiber composite manufacture include the desired product geometry, the performance needed, and the cost and the ease of manufacture. The fabrication methods for natural fiber composites are similar to those used for glass fibers. The most commonly used manufacturing processes are introduced in the following. Although many variants on these techniques exist, this overview gives a good indication of the production possibilities.

5.1.1. Hand Laminating. The fibers are placed in a mould and the resin is later applied by rollers. One option is to cure using a vacuum bag, as then excess air is removed and the atmospheric pressure exerts pressure to compact the part. The simplicity, low cost of tooling, and flexibility of design are the main advantages of the procedure. On the other end, the long production time, intensive labour, and low automation potential, consist some of the disadvantages.

5.1.2. Resin Transfer Molding (RTM). The resin transfer molding technique requires the fibers to be placed inside a mould consisting of two solid parts (close mould technique). A tube connects the mould with a supply of liquid resin, which is injected at low pressure through the mould, impregnating the fibers. The resulting part is cured at room temperature or above until the end of the curing reaction, when the mould is opened and the product removed. Parameters such as injection pressure, fiber content, and mould temperature have a great influence on the development of the temperature profiles and the thermal boundary layers, especially for thin cavities. This technique has the advantage of rapid manufacturing of large, complex, and high performance parts. Several types of resins (epoxy, polyester, phenolic, and acrylic) can be used for RTM as long as their viscosity is low enough to ensure a proper wetting of the fibers. Parameters such as injection pressure, fiber content, and mould temperature have a great influence on the development of the temperature profiles and the thermal boundary layers, especially for thin cavities. Good knowledge of all the operating steps is very important to obtain high-quality parts [68].
An alternative variant of this process is the vacuum injection or vacuum-assisted resin transfer molding (VARTM), where a single solid mould and a foil (polymeric film) are used. The VARTM process is a very clean and low cost manufacturing method: resin is processed into a dry reinforcement on a vacuum-bagged tool, using only the partial vacuum to drive the resin. As one of the tool faces is flexible, the moulded laminate thickness depends partially on the compressibility of the fiber-resin composite before curing and the vacuum negative pressure.

5.1.3. Compression Molding. Compression molding is another major technique for the construction of fiber-reinforced polymers, which involves a semifinished composite sheet widely known as sheet molding compound (SMC) that is later moulded into the final parts by compression. For the SMC the process consists of a rolling film of resin on which fibers are added. A second film of resin is then added, so as to later be compressed in a composite sheet that may be stored for few days. To get the final product the reinforced sheet is then placed into a press to take its desired shape.

Advantages of compression molding are the very high volume production ability, the excellent part reproducibility and the short cycle times. Processing times of $<2 \mathrm{~min}$ are reached during the compression molding of three-dimensional components with a high forming degree. It has also been shown that the adhesion of natural fibers and matrix resin is important in order to obtain good mechanical properties of natural fiber composites, and the mechanical properties were improved by the molding condition, the molding pressure and temperature. A big concern with compression molding that needs always to be considered is the maximum pressure before the damage of the fibers and the structure.

5.1.4. Injection Molding. Injection molding process is suitable to form complex shapes and fine details with excellent surface finish and good dimensional accuracy for high production rate and low labour cost. In the injection molding resin granules and short fibers are mixed into a heated barrel and transported to the mould cavity by a spindle. Injection molding is another process among the most important for the manufacturing of plastics/composites and can produce from very small products such as bottle tops to very large car body parts.

5.1.5. Pultrusion. Pultrusion is a continuous process to manufacture composite profiles at any length. The impregnated fibers are pulled through a die, which is shaped according to the desired cross-section of the product. The resulting profile is shaped until the resin is dry. Advantages of this process are the ability to build thin wall structures, the large variety of cross-sectional shapes and the possibility for high degree of automation.

5.2. Interfacial Interactions. All natural fibers are (in different extent) hydrophilic in nature. This is attributed mainly to the lignocellulose into their structure, which contain strongly polarized hydroxyl groups [68]. These fibers, therefore, are inherently incompatible with many well known and popular 
in composite manufacturing resins. Only some thermosets such as the phenol-formaldehyde and related polymers are less hydrophilic and thus less problematic.

This discrepancy leads often to the formation of ineffective interface between the fibers and the matrix. The major limitations of using these fibers as reinforcements in such matrices include poor interfacial adhesion between polarhydrophilic fibers and nonpolar-hydrophobic matrix, and difficulties in mixing due to poor wetting of the fibers with the matrix. The role of the matrix in a fiber-reinforced composite is to transfer the load to the stiff fibers through shear stresses at the interface. This process requires a good bond between the polymeric matrix and the fibers [70].

Poor adhesion at the interface means that the full capabilities of the composite cannot be exploited and leaves it vulnerable to environmental attacks that may weaken it, thus reducing its life span. Insufficient adhesion between the polymer and the fibers results in poor mechanical properties of the natural fiber-reinforced polymer composites.

Pretreatments of the fibers can clean the fiber surface, chemically modify the surface, stop the moisture absorption process, and increase the surface roughness [71, 72]. These properties may be improved by both physical treatments like cold plasma treatment or corona treatment, and chemical treatment such as maleic anhydride, organosilanes, isocyanates, sodium hydroxide, permanganate, and peroxide.

5.2.1. Physical Treatment. Physical treatments change the structural and surface properties of the fibers and thereby influence the mechanical bonding to polymers. Corona treatment is one of the most popular techniques for surface oxidation activation through electric discharge that changes the surface energy of the cellulose fibers. Cold plasma treatment is another electric discharge technique and can have the same surface effects and increase the fiber matrix adhesion [72]. A traditional physical method is mercerization. In this process, the fibers are treated with an aqueous solution of a strong base (alkali treatment) so as to produce great swelling that results in changes of their structure, dimensions, morphology, and mechanical properties [72].

5.2.2. Chemical Treatment. Among the most effective methods of chemical treatment is graft copolymerization [68, 72]. The cellulose is treated with an aqueous solution with selected ions and is exposed to a high energy radiation. Under the radiation, the cellulose molecule cracks and radicals are formed. Using then a suitable (compatible with the matrix) solution it is possible to create a copolymer with properties and characteristics of both the fibers and the matrix. Graft copolymers of natural fibers with vinyl monomers provide better adhesion between matrix and fiber. Gauthier et al. [73] reported that adhesion may be improved by using coupling agents like maleic anhydride to incorporate hydroxyl groups on the matrix through hydrophilization and consequently enhancing the wetting effect of the resin on the fibers. The hydroxyl groups then interact with $-\mathrm{OH}$ molecules on the lignocellulosic fibers via hydrogen bonding, thus producing stronger bond. George et al. [74] reviewed the physical and chemical treatments that may improve the fiber-matrix adhesion and manufactured biocomposites by applying an alkaline solution to the fibers. Natural fibers are mainly composed of cellulose, whose elementary unit, anhydro d-glucose, contains three hydroxyl $(\mathrm{OH})$ groups. These hydroxyl groups form intra- and intermolecular bonds, causing all vegetable fibers to be hydrophilic. The alkaline solution regenerated the lost cellulose and dissolved unwanted microscopic pits or cracks on the fibers resulting in better fiber-matrix adhesion.

Coupling agents are based on the concept that when two materials are incompatible, a third material with intermediate properties can bring the compatibility to the mixture [72]. The coupling agents have two functions: to react with $\mathrm{OH}$ groups of the cellulose and to react with the functional groups of the matrix with the goal of facilitating stress transfer between the fibers and the matrix. Numerous studies $[68,72]$ have been conducted on the use of coupling agents including organosilanes, triazine, and maleicanhydride (MAH). For instance, Xie et al. [75] used silanecoupling agents in natural fiber/polymer composites and concluded that proper treatment of fibers with silanes can increase the interfacial adhesion and improve the mechanical performance of the resulting composites. Gassan and Bledzki [76] improved the tensile and flexural strength and stiffness of jute/epoxy composites by treating the fibers with silane. Acetylation, isocyanate treatment, and treatment with stearic acid are some more chemical methods for modification and preparation of the fiber/matrix adhesion.

5.3. Characterization. Plant fibers are basically composite materials designed by nature and consist of a collection of long and thin cells made up of hollow cellulose fibrils held together by a lignin and hemicellulose matrix [77]. The strength and stiffness of the fibers are provided by hydrogen bonds and other linkages. The overall properties of the fibers depend on the individual properties of each of its components. Hemicellulose is responsible for the biodegradation, moisture absorption, and thermal degradation of the fiber. On the other hand, lignin (or pectin) is thermally stable but is responsible for UV degradation of the fiber. On average, natural fibers contain $60-80 \%$ cellulose, 5-20\% lignin (or pectin), and up to $20 \%$ moisture.

On a composite, the properties of the fibers are combined with those of the matrix, which is responsible to transfer the external loads to the stiff fibers through shear stresses at the interface as well as keep the fibers together in a specific structural form. Thus, the properties of the composite are a combination of the properties of the ingredients and their prediction and estimation becomes a difficult job.

5.3.1. Stiffness and Strength. The mechanical properties of natural fiber composites are much lower than those of glass fibers. However, their specific properties, especially stiffness, are comparable to the stated values of glass fibers. Moreover, natural fibers are about 50\% lighter than glass, and in general cheaper. It is widely acknowledged that natural fiber composites combine good mechanical properties with a low specific mass and offer an alternative material to glass fiber-reinforced plastics in some technical applications. 
For example, Bledzki and Gassan [72] observed that the characteristic values of natural fibers are comparable to those of glass fibers. Experimental data giving the tensile strength, flexural strength, modulus, impact force, and compressive force are available in the literature for different types of natural-fiber composites.

The ultimate strength of any composite depends on several factors, most important of which are the properties of the components and the volume fraction. Wambua et al. [70] studied the importance and effect of the volume fraction on the tensile strength of natural fiber composites. They reported that an increase in the fiber weight fraction produces an increase in the tensile strength. Testing different fiber reinforcement, they also found that hemp/polypropylene (PP) composites with a $30 \%$ volume fraction displayed a tensile strength of $52 \mathrm{MPa}$, higher than equivalent glass-reinforced composites with the same volume fraction. Further, hemp and kenaf-polypropylene composites registered a high tensile modulus of $6.8 \mathrm{GPa}$ compared to $6.2 \mathrm{GPa}$ of equivalent glass composites. The increase of the modulus and the tensile strength with increase of the volume or weight fraction was also showed by Bos et al. [78, 79] on flax/PP composites with maleic-anhydride grafted polypropylene for improved adhesion.

Studies and results of tensile tests on flax-fiber-reinforced PP composites were conducted by Garkhail et al. [80] which concluded that fiber length affect the strength and modulus of the composites for small fiber lengths whilst after a specific value for the length the two parameters are constant. The stiffness of a flax/PP composite was shown to be comparable to E-glass-based composite, especially when the specific properties are concerned due to the very low density of flax. However, the results also depicted a relatively low tensile strength.

Nishino [81] studied the mechanical properties of kenaf/ poly-L-lactide (PLLA) composites. He concluded that the modulus of the composites increases with the increase of the volume fraction, but only up to a certain level. When this threshold is achieved, further increase of the fiber fraction leads to a dramatic reduction of the composite properties.

Water content has also a dramatic effect on the properties of natural-fiber composites. Espert et al. [82] showed this effect on cellulose/PP composites by submerging samples into distilled water under different temperatures. The samples were removed from the water at certain times and the water absorption was measured. The results of tensile tests showed a significant effect of the water content to the young's modulus of the samples, and an even bigger effect on the tensile strength. The studies also concluded that the effect of the water to the properties is highly influenced by the fiber content, the matrix and mainly the temperature. Thwe and Liao [83] investigated the same effect on bamboo-fiber composites and resulted that both the tensile strength and modulus have decreased after aging in water at 25 and $75^{\circ} \mathrm{C}$ for prolonged period. The extent of strength and stiffness loss depends upon aging time and temperature. They also concluded that tensile strength and stiffness are enhanced by inclusion of a coupling agent, maleic anhydride polypropylene (MAPP), in matrix material as a result of improved interfacial bonding.

5.3.2. Impact Performance. There are only few studies known about the impact behaviour of natural-fiber reinforcedcomposites. The impact performance of several natural fiber composites was compared and reviewed by Wambua et al. [70]. Using kenaf-, coir-, sisal-, hemp-, and jutereinforced polypropylene the study concluded that natural fiber composites display low impact strengths compared to glass composites, whereas their specific impact strength can be comparable with those of glass mat composites. Among the materials studied, sisal and hemp showed the higher impact strength.

Pavithran et al. [84] determined the fracture energies for sisal, pineapple, banana, and coconut fiber-polyester composites in a Charpy impact test. They concluded that increased fiber toughness results in increased fracture energy and found that fibers with higher fibril angles have higher fracture-toughness than those with small spiral angle.

Fiber content and fiber length have also a contribution to the impact performance of the composite. Tobias [85] examined this influence with banana-fiber composites and concluded that smaller fiber lengths have higher impact strength which also increases for higher fiber content. Contradictorily, the fiber length was also studied by Garkhail et al. [80] on flax/PP composites. The results showed that (as in glass fiber composites) the impact strength increases with increasing fiber length until a plateau level is reached. After that level, the impact performance drops depending on the pretreatment of the fibers and the adhesion of the fiber/matrix interface.

Mueller [86] investigated the effect of several material parameters on the impact strength of compression-molding components of hemp-, flax- and kenaf-polypropylene composites. The studies showed a strong influence of the thermal process conditions during the molding. He concluded that for every material studied there is an optimum temperature that results to a peak of the impact strength. Higher and lower processing temperature resulted in lower mechanical values that could be explained by a thermal decomposition of the fibers. Strong impact of the fiber fineness was also proved, with the impact performance getting higher from composites with fiber of higher fineness.

The effect of temperature and water on the impact properties of natural-fiber thermoplastics were reviewed by De Bruijn [87] and showed not significant effect on the impact properties of the composites. However, the results showed that the impact strength was 20 to $25 \%$ to that of glass-reinforced thermoplastics.

A significant contribution of coupling agents on the impact strength has also been reported. When the composites have no coupling agent, a part of the energy is lost in the interface, by for example debonding and friction effects. Maleic-anhydride-treated jute composites showed higher impact strength than untreated samples made out of the same process. 
5.3.3. Fatigue Behaviour. The cyclic loading of natural fiber composites is still poorly investigated. Gassan [88] investigated the fatigue behaviour of flax and jute epoxy resin composites. Fiber type, textile architecture, interphase properties, and fiber properties and content were found to affect the fatigue behaviour strongly. It was also found that natural fiber-reinforced plastics with higher fiber strength and modulus, stronger fiber-matrix adhesion, or higher fiber fractions possess higher critical loads for damage initiation and higher failure loads. In addition, damage propagation rates were reduced. Furthermore, unidirectional composites were less sensitive to fatigue-induced damage than woven reinforced ones.

Savastano et al. [89] presented the results of experimental studies of resistance-curve behaviour and fatigue crack growth in cementitious matrices reinforced with natural fibers such as sisal, banana, and bleached eucalyptus pulp. Fatigue crack growth was observed to occur in three stages: an initial decelerated growth, a steady-state growth, and a final catastrophic crack growth. In the case of the composites reinforced with sisal and banana fibers, most of fatigue life was spent in the second stage of steady-state crack growth. The results showed that fatigue crack growth in the composites occurred via matrix cracking, crack deflection around fibers, and crack-bridging by uncracked fibers and ligaments, whilst fiber pullout was also observed.

The fatigue performance of sisal/epoxy composites was also studied by Towo and Ansell $[90,91]$ which looked into the effect of surface modification on the fatigue performance of the composite. The results show that an $\mathrm{NaOH}$ surface treatment has a significant effect on the tensile modulus and strength of the material, but the fatigue life is not highly influenced, especially in low stress levels. Their conclusion states that the behaviour of sisal fiber composites is similar to that of conventional synthetic fiber composites and static and fatigue strengths are suitably high for many commercial applications. Towo et al. also studied the fatigue properties of flax/polyester with alkali-treated and untreated fibers. In this case they observed a high influence of the treatment on the fatigue life of the components and they also underlined that the polyester matrix samples had lower life than the epoxy samples.

A comparison between hemp- and flax-reinforced polyester composites with focus on the fatigue behaviour was conducted by Yuanjian and Isaac [92]. A steeper gradient of the S-N curve for the hemp-fiber composite was indicative of a higher rate of reduction in fatigue strength. However, the fatigue performance levels of this hemp mat composite were comparable and slightly greater than those of the glass fiber composite.

\section{Cellulose Nanofiber-Reinforced Nanocomposites}

The potential of nanocomposites in various sectors of research and application is promising and attracting increasing investments. In the nanocomposite industry, a reinforcing particle is usually considered as a nanoparticle when at least one of its linear dimensions is smaller than $100 \mathrm{~nm}$.
Owing to the hierarchical structure and semicrystalline nature of cellulose, nanoparticles can be extracted from this naturally occurring polymer. Native cellulose fibers are built up by smaller and mechanically stronger long thin filaments, the microfibrils consisting of alternating crystalline and noncrystalline domains. Multiple mechanical shearing actions can be used to release more or less individually these microfibrils. This material is usually called microfibrillated cellulose (MFC). Figure 11 [93-96] shows transmission electron micrographs from dilute suspensions of MFC obtained from different sources.

Longitudinal cutting of these microfibrils can be performed by submitting the biomass to a strong acid hydrolysis treatment, allowing dissolution of amorphous domains. The ensuing nanoparticles occur as rod-like nanocrystals or whiskers with dimensions depending on the source of cellulose and preparation procedure. Examples are shown in Figure 12 [97-104]. The typical geometrical characteristics for nanocrystals derived from different species and reported in the literature are collected in Table 1 [105-139].

Impressive mechanical properties and reinforcing capability, abundance, low weight, and biodegradability of cellulose nanocrystals make them ideal candidates for the processing of polymer nanocomposites [140-143]. With a Young's modulus around $150 \mathrm{GPa}$ and a surface area of several hundred $\mathrm{m}^{2} \cdot \mathrm{g}^{-1}[144]$, they have the potential to significantly reinforce polymers at low filler loadings. A broad range of applications of nanocellulose exists even if a high number of unknown remains at date. Tens of scientific publications and experts show its potential even if most of the studies focus on their mechanical properties as reinforcing phase and their liquid crystal self-ordering properties. However, as for any nanoparticle, the main challenge is related to their homogeneous dispersion within a polymeric matrix.

6.1. Nanocomposite Processing. Cellulose nanoparticles are obtained as stable aqueous suspensions and most investigations focused on hydrosoluble (or at least hydrodispersible) or latex-form polymers. The main advantage is that the dispersion state of the nanoparticles is kept when using an aqueous medium for the processing.

After dissolution of the hydrosoluble or hydrodispersible polymer, the aqueous solution can be mixed with the aqueous suspension of cellulosic nanoparticles. The ensuing mixture is generally cast and evaporated to obtain a solid nanocomposite film. It can also be freeze-dried and hot-pressed. The preparation of cellulose nanofiber reinforced starch [145-150], silk fibroin [151], poly(oxyethylene) (POE) [152-156], polyvinyl alcohol (PVA) [157-161], hydroxypropyl cellulose (HPC) [157, 158], carboxymethyl cellulose (CMC) [162], or soy protein isolate (SPI) [163] has been reported in the literature.

The first publication reporting the preparation of cellulose nanocrystals-reinforced polymer nanocomposites was carried out using a latex obtained by the copolymerization of styrene and butyl acrylate (poly $(\mathrm{S}-\mathrm{co}-\mathrm{BuA}))$ and tunicin (the cellulose extracted from tunicate-a sea animal) whiskers [137]. The same copolymer was used in association 


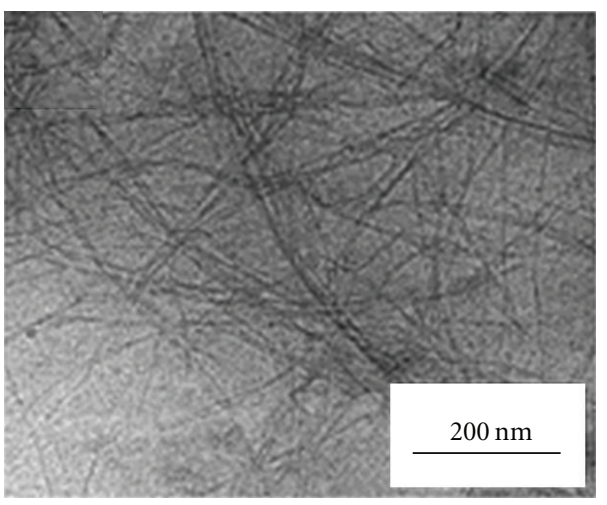

(a)

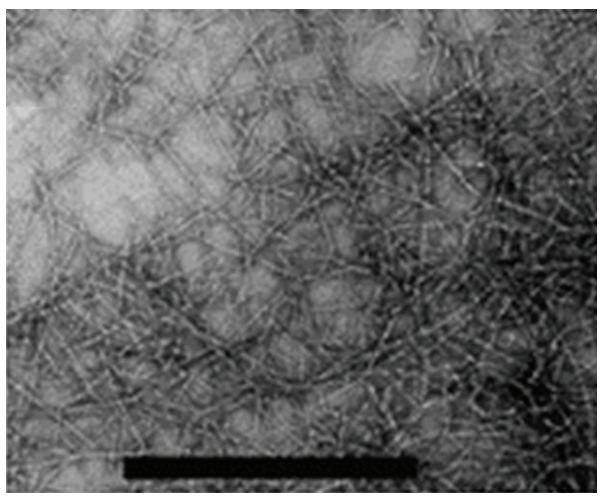

(c)

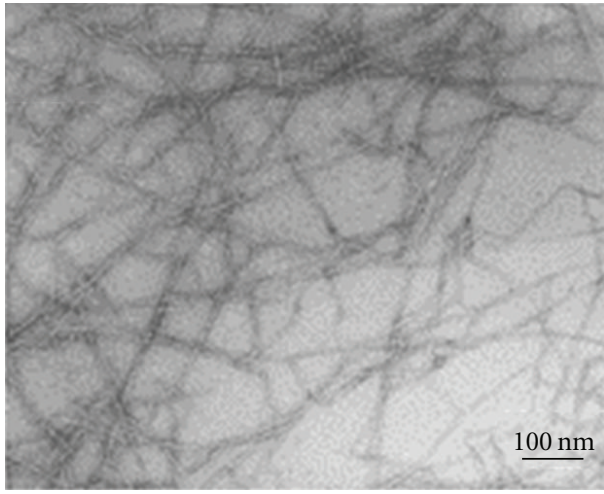

(b)

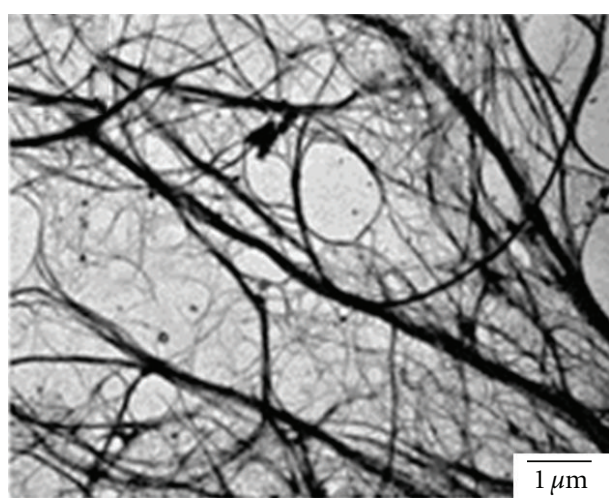

(d)

Figure 11: Transmission electron micrographs from dilute suspension of MFC obtained from wood fibers by mechanical processing combined to (a) enzymatic [93], (b) TEMPO-mediated oxidation [94], (c) carboxylmethylation pretreatment [95], and (d) extracted from Opuntia ficus-indica [96].

with wheat straw $[103,164]$ or sugar beet [101] cellulose nanocrystals. Other latexes such as poly $(\beta$-hydroxyoctanoate) (PHO) [165-167], polyvinylchloride (PVC) [168-171], waterborne epoxy [172], natural rubber (NR) [122, 173, 174], and polyvinyl acetate (PVAc) [99] were also used as matrix. Recently, stable aqueous nanocomposite dispersionscontaining cellulose whiskers and a poly(styrene-co-hexylacrylate) matrix were prepared via miniemulsion polymerization [106]. Addition of a reactive silane was used to stabilize the dispersion. Solid nanocomposite films can be obtained by mixing and casting the two aqueous suspensions followed by water evaporation.

The possibility of dispersing cellulosic nanofibers in nonaqueous media has been investigated using surfactants or chemical grafting and it opens other possibilities for nanocomposites processing. Cellulose nanoparticles possess a reactive surface covered with hydroxyl groups, providing the possibility to extensive chemical modification. Although this strategy decreases the surface energy and polar character of the nanoparticles, improving by the way the adhesion with nonpolar polymeric matrix, a detrimental effect is generally reported for the mechanical performances of the composite. This unusual behavior is ascribed to the originality of the reinforcing phenomenon of polysaccharide nanocrystals resulting from the formation of a percolating network thanks to hydrogen bonding forces. Therefore, grafting of long chains instead of small molecules can be used to preserve the mechanical properties of the material.

Very few studies have been reported concerning the processing of cellulose nanofibers-reinforced nanocomposites by extrusion methods. The hydrophilic nature of cellulose causes irreversible agglomeration during drying and aggregation in nonpolar matrices because of the formation of additional hydrogen bonds between amorphous parts of the nanoparticles. Therefore, the preparation of cellulose whiskers-reinforced PLA nanocomposites by melt extrusion was carried out by pumping the suspension of nanocrystals into the polymer melt during the extrusion process [175]. An attempt to use PVA as a compatibilizer to promote the dispersion of cellulose whiskers within the PLA matrix was reported [176]. Organic acid chlorides-grafted cellulose whiskers were extruded with LDPE [177]. The homogeneity of the ensuing nanocomposite was found to increase with the length of the grafted chains. Polycaprolactone-grafted cellulose nanocrystals obtained by ring-opening polymerization (ROP) of the corresponding lactone were also used as "masterbatches" by melt blending with a PCL matrix [178].

An attempt to use a recently patented concept (Dispersed nanoobjects protective encapsulation-DOPE process) intended to disperse carbon nanotubes in polymeric 


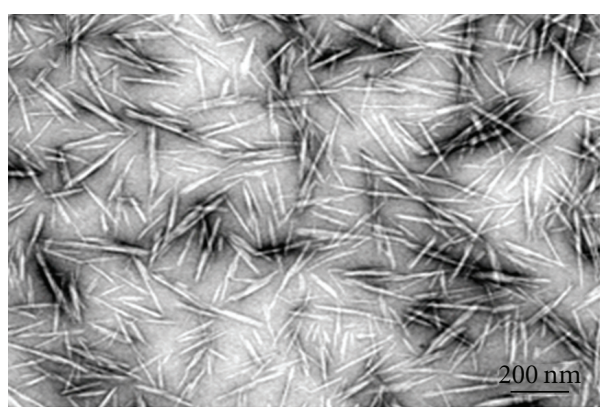

(a)

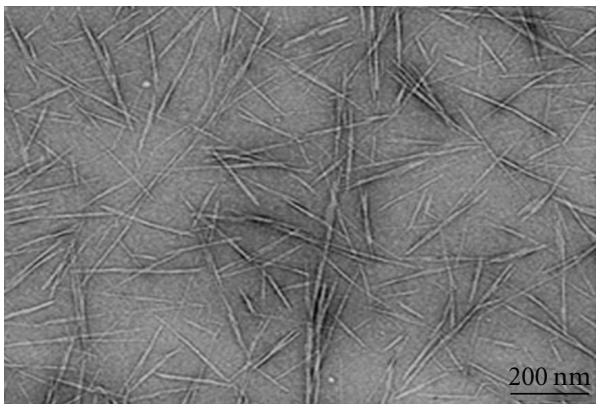

(c)

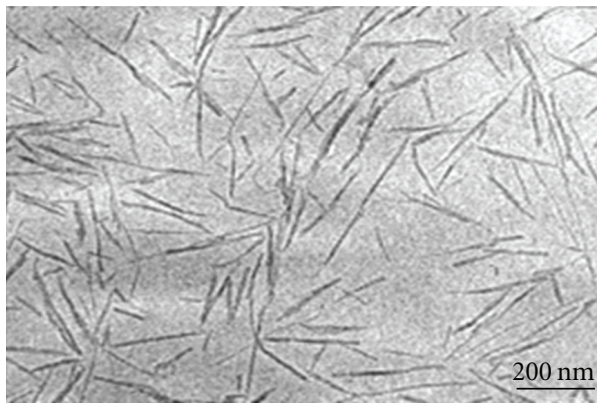

(e)

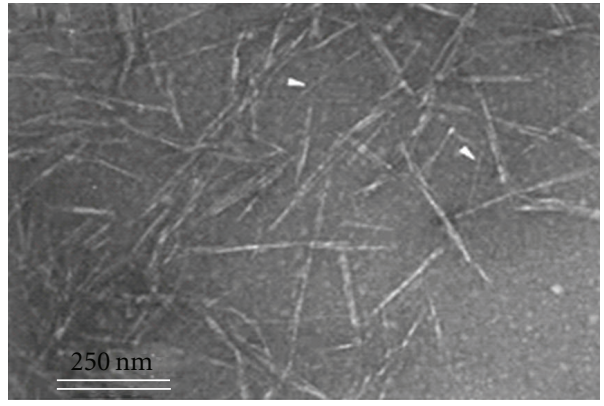

(g)

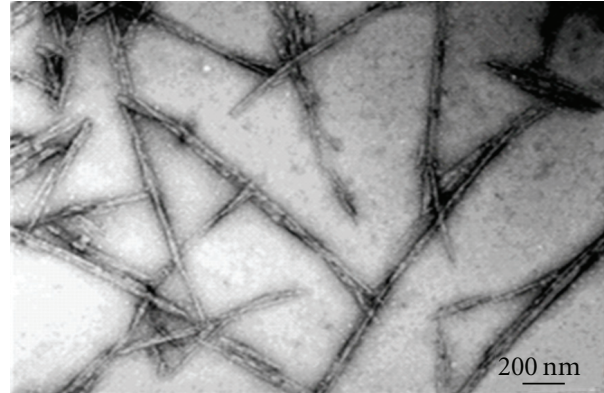

(b)

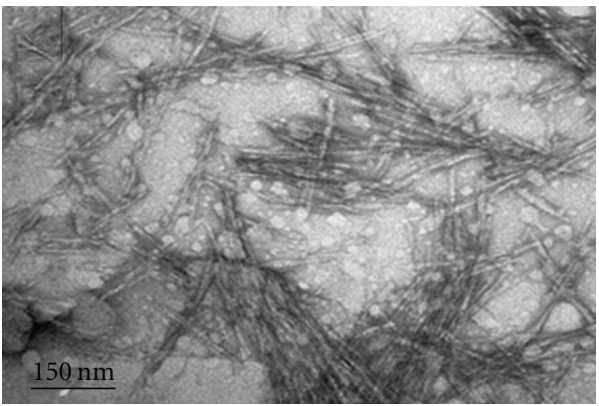

(d)

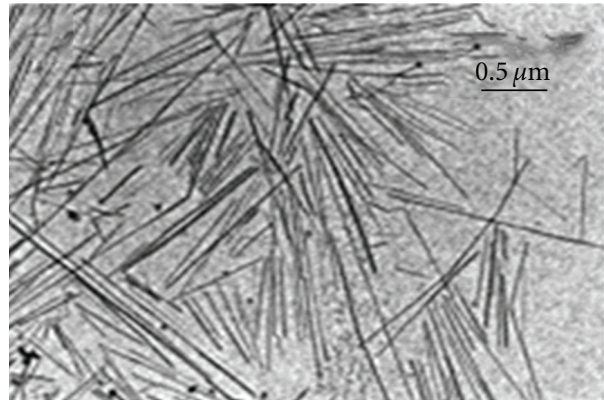

(f)

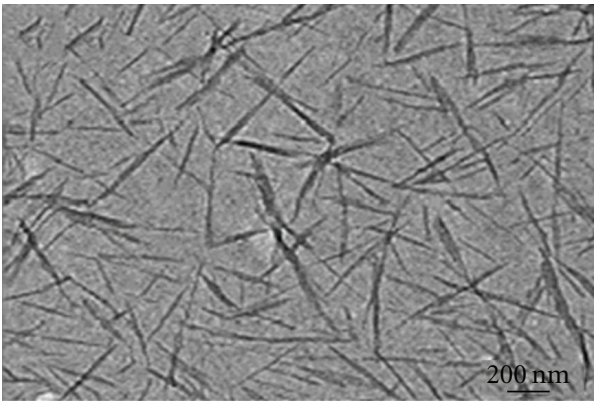

(h)

FiguRE 12: Transmission electron micrographs from dilute suspension of cellulose nanocrystals from: (a) ramie [97], (b) bacterial [98], (c) sisal [99], (d) microcrystalline cellulose [100], (e) sugar beet pulp [101], (f) tunicin [102], (g) wheat straw [103], and (h) cotton [104].

matrices was reported. Physically cross-linked alginate capsules were successfully formed in the presence of either cellulose whiskers or microfibrillated cellulose [179]. The ensuing capsules have been extruded with a thermoplastic material.

6.2. Interfacial Interactions. Strong interactions between cellulose nanofibers prepared from cottonseed linters and between the filler and the glycerol-plasticized starch matrix were reported to play a key role in reinforcing properties [120]. In nonpercolating systems, for instance for materials processed from freeze-dried cellulose nanocrystals, strong matrix/filler interactions enhance the reinforcing effect of the filler. This observation was reported using EVA matrices with different vinyl acetate contents and then different 
TABLE 1: Geometrical characteristics of cellulose nanocrystals from various sources: length (L), cross section (D), and aspect ratio (L/d).

\begin{tabular}{|c|c|c|c|c|}
\hline Source & $\mathrm{L}(\mathrm{nm})$ & $\mathrm{D}(\mathrm{nm})$ & $\mathrm{L} / \mathrm{D}$ & Reference \\
\hline Acacia pulp & $100-250$ & $5-15$ & - & {$[105]$} \\
\hline Alfa & 200 & 10 & 20 & {$[106]$} \\
\hline Algal (Valonia) & $>1,000$ & $10-20$ & $\infty$ & {$[107,108]$} \\
\hline Bacterial & 100-several 1,000 & $5-10 \times 30-50$ & - & {$[98,109,110]$} \\
\hline Banana rachis & $500-1,000$ & 5 & - & [111] \\
\hline Bioresidue from wood bioethanol production & several 100 & $10-20$ & - & {$[112]$} \\
\hline Capim dourado & 300 & 4.5 & 67 & {$[113]$} \\
\hline Cassava bagasse & $360-1,700$ & $2-11$ & - & {$[114]$} \\
\hline Cladophora & - & $20 \times 20$ & - & {$[115]$} \\
\hline Coconut husk fibers & $80-500$ & 6 & 39 & {$[116]$} \\
\hline Cotton & $100-300$ & $5-15$ & 10 & {$[117-119]$} \\
\hline Cottonseed linter & $170-490$ & $40-60$ & - & {$[120]$} \\
\hline Curaúa & $80-170$ & $6-10$ & $13-17$ & {$[121]$} \\
\hline Date palm tree (rachis/leaflets) & $260 / 180$ & 6.1 & $43 / 30$ & {$[122]$} \\
\hline Eucalyptus wood pulp & 145 & 6 & 24 & {$[123]$} \\
\hline Flax & $100-500$ & $10-30$ & 15 & [124] \\
\hline Grass Zoysia & $200-700$ & $10-60$ & - & {$[125,126]$} \\
\hline Hemp & several 1,000 & $30-100$ & - & [127] \\
\hline Luffa cylindrica & 242 & 5.2 & 47 & {$[128]$} \\
\hline MCC & $150-300$ & $3-7$ & - & {$[100]$} \\
\hline Mulberry & $400-500$ & $20-40$ & - & [129] \\
\hline Pea hull & $240-400$ & $7-12$ & 34 & {$[130]$} \\
\hline \multirow{2}{*}{ Ramie } & $350-700$ & $70-120$ & \multirow{2}{*}[97,131,132]{} & \\
\hline & $150-250$ & $6-8$ & & \\
\hline Recycled pulp & $100-1,800$ & $30-80$ & - & {$[133]$} \\
\hline \multirow{2}{*}{ Sisal } & $100-500$ & $3-5$ & \multirow{2}{*}{$60 / 43$} & \multirow{2}{*}[99,134,135]{} \\
\hline & 215 & 5 & & \\
\hline Sugar beet pulp & 210 & 5 & 42 & {$[101]$} \\
\hline Sugarcane bagasse & $200-310$ & $2-6$ & 64 & {$[136]$} \\
\hline Tunicin & 100 -several 1,000 & $10-20$ & 67 & [137] \\
\hline Wheat straw & $150-300$ & 5 & 45 & {$[103]$} \\
\hline Wood & $100-300$ & $3-5$ & 50 & {$[115,138,139]$} \\
\hline
\end{tabular}

polarities [180]. Improvement of matrix/filler interactions by using cellulose whiskers coated with a surfactant was shown to play a major role on the nonlinear mechanical properties, especially on the elongation at break [181]. Grunert and Winter [98] founded a higher reinforcing effect for unmodified cellulose whiskers than for trimethylsilylated whiskers. Apart from the fact that $18 \%$ of the weight of the silylated crystals was due to the silyl groups, they attributed this difference to restricted filler/filler interactions.

6.3. Mechanical Performance. The first demonstration of the reinforcing effect of cellulose nanocrystals in a poly $(\mathrm{S}$ co-BuA) matrix was reported by Favier et al. [137]. The authors measured by DMA in the shear mode a spectacular improvement in the storage modulus after adding tunicin whiskers even at low content into the host polymer. This increase was especially significant above the glass-rubber transition temperature of the thermoplastic matrix because of its poor mechanical properties in this temperature range. Figure 13 shows the isochronal evolution of the logarithm of the relative storage shear modulus $\left(\log G_{T}^{\prime} / G_{200}^{\prime}\right.$, where $G_{200}^{\prime}$ corresponds to the experimental value measured at $200 \mathrm{~K}$ ) at $1 \mathrm{~Hz}$ as a function of temperature for such composites prepared by water evaporation.

In the rubbery state of the thermoplastic matrix, the modulus of the composite with a loading level as low as $6 \mathrm{wt} \%$ is more than two orders of magnitude higher than the one of the unfilled matrix. Moreover, the introduction of $3 \mathrm{wt} \%$ or more cellulosic whiskers provides an outstanding thermal stability of the matrix modulus up to the temperature at which cellulose starts to degrade $(500 \mathrm{~K})$.

The macroscopic behavior of cellulose nanofibers-based nanocomposites depends as for any heterogeneous materials, on the specific behavior of each phase, the composition (volume fraction of each phase), the morphology (spatial arrangement of the phases) and the interfacial properties. 


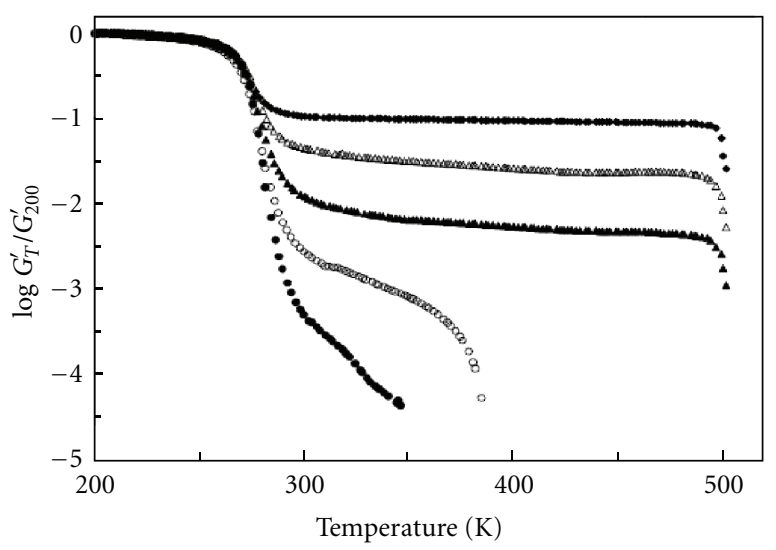

FIGURE 13: Logarithm of the normalized storage shear modulus $\left(\log G_{T}^{\prime} / G_{200}^{\prime}\right.$, where $G_{200}^{\prime}$ corresponds to the experimental value measured at $200 \mathrm{~K}$ ) versus temperature at $1 \mathrm{~Hz}$ for tunicin whiskers reinforced poly(S-co-BuA) nanocomposite films obtained by water evaporation and filled with $0(\bullet), 1(\bigcirc), 3(\Delta), 6(\triangle)$ and $14 \mathrm{wt} \%$ ( ) of cellulose whiskers [140].

The outstanding properties observed for these systems were ascribed to a mechanical percolation phenomenon [137]. A good agreement between experimental and predicted data was reported when using the series-parallel model of Takayanagi modified to include a percolation approach. Therefore, the mechanical performances of these systems were not only due to the high mechanical properties of the reinforcing nanoparticles. It was suspected that the stiffness of the material was due to infinite aggregates of cellulose whiskers. Above the percolation threshold, the cellulosic nanoparticles can connect and form a 3D continuous pathway through the nanocomposite film. For rod-like particles such as tunicin whiskers with an aspect ratio of 67 , the percolation threshold is close to $1 \mathrm{vol} \%$. The formation of this cellulose network was supposed to result from strong interactions between nanofibers, like hydrogen bonds. This phenomenon is similar to the high mechanical properties observed for a paper sheet, which result from the hydrogenbonding forces that hold the percolating network of fibers. This mechanical percolation effect allows explaining both the high reinforcing effect and the thermal stabilization of the composite modulus for evaporated films.

Any factor that affects the formation of the percolating whiskers network or interferes with it changes the mechanical performances of the composite [141]. Three main parameters were reported to affect the mechanical properties of such materials, namely, the morphology and dimensions of the nanoparticles, the processing method, and the microstructure of the matrix and matrix/filler interactions.

6.4. Thermal Stability. Thermogravimetric analysis (TGA) experiments were performed to investigate the thermal stability of tunicin whiskers/POE nanocomposites [152, 153]. No significant influence of the cellulosic filler on the degradation temperature of the POE matrix was reported. Cotton cellulose nanocrystals content appeared to have an effect on the thermal behavior of CMC plasticized with lycerin suggesting a close association between the filler and the matrix [162]. The thermal degradation of unfilled CMC was observed from its melting point $\left(270^{\circ} \mathrm{C}\right)$ and had a very narrow temperature range of degradation. Cellulose nanocrystals were found to degrade at a lower temperature $\left(230^{\circ} \mathrm{C}\right)$ than $\mathrm{CMC}$, but shown a very broad degradation temperature range. The degradation of cellulose whiskersreinforced CMC was observed between these two limits, but of interest was the lack of steps. Composites were reported to degrade as a unit.

\section{Applications of Polymer Composites}

7.1. Biocomposites. The charm of the use of synthetic fibres in polymer composites is fading, because these are expensive, nonbiodegradable, and pollute the environment. There is an increasing movement of scientists and engineers who are dedicated to minimizing the environmental impact of polymer composite production. Environmental footprints must be diminished at every stage of the life cycle of the polymer composite. Using natural fibers with polymers based on renewable resources will allow many environmental issues to be solved. By embedding biofibers with renewable resourcebased biopolymers such as cellulosic plastics; polylactides; starch plastics; polyhydroxyalkanoates (bacterial polyesters); soy-based plastics, the so-called green biocomposites could soon be the future.

Nowadays, biocomposites have been the subject of extensive research, specifically in construction and building industry due to their many advantages such as lower weight, and lower manufacturing costs. Currently, not only builders, but also many home owners are interested in using biocomposites for different products such as decking, fencing, and so on. Biocomposites may be classified, with respect to their applications in building industry into two main groups: structural and nonstructural biocomposites $[182,183]$.

\subsubsection{Structural Application. A structural Biocomposite can} be defined as one that is needed to carry a load in use. For instance, building industry, load-bearing walls, stairs, roof systems, and subflooring are examples of structural biocomposites. Structural biocomposites can range broadly in performance, from high performance to low performance materials. Biobased composite materials have been tested for suitability in roof structure (Figure 14) [184]. Structural beams have been designed, manufactured, and tested, yielding good results. Soy oil-based resin and cellulose fibers, in the form of paper sheets made from recycled cardboard boxes may be used for the manufacture of the composite structures.

Figure 15 represents, stay-in-place bridge forms (SIP) are utilized to span the distance between bridge girders. The SIP forms made from biocomposites have many benefits in comparison to steel forms. Biocomposite-based SIP forms are porous or breathable. Therefore, this lets water to evaporate through the form and to avoid any rebar corrosion. The form is also biodegradable; a biobased form has the potential to break down in the future, allowing underside inspection of the bridge deck. In addition, the form is 


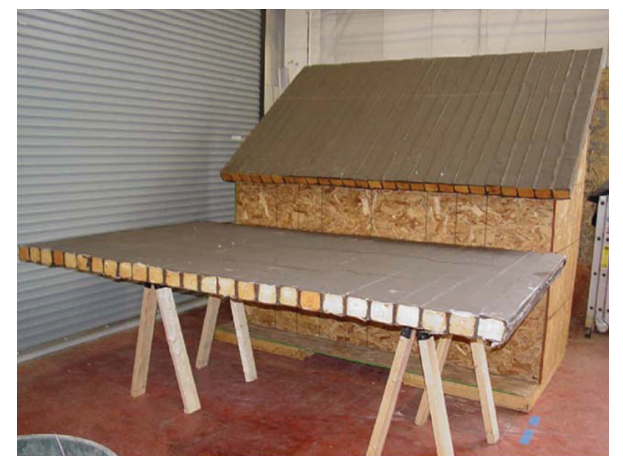

FIGURE 14: Biobased composite roof panels; one of them is mounted on a demonstration house made of timber [184].

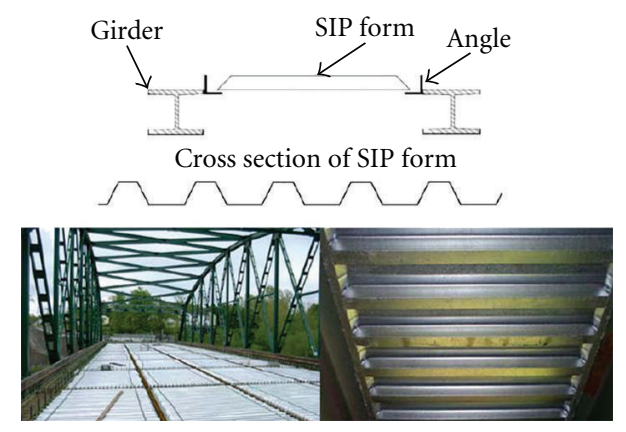

FIGURE 15: Stay-in-place bridge form.

lighter compared to a steel form, allowing faster and cheaper installations.

7.1.2. Nonstructural Application. A nonstructural biocomposite can be defined as one that need not carry a load during service. Materials such as thermoplastics, wood particles, and textiles are used to make this kind of Biocomposites. Nonstructural biocomposites are used for products such as ceiling tiles, furniture, windows, and doors.

Wood fiber plastic composites are made in standard lumber profile cross-section dimensions in exterior construction. These bioproducts are utilized as dock surface boards, deck, picnic tables, landscape timbers, and industrial flooring. Many manufacturers recommend that biocomposites need gaps on both edges and ends for their thermal expansion. Furthermore, wood-based bioproducts are gapped for expansion due to the moisture absorption.

Clear ponderosa pine is utilized in clad components. Currently, it is becoming limited and expensive. In addition, ponderosa pine needs broad cutting, edge gluing, and finger jointing to get clear sections for window and door fabrication. Also, the glued up material have to be milled to the accurate cross section to be used in the assembly which results in increasing cost and waste wood. Therefore, manufacturers use wood fiber plastic composites as an alternative for solid wood in clad components.

Biocomposites are utilized for the construction of composite panels. There are three types of panels: fiberboard, particleboard, and mineral-bonded panels. Bagasse fibers are used for particleboards, fiberboards, and composition panel production. Cereal straw is the second most usual agrobased fiber in panel production. The high percentages of silica in cereal straw make them naturally fire resistant. Also, the low density of straw panels has made them resilient. Results show that houses built by these panels are resistant to earthquake. Straw is also used in particleboards. Rice husks are also fibrous and need little energy input to make the husks ready for use. Rice husks or their ash are used in fiber cement blocks and other cement products. The presence of rice husks in building products helps to increase acoustic and thermal properties. A stress-skin panel-type product has been made by using polyurethane or polyester foam in the core and ply-bamboo in the faces [185]. Figure 16 indicates performance of cellular biocomposite panels against conventional slab and panel systems for commercial and residential construction [186].

7.2. Nanocomposites. The potential applicability of nanocellulose is widely extended. Applications of nanocellulose are mainly considered to be in paper and packaging products, although construction, automotive, furniture, electronics, pharmacy, and cosmetics are also being considered. For companies producing electroacoustic devices, nanocellulose is used as a membrane for high quality sound. Additionally, nanocellulose is applied in membrane for combustible cells (hydrogen); additives for high quality electronic paper (e-paper); ultrafiltrating membranes (water purification); membranes used to retrieve mineral and oils [187], and nowadays, nanocellulose has been greatly discussed and researched a huge variety of applications. The high strength and stiffness as well as the small dimensions of nanocellulose may well impart useful properties to composite materials reinforced with these fibers, which could subsequently be used in wide range of applications.

\subsubsection{Electronic Industry}

Diaphragms. Among various applications studied so far, which has already reached the level of practical use is related to acoustic diaphragms, nanocellulose has been found to bear two essential properties: high sonic velocity and low dynamic loss. In fact, the sonic velocity of pure film was almost equivalent to those of aluminium and titanium [63]. Jonas and Farah [188] stated that SONY had already been using it in headphones diaphragm (Figure 17).

The nanocellulose diaphragms are developed by dehydration and compressed to a thickness of 20 microns in a diaphragm die. The advantage of the ultrathin nanocellulose diaphragm is that it can produce the same sound velocity as an aluminum or titanium diaphragm, along with the warm, delicate sound that a paper diaphragm provides. Trebles are sparkling clear, and bass notes are remarkably deep and rich in these types of headphones.

Digital Displays. Cellulose has always been the prime medium for displaying information in our society; nowadays, efforts have been made to find dynamic display technology, for 


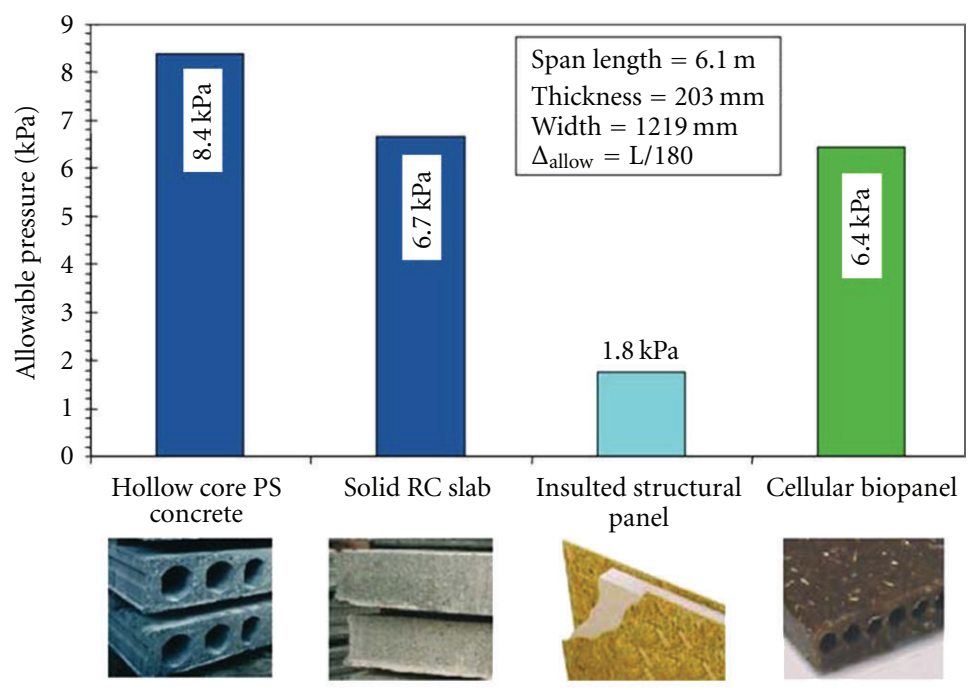

FIGURE 16: Performance of cellular biocomposite panels against conventional slab and panel systems for commercial and residential construction [186].

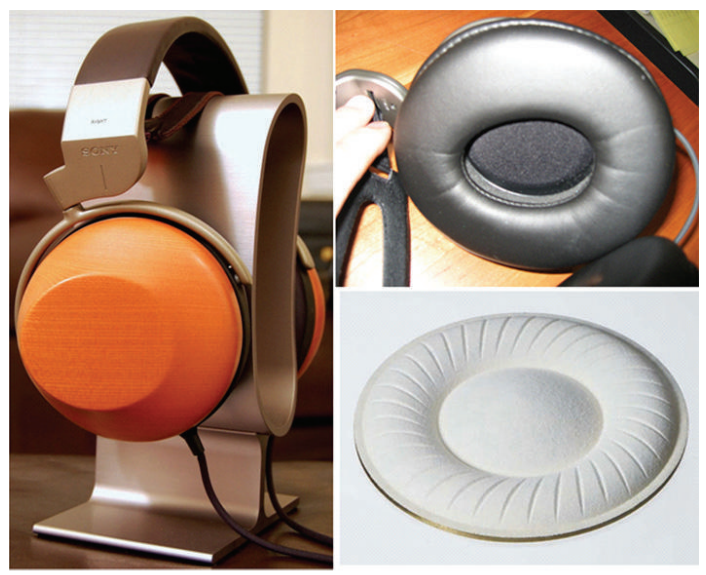

FIgURE 17: Nanocellulose diaphragm used in SONY headphones.

example in electronic paper. Nanocellulose is dimensionally stable and has a paper-like appearance which puts it into the leading role for the electronic paper's basic structure [189]. Shah and Brown [189] proved the concept in a device that holds many advantages such as high paper-like reflectivity, flexibility, contrast, and biodegradability. Figures 18 and 19 show the fabrication process of display device using nanocellulose. Summarizing, the whole idea is to integrate an electronic dye into the nanostructure of the microbial cellulose, and when integrated, a simple pixel can reversibly switch from the ON to the OFF state. The pixel size is controlled by the minimum addressing resolution of backplane drive circuits [189]. Yano et al. [190] have shown nanocellulose extraordinary potential as a reinforcement material in optically transparent plastics, for instance, as a substrate for bendable displays. According to the author, the composite remained optically transparent even at high fiber contents.
Legnani et al. [191] developed biodegradable and biocompatible flexible organic light emitting diode (FOLED) (Figure 20) based on nanocellulose (NC) membrane as substrate. Nanocomposite substrates based on nanocellulose (NC) and Boehmite-siloxane systems with improved optical transmittance in the visible region were used as flexible substrate for OLED applications. The nanocomposites formations improve the optical transmittance in visible range. Transmittance of $66 \%$ at $550 \mathrm{~nm}$ was found for the NCnanocomposite/ITO (Indium Tin Oxide) substrate when compared to the $40 \%$ value at the same wavelength for the NC/ITO substrate. ITO film was deposited at room temperature onto membranes and glass using rf magnetron sputtering with a $r_{f}$ power of $60 \mathrm{~W}$ and at pressure of $1 \mathrm{mtorr}$ in $\mathrm{Ar}$ atmosphere.

Other Electronic Usages. Evans et al. [192] found that nanocellulose catalyzed the deposition of metals within its structure, thus a finely divided homogeneous catalyst layer is generated. Experimental data suggested that nanocellulose possessed reducing groups capable of initiating the precipitation of palladium, gold, and silver from aqueous solution. Thus, the structure is suitable for the construction of membrane electrode assemblies. Olson et al. [193] showed that freeze-dried cellulose nanofibril aerogels can be used as templates for making lightweight porous magnetic aerogels, which can be compacted into a stiff magnetic nanopaper.

7.2.2. Pharmaceutical. Cellulose has a long history of use in the pharmaceutical industry. The material has excellent compaction properties when blended with other pharmaceutical excipients so that drug-loaded tablets form dense matrices suitable for the oral administration of drugs. Polysaccharides, natural polymers, fabricated into hydrophilic matrices remain popular biomaterials for controlled-release dosage forms and uses of a hydrophilic polymer matrix is one of the most popular approaches in formulating an extended 


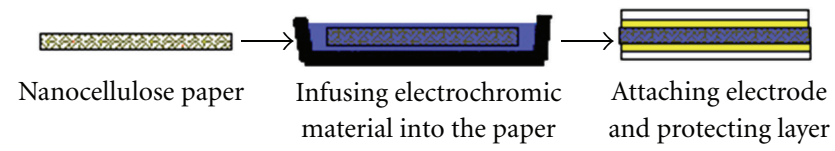

FIGURE 18: Fabrication process of the display using nanocellulose.

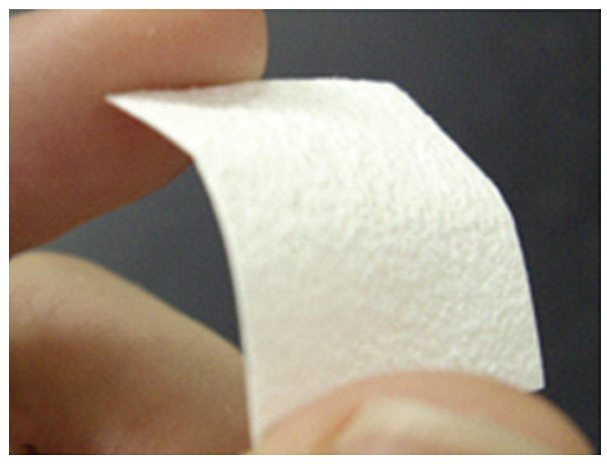

(a)

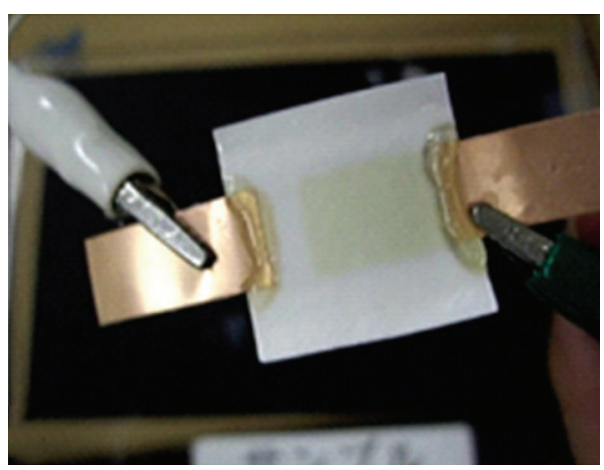

(c)

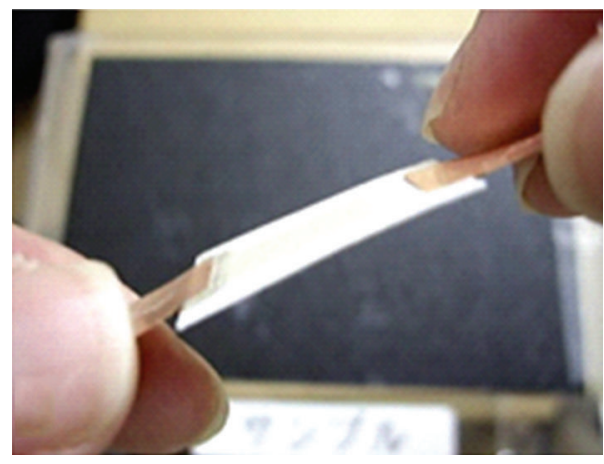

(b)

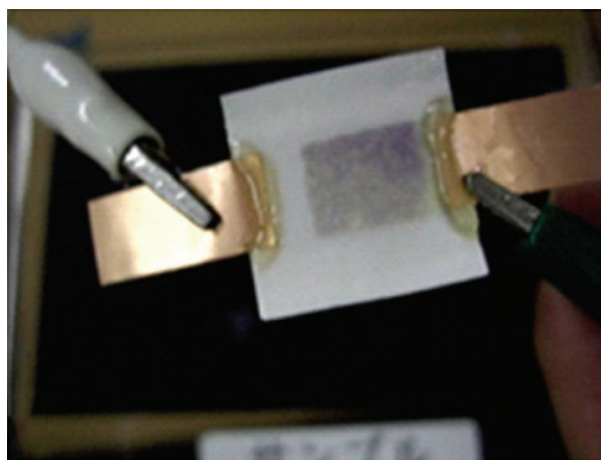

(d)

Figure 19: (a) The paper made of nanocellulose; (b) display device; (c) and (d) show the result of the chromogenic testing [189].

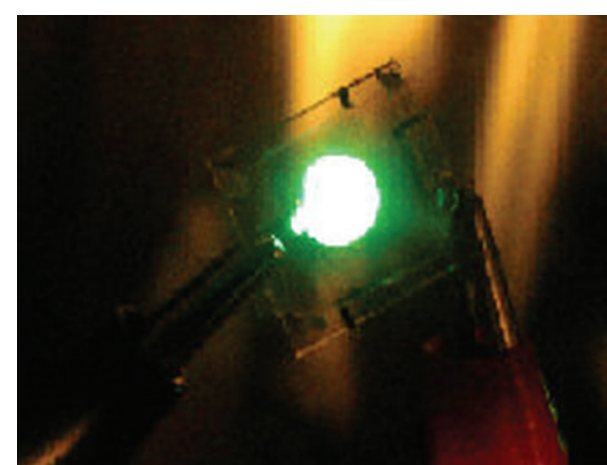

FIgure 20: Cellulose Nanocomposite based Flexible Organic Light Emitting Diode (FOLED).

release dosage forms [194-196]. This is due to the fact that these formulations are relatively flexible, and a well-designed system usually gives reproducible release profiles. Drug release is the process by which a drug leaves a drug product and is subjected to absorption, distribution, metabolism, and excretion (ADME), eventually becoming available for phar- macologic action. Crystalline nanocellulose offers several potential advantages as a drug delivery excipient. Crystalline nanocellulose and other types of cellulose in advanced pelleting systems whereby the rate of tablet disintegration and drug release may be controlled by microparticle inclusion, excipient layering or tablet coating [197, 198].

The very large surface area and negative charge of crystalline nanocellulose suggest that large amounts of drugs might be bound to the surface of this material with the potential for high payloads and optimal control of dosing. Other nanocrystalline materials, such as nanocrystalline clays, have been shown to bind and subsequently release drugs in a controlled manner via ion exchange mechanisms and are being investigated for use in pharmaceutical formulations [199]. The established biocompatibility of cellulose supports the use of nanocellulose for a similar purpose. The abundant surface hydroxyl groups on crystalline nanocellulose provide a site for the surface modification of the material with a range of chemical groups by a variety of methods. Surface modification may be used to modulate the loading and release of drugs that would not normally bind to nanocellulose, such as nonionized and hydrophobic 


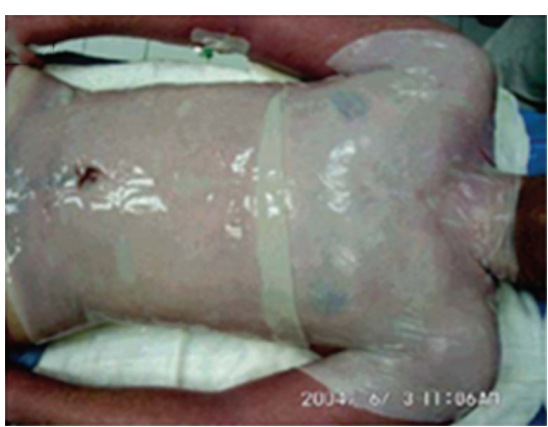

(a)

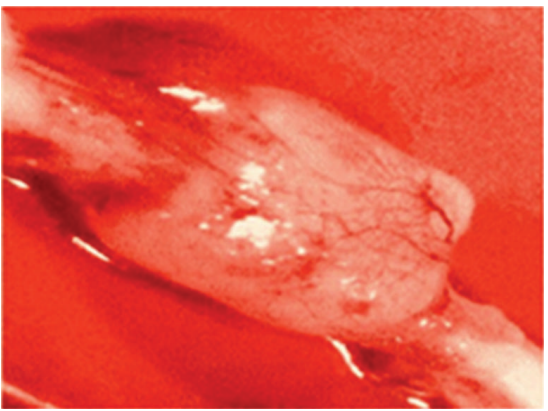

(d)

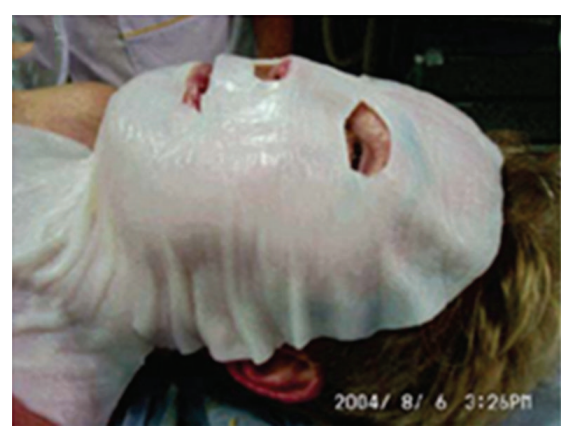

(b)

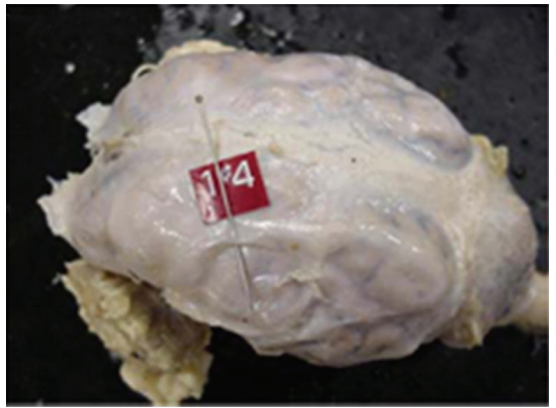

(e)

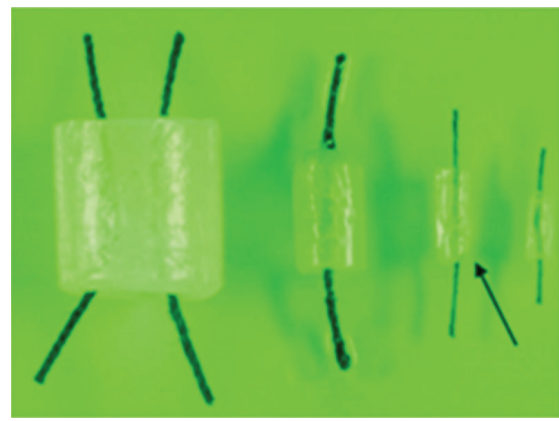

(c)

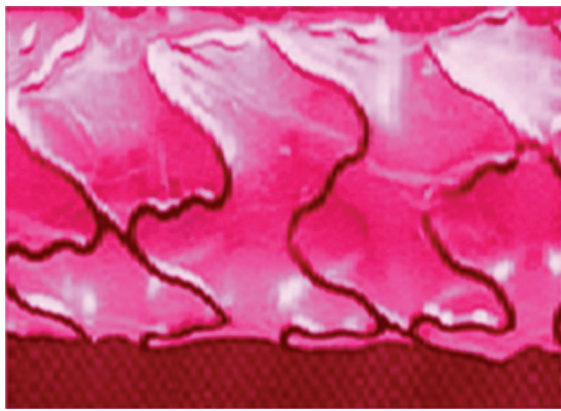

(f)

FIGURE 21: Biomedical applications of nanocellulose (a) and (b) never dried nanocellulose membrane [203]; (c) and (d) artificial blood vessels [205]; (e) dura mater reconstruction [202] (f) covering Stents [204].

drugs. For example, Lönnberg et al. suggested that poly(caprolactone) chains might be conjugated onto nanocrystalline cellulose for such a purpose [200].

Additionally, since crystalline nanocellulose is a low-cost, readily abundant material from a renewable and sustainable resource, its use provides a substantial environmental advantage compared with other nanomaterials.

7.2.3. Medical. Recently, nanocellulose has been called as the eyes of biomaterial highly applicable to biomedical industry which includes skins replacements for burnings and wounds; drugs releasing system; blood vessel growth; nerves, gum and duramater reconstruction; scaffolds for tissue engineering; stent covering and bone reconstruction [201205]. Figure 21 shows some applications for nanocellulose within biomedical field.

Tissue engineering looks for new material and devices which could interact positively with biological tissues [206], either working as an in vitro basis for cell growth or rearranging and developing tissue about to be implanted. They also aim new classes of degradable biopolymers that are biocompatible and whose activities are controllable and specific [207], more likely to be used as cell scaffolds [208] or in vitro tissue reconstruction.

As described above, a great variety of biomaterials have been developed recently. They have all sorts of properties (physical,chemical, and mechanical) depending mostly in the final application (tissue regeneration, medication holding and releasing, tissue grafting, or scaffolding) [203]. The scaffold's success depends much on the cellular adhesion and growth onto the surface, thus biopolymer's chemical surface can dictates cellular response by interfering in cellular adhesion, proliferation, migration, and functioning.

The surface-cell interaction is extremely important in implant effectiveness, including its rejection. Since the interaction is fully understood in a cell level, new biomaterials and products can be easily developed [209]. The problems still arise due to some methods inefficiency such as cell seeds and sources, scaffolding, ambient, extracellular matrix producing, and analysis and appropriate models [210].

On the other hand, to regenerate tissues, three specific foundations are taken: cells, support, and growth factors. Cells synthesize the matrix for the new tissues, support holds and keeps the ambient proper for the growth, while the growth factors facilitate and promote the cell regeneration [210]. Material used for implants cannot be either rejected or causes inflammatory response, in others, it should be biocompatible. Furthermore, it should promote regeneration and if necessary, be absorbed after a while or biodegradable [211]. Studies on support-cell interactions are crucial to implants viability. Many cell responses are observed out of different materials, so the cell ability to discriminate and adapt to it whether adhere or not to its surface [212]. This is crucial as it will direct further responses as cell proliferation, migration, and viability.

Due to the clinical importance of skin lesions, many laboratories had been aroused to the search for healing products having benefits including immediate pain relief, close adhesion to the wound bed, and reduced infection rate. The nanocellulose developed having huge superficial area that 


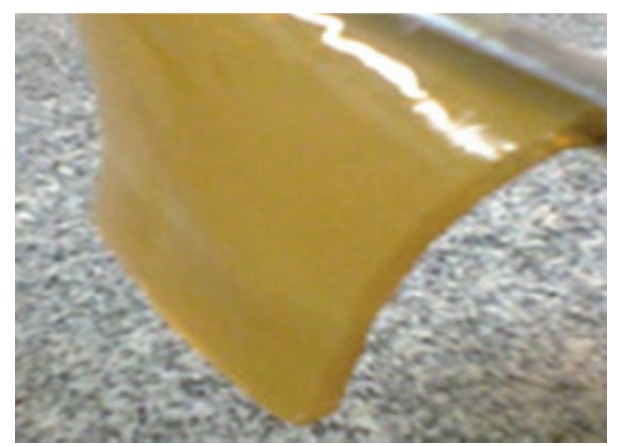

FIGURE 22: Nanocellulose and propolis-based bandage [213].

gives great water absorption capacity and elasticity. These are characteristics from an ideal healing bandage. On the other hand, it holds no microbial activity. Nanocellulose mats are very effective in promoting autolytic debridement, reducing pain, and accelerating granulation, all of which are important for proper wound healing. These nanobiocellulose membranes can be created in any shape and size, which is beneficial for the treatment of large and difficult to cover areas of the body.

Barud [213] has developed a biological membrane with bacterial cellulose and standardized extract of propolis. Propolis has many biological properties including antimicrobial and anti-inflammatory activities. All the above mentioned characteristics present, which make the membrane (Figure 22) a good treatment for burns and chronic wounds.

Odontology is challenged to find ideal materials to replace the bones in several procedures, as bones malformation, maxillary, and facial deformities. The biggest challenge is the loss of alveolar bone. Nanocellulose having suitable porosity which gives the mat an infection barrier, loss of fluids, painkiller effect, allows medicines to be easily applied and it also absorbs the purulent fluids during all inflammatory stages, expelling it later on in a controlled and painless manner [214].

Polyvinyl alcohol (PVA) is a hydrophilic biocompatible polymer with various characteristics desired for biomedical applications. PVA can be transformed into a solid hydrogel with good mechanical properties by physical crosslinking, using freeze-thaw cycles. Hydrophilic nanocellulose fibers of an average diameter of $50 \mathrm{~nm}$ are used in combination with PVA to form biocompatible nanocomposites. According to Millon and Wan [215], the resulting nanocomposites possess a broad range of mechanical properties and can be made with mechanical properties similar to that of cardiovascular tissues, such as aorta and heart valve leaflets. On their studies, the stress-strain properties for porcine aorta are matched by at least one type of PVA-nanocellulose nanocomposite in both the circumferential and the axial tissue directions. A PVA-nanocellulose nanocomposite with similar properties as heart valve tissue is also developed. Relaxation properties of all samples, which are important for cardiovascular applications, were also studied and found to relax at a faster rate and to a lower residual stress than the tissues they might replace. So, finally the new PVA-nanocellulose composite is a promising material for cardiovascular softtissue replacement applications.

Cai and Kim [216] have three different methods to prepare nanocellulose/PEG composite. In the method I, PEG was incorporated in nanocellulose hydrogels by adding PEG solution to the culture medium for Gluconacetobacter xylinus. In the method II, suspensions of microbial cellulose nanofibers are mixed with PEG solution with mechanical stirring followed by freezing-thawing process. The composite is a hydrogel and can be used for soft tissue replacement devices. In the method III, a previously produced nanocellulose hydrogel was soaked with PEG solution, allowing the PEG molecules to penetrate the nanocellulose [217]. The third method seems simple and effective. It has also been used to prepare other nanocellulose-based composite. For instance, nanocellulose has been soaked into hydroxyapatite to develop a composite scaffold for bone regeneration [218]. Nanocellulose has also been augmented by immersion in solutions of polyacrylamide and gelatin, yielding hydrogels with improved toughness [219]. Similarly, immersion of nanocellulose into poly (vinyl alcohol) has yielded hydrogels having a wide range of mechanical properties of interest for cardiovascular implants [215]. In this study, authors reported method III. SEM images showed that PEG molecules were not only coated on the nanocellulose fibrils surface but also penetrated into the nanocellulose fiber networks. The prepared scaffold has very well-interconnected porous network structure and large aspect surface. The TGA results prove the improved thermal stability. Tensile test results indicated that Young's Modulus and tensile strength tended to decrease while the elongation at break had a slight increase. It showed much better biocompatibility compared with the pure nanocellulose. Thus, the prepared Nanocellulose/PEG composite scaffolds are suitable for cell adhesion/attachment, suggesting that these scaffolds can be used for wound dressing or tissue-engineering applications.

Lin et al. [220] used gelatin and its enzymatically modified form (EMG) to prepare nanocellulose nanocomposites in an attempt to enhance the property of rehydration ability of nanocellulose. Referencing SEM photographs of the low gelatin/nanocellulose composites (LG/NC), gelatin is shown to lodge in nanocellulose networks and wrap up parts of cellulose ribbons (Figure 23(a)). As gelatin content in this sample was around 50\% (less than in high gelatin/ nanocellulose composites (HG/NC)), a certain quantity of cellulose ribbons emerged. EMG filled up some of the space in the nanocellulose network and some thickened cellulose ribbons could be observed in EMG/NC composites (Figure 23(b)). Film-like structures were observed only less in nonpolar EMG/nanocellulose (NPEMG/NC) and polar (PEMG/NC) composites. Porous networks and thickened cellulose ribbons could be found in these two composites (Figures 23(c) and 23(d)).

It appears that NPEMG and PEMG permeated into the network and adsorbed on the cellulose ribbons, allowing the continuance of porous structures in these composites. According to the results, they concluded that gelatin and its hydrolysates in combination with nanocellulose can effectively improve the rehydration properties of composites. 


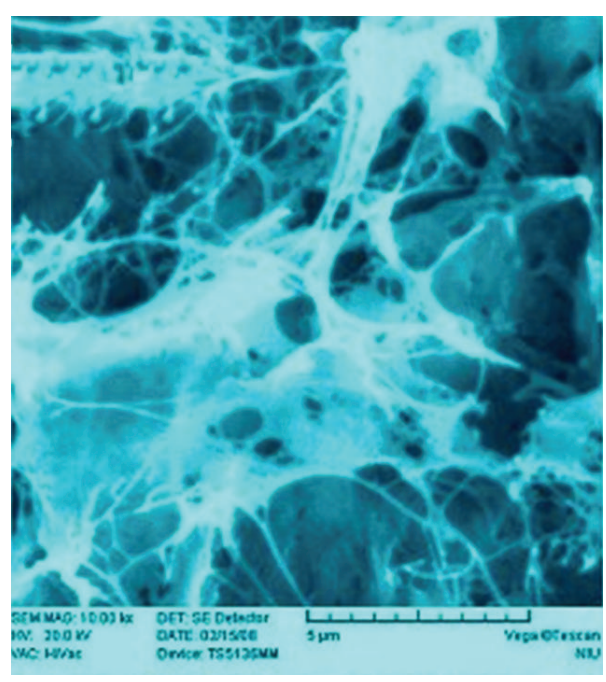

(a)

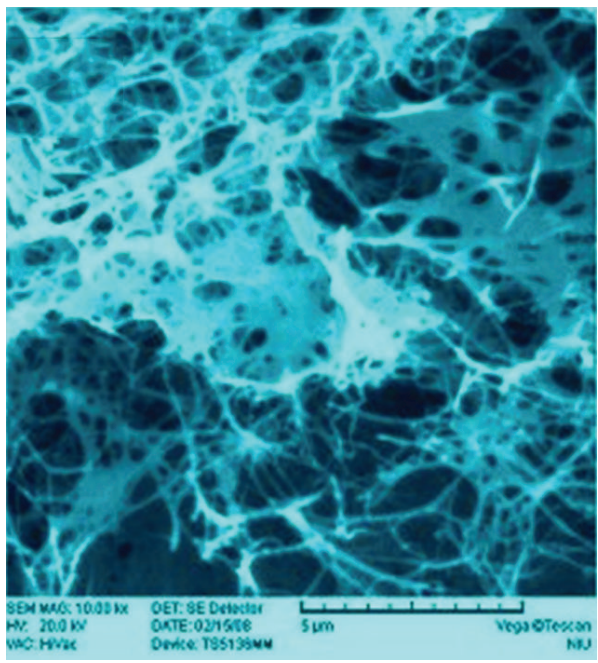

(c)

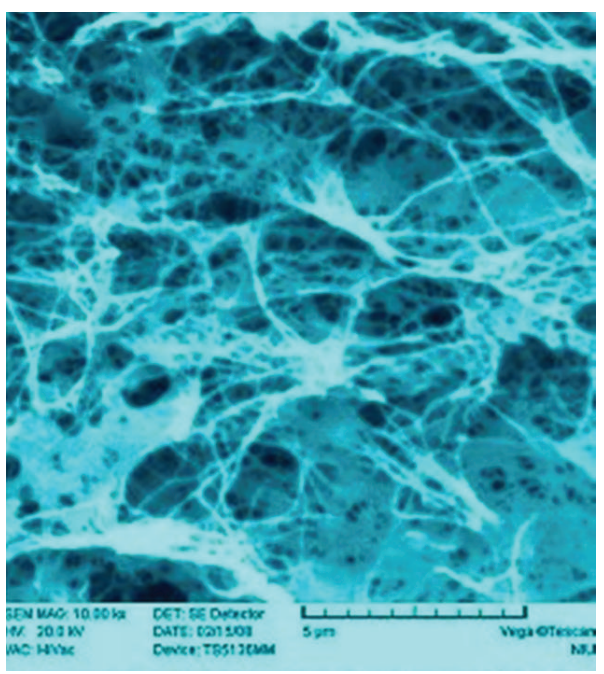

(b)

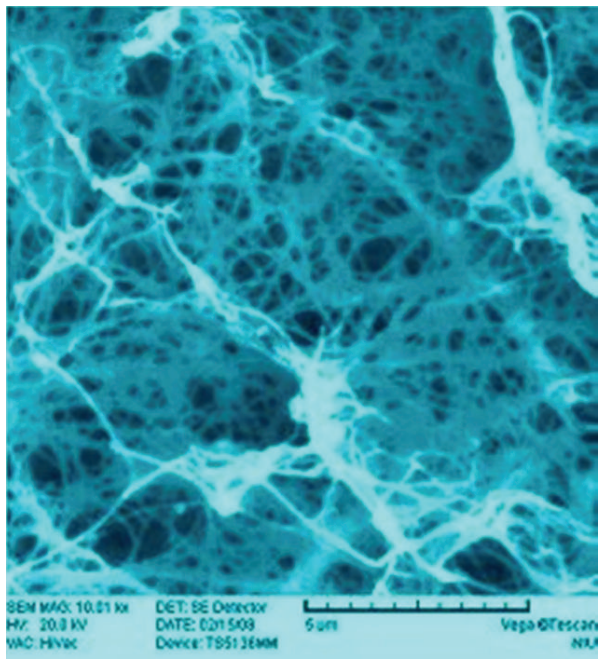

(d)

FIGUre 23: SEM photographs (10000X) of LG/NC (a) Gelatin/NC (b) EMG/NC (c) NPEMG/NC (d) PEMG/NC [220].

The polar functional groups of gelatin and EMG as well as nanocellulose porous networks with lower level of crystallinity contributed to the rehydration ability of composites. Nanocellulose immersed in 0.5\% EMG solution was sufficient to prepare the desirable composites and may be applied in a rehydratable membrane.

In ophthalmologist area, Huia et al. [221] explored the potentiality of nanocellulose applied as the scaffold of tissue engineering cornea. They studied the growth of human corneal stromal cells on nanocellulose. The ingrowth of corneal stromal cells into the scaffold was verified by laser-scanning confocal microscope. The results suggest the potentiality for this biomaterial as a scaffold for tissue engineering of artificial cornea. The surface of nanocellulose is lumpy with rills. In Figures 24(a) and 24(b), the red regions are corneal stromal cells immunofluorescent stained by Vim and the blue region is the nanocellulose scaffold. It is clearly illustrated that corneal stromal cells ingrew into the scaffold.
For otorhinolaryngologist, surgery of the lateral wall of the nose is common procedure in the ENT specialty and was recommended for resection of soft lush, removal of tumors, or to promote aeration of the sinuses. The evolution of surgical techniques provided increased safety to patients, drastically reducing the complications and postoperative morbidity. The nasal bleeding, surgical wound infections, local pain, and the presence of adhesions are the major complicating factors related to nasal surgery. Several types of materials have been developed in order to prevent these complications. Nasal packing has been used in these postsurgical procedures and, although effective in preventing bleeding, requires removal causing great discomfort to the patient. Moreover, their presence has been associated with systemic infections graves.

The use of a material that, in addition to preventing bleeding, could provide more rapid healing without the formation of crusts and prevent infection without the need 


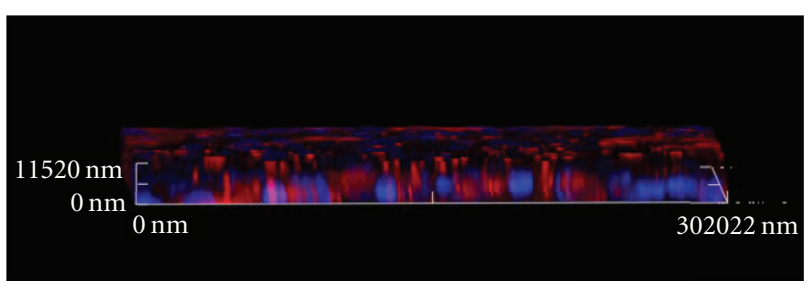

(a)

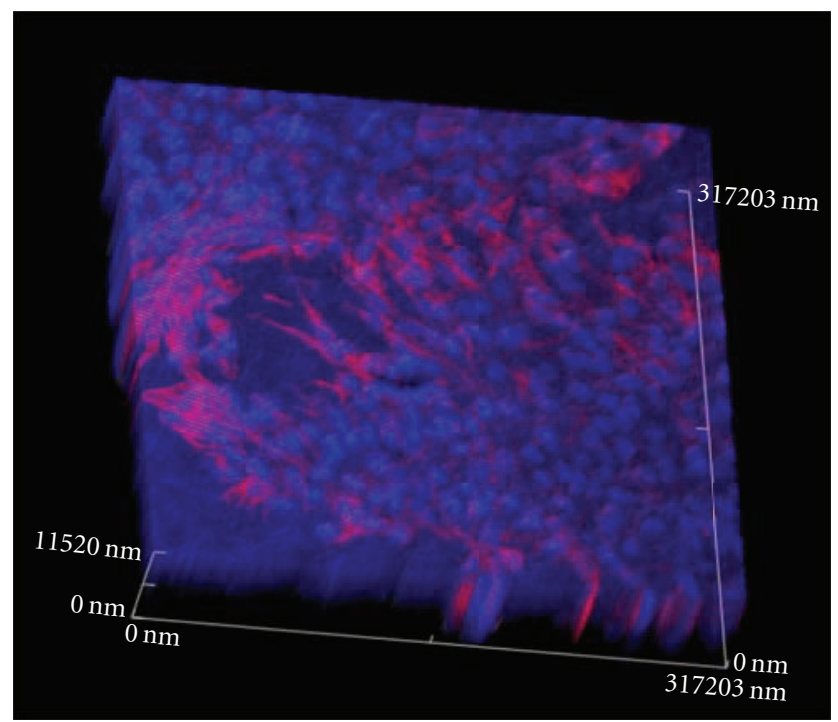

(b)

FIGURE 24: Growth of Vim immune fluorescent stained human corneal stromal cells in nanocellulose scaffold, observed by LSCM (400X) [221].

for removal would be of great aid in the postoperative period of patients undergoing resection of the lower nasal concha and other nasal surgeries. In 1984, microbiologist Louis Farah Fernando Xavier was able, through the fermentation of bacteria of the genus Acetobacter, to produce bacterial cellulose. The resulting film of this synthesis, after processing, is endowed with selective permeability, allowing passage of water vapour but preventing the passage of microorganisms. It is semitransparent, homogeneous, with an average thickness of $0.05 \mathrm{~mm}$ and visually very similar to human skin. Schumann et al. [222] studied the artificial vascular implants from nanocellulose by two studies. In a first microsurgical study, the nanocellulose implants were attached in an artificial defect of the carotid artery of rats for 1 year. These long-term results show the incorporation of the nanocellulose under formation of neointima and ingrowth of active fibroblasts. In a second study, the grafts were used to replace the carotid arteries of pigs. After 3 months, these grafts were removed and analyzed both macro- and microscopically. Seven grafts $(87.5 \%)$ were patent whereas one graft was found occluded. These data indicate that the innovative nanocellulose engineering technique results in the production of stable vascular conduits and confirm a highly attractive approach to in vivo tissue-engineered blood vessels as part of programs in cardiovascular surgery. The Figure 25 shows the untreated segment of carotid artery revealing a homogeneous endothelialization inside the grafts with an almost smooth transition to the artery.

Another use of nanocellulose is for nasal reconstruction. The desire for an ideal shape has always been part of mankind. Nose, centrally located in the face, is better susceptible to traumas, deformities, thus social disorders. Even since having a major breathing function, it has a great esthetic function, highlighting face's genetics. Amorim et al. [223] evaluated the tissue response to the presence of nanocellulose in the nose bone (Figure 26). It had been used 22 rabbits, being that, in 20 a cellulose blanket was implanted in the nasal dorsum, 2 were kept as control group. After three and six months, the back bone was extirpated for further histopathological study, parameter, were such as blood vessels clogging, inflammation intensity, and presence of purulent fluids.

Inflammation was found to be stable, which is probably due to the surgical procedure itself and not to the cellulosic blanket. For the other parameters, there was no statistical significance. Nanocellulosic blanket showed good biocompatibility and did not change over time, thus an excellent material to elevate the nose bone.

7.2.4. Veterinary. Hart et al. [224] studied the pellicle and its ability to promote fibroblast migration and cellular proliferation in diabetic rats. The treatment accelerated the wound healing for the diabetic rats and improved histological outcome. Diabetic rat is a recognized model for chronic wounds, thus sharing some features with the chronic human wound. So they could predict the applicability in humans.

Helenius et al. [225] studied for the first time the in vivo biocompatibility of nanocellulose systematically. Thus, in the development nanocellulose membrane was implanted into the subcutaneous space of rats for 1,4 , and 12 weeks. The implants were evaluated in aspects of chronic inflammation, foreign body responses, cell ingrowth, and angiogenesis, using histology, immunohistochemistry, and electron microscopy. There were no macroscopic signs of inflammation around the implants (redness, edema or exudates) (Figure 27). There were no microscopic signs of inflammation either (i.e., a high number of small cells around the implants or the blood vessels). No fibrotic capsule or giant cells were present. Fibroblasts infiltrated nanocellulose (Figure 28), which was well integrated into the host tissue and did not elicit any chronic inflammatory reactions, so the biocompatibility of nanocellulose is proved and the material has potential to be used as a scaffold in tissue engineering.

Helenius et al. [225] brought up more knowledge on biomaterial and its interaction with the cell. In their study, membranes of nanocellulose had been implanted into rats and the biocompatibility was evaluated in vivo. Implants did not cause "foreign body reaction," fibrosis or encapsulation, and the rat's conjunctive tissues were well integrated to nanocellulose. Some weeks after the implantation, the rearrangement kept on happening and fibroblasts were fully integrated to the cellulosic structure, they had started to synthesize collagen. 


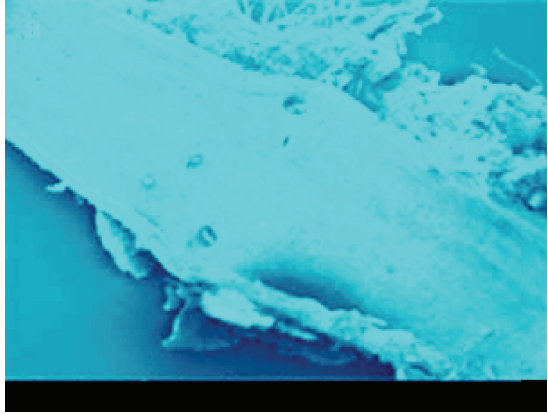

(a)

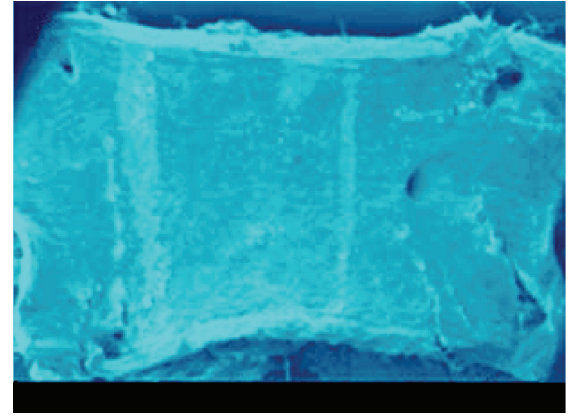

(b)

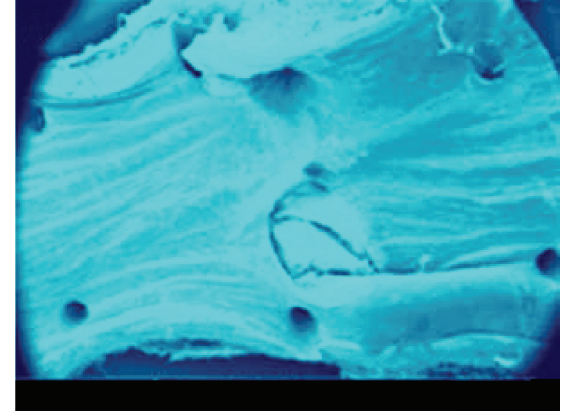

(c)

FIgURE 25: SEM (magnification 169× to 199×): (a) untreated segment of the carotid artery, (b) and (c) good endothelialization of nanocellulose grafts [222].

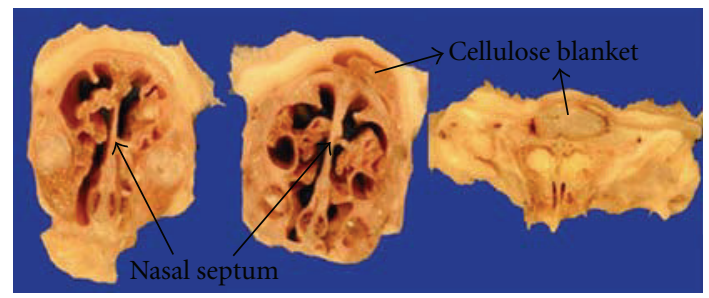

Figure 26: Serial cut from the nasal septum and front part of the nose showing the cellulose blanket in the nose bone structure.

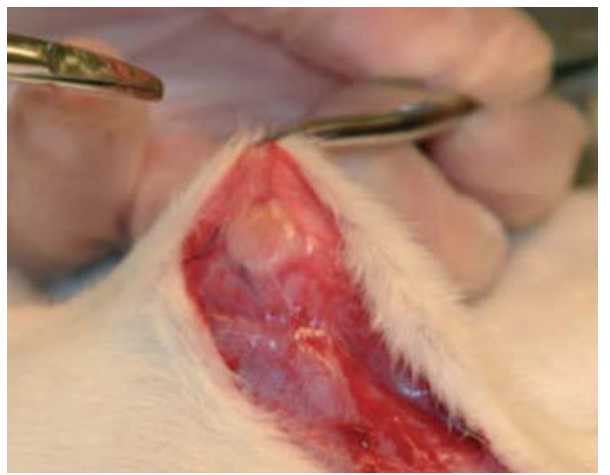

FIGURE 27: Explantation of implants after 1 week [225].

Helenius et al. [225] had also shown that the density influenciates the morphology and cell penetration such as density increased, cell migration lowed. It was observed that nucleus morphology depends on the direction taken by the cellulosic nanofiber, blood flow was also observed.

Fewer cells are present compared to that after 1 and 4 weeks and the fibroblasts inside the nanocellulose have synthesized collagen (B) high magnification of the interface area at the porous side of nanocellulose after 12 weeks. Arrow heads show collagen synthesized by the fibroblasts

Silva [226] had evaluated the biological behavior of synthetic hydroxyapatite (HAP-91) when implanted in the dental cavities and covered by nanocellulose. Membranes were shaped into triangles fully covering the cavities avoiding the contact between hydroxyapatite and the oral cavity (a source of contaminants, Figure 29). Silva found that nanocellulose associated to the HAP promoted faster bone regeneration if compared with the control group. 8 days after procedure and a delay of 30 days, although after 50 days they had tissues alike.

Costa and de Souza [227] studied the skin healing in white swines; they underwent thermal abrasion, (metal temperature at $100^{\circ} \mathrm{C}$ ). Comparing Bionext to the daily healing bandage, all the animals had the healing process completed equally. No differences were seen between the daily bandage and the cellulose pellicle (Bionext ${ }^{\circledR}$ ).

For dogs whose peritoneum had been replaced, it was observed that 45 days after the implant, fibroblasts and blood vessels numbers increased. After 90 days, collagen and fibroblasts penetrated into nanocellulose and 180 days after implantation nanocellulose formed a net along the conjunctive tissue, little evidence of neovascularization was found [228].

7.2.5. Dental. Nanocellulose was tested in dental tissue regeneration. Microbial cellulose, produced by the Glucanacetobacter xylinus strain, can be used to regenerate dental tissues in humans (Figure 30).

Nanocellulose product Gengiflex and Gore-Tex has intended applications within the dental industry. It was developed to aid periodontal tissue recovery [229]. A description was given of a complete restoration of an osseus defect around an IMZ implant in association with a Gengiflex therapy. The benefits included the reestablishment of aesthetics and function of the mouth and that a reduced number of surgical steps were required.

The bandage, called Gengiflex, consists of two layers: the inner layer is composed of microbial cellulose, which offers rigidity to the membrane, and the outer alkalicellulose layer is chemically modified [230]. Salata et al. [231] compared the biological performance of Gengiflex and GoreTex membranes using the in vivo nonhealing bone-defect model proposed by Dahlin et al. [232].

The study showed that Gore-Tex membranes (a composite with polytetrafluoroethylene, urethane, and nylon) were associated with significantly less inflammation and both membranes promoted the same amount of bone formation 


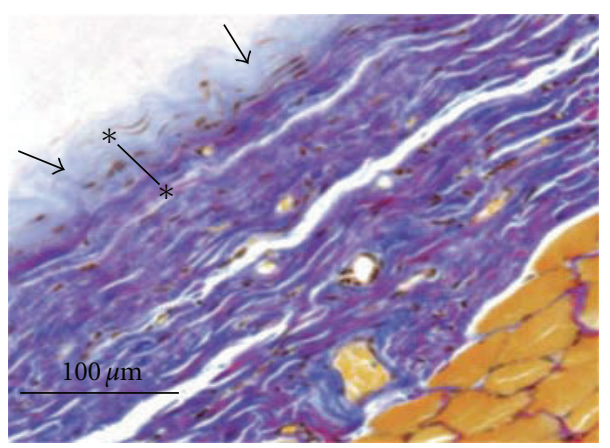

(a)

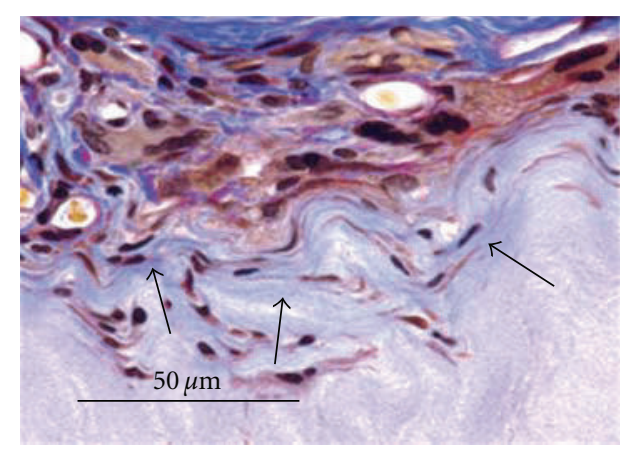

(b)

FIGURE 28: Ladewig's trichrome staining. (a) The compact side after 12 weeks showing the fibroblasts inside the nanocellulose have synthesized collagen (seen as blue staining; indicated with arrow heads), (b) High magnification of the interface area at the porous side of nanocellulose after 12 weeks (Arrow heads show collagen synthesized by the fibroblasts) [225].

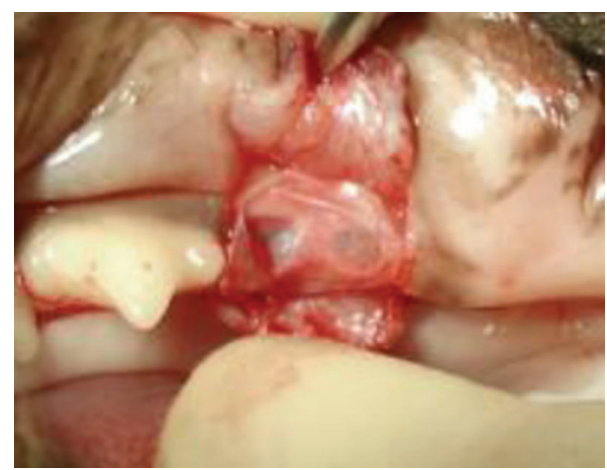

Figure 29: Cellulosic membranes used as dental cavities covering in cats [226].

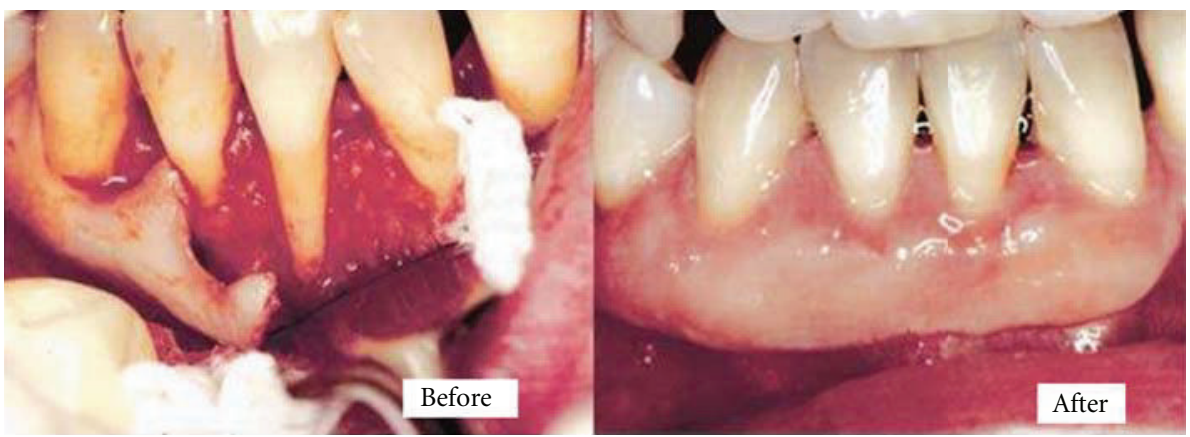

FIGURE 30: Nanocellulose used in dental tissue regeneration in 39-year-old female patient.

during the same period of time. A greater amount of bone formation was present in bone defects protected by either Gore-Tex or microbial cellulose membrane, when compared to the control sites. Gore-Tex is better tolerated by the tissues than Gengiflex. Recently, in a similar vein, Macedo et al. [233] also compared bacterial cellulose and polytetrafluoroethylene (PTFE) as physical barriers used to treat bone defects in guided tissue regeneration. In this study, two osseous defects ( $8 \mathrm{~mm}$ in diameter) were performed in each hind-foot of four adult rabbits, using surgical burs with constant sterile saline solution irrigation. The effects obtained on the right hind-feet were protected with PTFE barriers, while
Gengiflex membranes were used over wounds created in the left hind-feet. After 3 months, the histological evaluation of the treatments revealed that the defects covered with PTFE barriers were completely repaired with bone tissue, whereas incomplete lamellar bone formation was detected in defects treated with Gengiflex membranes, resulting in voids and lack of continuity of bone deposition.

Nanocellulose with its characteristics like nanofibers size and distribution, mechanical properties, compatibility, and ability to mold create it has a unique biomaterial indispensable in health area. The nanocellulose composite scaffolds are biocompatible with less rejection with cellular contact and 
blood contact cells interaction to be a promissory biomaterial and may be suitable for cell adhesion/attachment suggesting that these scaffolds can be used for wound-dressing or tissueengineering scaffolds.

\section{Conclusions}

The potential applicability of cellulose-based biocomposites and nanocomposites is widely extended. Due to a great number of properties, applications of nanocellulose-based materials are mainly considered to be in a wide range of applications such as paper and packaging products, construction, automotive, furniture, and electronics. Pharmacy, cosmetics, and biomedical applications are also being considered. The mechanical properties such as high strength and stiffness, the surface reactivity (with numerous hydroxyl groups), the specific organization as well as the small dimensions of nanocellulose may well impart useful properties to (nano)composite materials reinforced with these fibers.

\section{References}

[1] S. Kalia, B. S. Kaith, and I. Kaur, "Pretreatments of natural fibers and their application as reinforcing material in polymer composites-a review," Polymer Engineering and Science, vol. 49, no. 7, pp. 1253-1272, 2009.

[2] I. Siro and D. Plackett, "Microfibrillated cellulose and new nanocomposite materials: a review," Cellulose, vol. 17, no. 3, pp. 459-494, 2010.

[3] S. J. Eichhorn, A. Dufresne, M. Aranguren et al., "Review: current international research into cellulose nanofibres and nanocomposites," Journal of Materials Science, vol. 45, no. 1, pp. 1-33, 2010.

[4] A. K. Bledzki, S. Reihmane, and J. Gassan, "Properties and modification methods for vegetable fibers for natural fiber composites," Journal of Applied Polymer Science, vol. 59, no. 8, pp. 1329-1336, 1996.

[5] P. R. Hornsby, E. Hinrichsen, and K. Tarverdi, "Preparation and properties of polypropylene composites reinforced with wheat and flax straw fibres: part II analysis of composite microstructure and mechanical properties," Journal of Materials Science, vol. 32, no. 4, pp. 1009-1015, 1997.

[6] K. Oksman, L. Wallstrom, L. A. Berglund, and R. D. T. Filho, "Morphology and mechanical properties of unidirectional sisal-epoxy composites," Journal of Applied Polymer Science, vol. 84, no. 13, pp. 2358-2365, 2002.

[7] D. N. Saheb and J. P. Jog, "Natural fiber polymer composites: a review," Advances in Polymer Technology, vol. 18, no. 4, pp. 351-363, 1999.

[8] S. T. Georgopoulos, P. A. Tarantili, E. Avgerinos, A. G. Andreopoulos, and E. G. Koukios, "Thermoplastic polymers reinforced with fibrous agricultural residues," Polymer Degradation and Stability, vol. 90, no. 2, pp. 303-312, 2005.

[9] R. L. Crawford, Lignin Biodegradation and Transformation, John Wiley \& Sons, New York, NY, USA, 1981.

[10] A. Payen, "Mémoire sur la composition du tissu propre des plantes et du ligneux," Comptes Rendus, vol. 7, pp. 1052$1056,1838$.

[11] Dorée, The Methods of Cellulose Chemistry, Chapman \& Hall, London, UK, 1947.

[12] The Merck Index, Merck \& Co, Rahway, NJ, USA, 8th edition, 1968.
[13] http://www.fibersource.com/f-tutor/cellulose.htm.

[14] P. M. Visakh and S. Thomas, "Preparation of bionanomaterials and their polymer nanocomposites from waste and biomass," Waste and Biomass Valorization, vol. 1, no. 1, pp. 121-134, 2010.

[15] G. I. Williams and R. P. Wool, "Composites from natural fibers and soy oil resins," Applied Composite Materials, vol. 7, no. 5-6, pp. 421-432, 2000.

[16] F. G. Torres and R. M. Diaz, "Morphological characterisation of natural fibre reinforced thermoplastics (NFRTP) processed by extrusion, compression and rotational moulding," Polymers \& Polymer Composites, vol. 12, no. 8, pp. 705-718, 2004.

[17] M. Z. Rong, M. Q. Zhang, Y. Liu, G. C. Yang, and H. M. Zeng, "The effect of fiber treatment on the mechanical properties of unidirectional sisal-reinforced epoxy composites," Composites Science and Technology, vol. 61, Article ID 10.1016/S02663538(01)00046-X, pp. 1437-1447, 2001.

[18] K. Van de Velde and P. Kiekens, "Thermoplastic pultrusion of natural fibre reinforced composites," Composite Structures, vol. 54, no. 2-3, pp. 355-360, 2001.

[19] H. L. Bos, M. J. A. van den Oever, and O. C. J. J. Peters, "Tensile and compressive properties of flax fibres for natural fibre reinforced composites," Journal of Materials Science, vol. 37, no. 8, pp. 1683-1692, 2002.

[20] C. Baley, "Analysis of the flax fibres tensile behaviour and analysis of the tensile stiffness increase," Composites Part A, vol. 33, no. 7, pp. 939-948, 2002.

[21] B. Lamy and C. Baley, "Stiffness prediction of flax fibersepoxy composite materials," Journal of Materials Science Letters, vol. 19, no. 11, pp. 979-980, 2000.

[22] A. Jähn, M. W. Schröder, M. Füting, K. Schenzel, and W. Diepenbrock, "Characterization of alkali treated flax fibres by means of FT Raman spectroscopy and environmental scanning electron microscopy," Spectrochimica Acta Part A, vol. 58, no. 10, pp. 2271-2279, 2002.

[23] J. Gassan and A. K. Bledzki, "Einfluß von haftvermittlern auf das feuchteverhalten naturfaserverstärkter kunststoffe," Die Angewandte Makromolekulare Chemie, vol. 236, pp. 129-138, 1996.

[24] A. J. Michell, "Wood cellulose-organic polymer composites," in Composite Asia Pacific, vol. 89, p. 19, Institute of Australia, Adelaide, Australia, 1989.

[25] T. M. Maloney, in International Encyclopedia of Composites, S. M. Lee and R. M. Rowell, Eds., p. 656, VCH Publishers, New York, USA, 1995.

[26] K. P. Mieck, A. Nechwatal, and C. Knobelsdorf, "Potential applications of natural fibres in composite materials," Melliand Textilberichte, vol. 75, no. 11, p. 892, 1994.

[27] P. S. Mukherjee and K. G. Satyanarayana, "An empirical evaluation of structure-property relationships in natural fibres and their fracture behaviour," Journal of Materials Science, vol. 21, no. 12, pp. 4162-4168, 1986.

[28] A. Alemdar and M. Sain, "Biocomposites from wheat straw nanofibers: morphology, thermal and mechanical properties," Composites Science and Technology, vol. 68, no. 2, pp. 557-565, 2008.

[29] A. Alemdar and M. Sain, "Isolation and characterization of nanofibers from agricultural residues-wheat straw and soy hulls," Bioresource Technology, vol. 99, no. 6, pp. 1664-1671, 2008.

[30] T. Zimmermann, N. Bordeanu, and E. Strub, "Properties of nanofibrillated cellulose from different raw materials and its 
reinforcement potential," Carbohydrate Polymers, vol. 79, no. 4, pp. 1086-1093, 2010.

[31] B. Wang and M. Sain, "Dispersion of soybean stock-based nanofiber in a plastic matrix," Polymer International, vol. 56, no. 4, pp. 538-546, 2007.

[32] A. Kaushik, M. Singh, and G. Verma, "Green nanocomposites based on thermoplastic starch and steam exploded cellulose nanofibrils from wheat straw," Carbohydrate Polymers, vol. 82, no. 2, pp. 337-345, 2010.

[33] S. Kalia, S. Vashistha, and B. S. Kaith, "Cellulose nanofibers reinforced bioplastics and their applications," in Handbook of Bioplastics and Biocomposites Engineering Applications, S. Pilla, Ed., chapter 16, Wiley-Scrivener Publishing, New York, NY, USA, 2011.

[34] E. M. Teixeira, A. C. Corrêa, C. R. de Oliveira et al., "Cellulose nanofibers from white and naturally colored cotton fibers," Cellulose, vol. 17, no. 3, pp. 595-606, 2010.

[35] W. Stelte and A. R. Sanadi, "Preparation and characterization of cellulose nanofibers from two commercial hardwood and softwood pulps," Industrial and Engineering Chemistry Research, vol. 48, no. 24, pp. 11211-11219, 2009.

[36] S. Kalia, B. S. Kaith, S. Sharma, and B. Bhardwaj, "Mechanical properties of flax-g-poly(methyl acrylate) reinforced phenolic composites," Fibers and Polymers, vol. 9, no. 4, pp. 416422, 2008.

[37] R. Agrawal, N. S. Saxena, K. B. Sharma, S. Thomas, and M. S. Sreekala, "Activation energy and crystallization kinetics of untreated and treated oil palm fibre reinforced phenol formaldehyde composites," Materials Science and Engineering A, vol. 277, no. 1-2, pp. 77-82, 2000.

[38] F. M. B. Coutinho, T. H. S. Costa, and D. L. Carvalho, "Polypropylene-wood fiber composites: effect of treatment and mixing conditions on mechanical properties," Journal of Applied Polymer Science, vol. 65, no. 6, pp. 1227-1235, 1997.

[39] L. González, A. Rodríguez, J. L. de Benito, and A. MarcosFernández, "Applications of an azide sulfonyl silane as elastomer crosslinking and coupling agent," Journal of Applied Polymer Science, vol. 63, no. 10, pp. 1353-1359, 1997.

[40] S. R. Culler, H. Ishida, and J. L. Koenig, "silane interphase of composites: effect of process conditions on gamma aminopropyltriethoxysilane," Polymer Composites, vol. 7, no. 4, pp. 231-238, 1986.

[41] N. D. Ghatge and R. S. Khisti, "Performance of new silane coupling agents along with phenolic nobake binder for sand core," Journal of Polymer Materials, vol. 6, no. 3, pp. 145-149, 1989.

[42] M. S. Sreekala, M. G. Kumaran, S. Joseph, M. Jacob, and S. Thomas, "Oil palm fibre reinforced phenol formaldehyde composites: influence of fibre surface modifications on the mechanical performance," Applied Composite Materials, vol. 7, no. 5-6, pp. 295-329, 2000.

[43] I. Van De Weyenberg, J. Ivens, A. De Coster, B. Kino, E. Baetens, and I. Verpoest, "Influence of processing and chemical treatment of flax fibres on their composites," Composites Science and Technology, vol. 63, no. 9, pp. 12411246, 2003.

[44] A. Valadez-Gonzalez, J. M. Cervantes-Uc, R. Olayo, and P. J. Herrera-Franco, "Chemical modification of henequen fibers with an organosilane coupling agent," Composites Part B, vol. 30, no. 3, pp. 321-331, 1999.

[45] D. Ray, B. K. Sarkar, A. K. Rana, and N. R. Bose, "Effect of alkali treated jute fibres on composite properties," Bulletin of Materials Science, vol. 24, no. 2, pp. 129-135, 2001.
[46] K. Joseph, L. H. C. Mattoso, R. D. Toledo et al., "Natural fiber reinforced thermoplastic composites," in Natural Polymers and Agrofibers Composites, E. Frollini, A. L. Leão, and L. H. C. Mattoso, Eds., chapter 4, pp. 159-201, Embrapa, Sãn Carlos, Brazil, 2000.

[47] J. Gassan and A. K. Bledzki, "Alkali treatment of jute fibers: relationship between structure and mechanical properties," Journal of Applied Polymer Science, vol. 71, no. 4, pp. 623-629, 1999.

[48] C. Garcia-Jaldon, D. Dupeyre, and M. R. Vignon, "Fibres from semi-retted hemp bundles by steam explosion treatment," Biomass and Bioenergy, vol. 14, no. 3, pp. 251-260, 1998.

[49] E. S. Rodriguez, P. M. Stefani, and A. Vazquez, "Effects of fibers' alkali treatment on the resin transfer molding processing and mechanical properties of Jute-Vinylester composites," Journal of Composite Materials, vol. 41, no. 14, pp. 1729-1741, 2007.

[50] L. A. Pothan, C. N. George, M. Jacob, and S. Thomas, "Effect of chemical modification on the mechanical and electrical properties of banana fiber polyester composites," Journal of Composite Materials, vol. 41, no. 19, pp. 2371-2386, 2007.

[51] A. Paul, S. Joseph, and S. Thomas, "A study of the influence of interfacial damage on stress concentrations in unidirectional composites," Composites Science and Technology, vol. 57, p. 67, 1997.

[52] M. S. Sreekala, M. G. Kumaran, and S. Thomas, "Water sorption in oil palm fiber reinforced phenol formaldehyde composites," Composites Part A, vol. 33, no. 6, pp. 763-777, 2002.

[53] B. Wang, S. Panigrahi, L. Tabil, and W. Crerar, "Pre-treatment of flax fibers for use in rotationally molded biocomposites," Journal of Reinforced Plastics and Composites, vol. 26, no. 5, pp. 447-463, 2007.

[54] S. Kalia, V. K. Kaushik, and R. K. Sharma, "Effect of benzoylation and graft copolymerization on morphology, thermal stability, and crystallinity of sisal fibers," Journal of Natural Fibers, vol. 8, no. 1, p. 27, 2011.

[55] B. Wang, "Pre-treatment of flax fibers for use in rotationally molded biocomposites," M.S. thesis, University of Saskatchewan, Saskatoon, Canada, 2004.

[56] B. S. Kaith, A. S. Singha, S. Kumar, and B. N. Misra, "FAS$\mathrm{H} 2 \mathrm{O} 2$ initiated graft copolymerization of methylmethacrylate onto flax and evaluation of some physical and chemical properties," Journal of Polymer Materials, vol. 22, no. 4, pp. 425-432, 2005.

[57] S. Kalia, A. Kumar, and B. S. Kaith, Advanced Materials Letters, vol. 2, p. 17, 2011.

[58] M. Tsukada, S. Islam, T. Arai, A. Boschi, and G. Freddi, "Microwave irradiation technique to enhance protein fibre properties," Autex Research Journal, vol. 5, no. 1, pp. 40-48, 2005.

[59] B. S. Kaith and S. Kalia, "Preparation of microwave radiation induced graft copolymers and their applications as reinforcing material in phenolic composites," Polymer Composites, vol. 29, no. 7, pp. 791-797, 2008.

[60] B. S. Kaith and S. Kalia, "Graft copolymerization of MMA onto flax under different reaction conditions: a comparative study," Express Polymer Letters, vol. 2, no. 2, pp. 93-100, 2008.

[61] M. Pommet, J. Juntaro, J. Y. Y. Heng et al., "Surface modification of natural fibers using bacteria: depositing bacterial cellulose onto natural fibers to create hierarchical fiber reinforced nanocomposites," Biomacromolecules, vol. 9, no. 6, pp. 1643-1651, 2008. 
[62] M. Shoda and Y. Sugano, "Recent advances in bacterial cellulose production," Biotechnology and Bioprocess Engineering, vol. 10, no. 1, pp. 1-8, 2005.

[63] M. Iguchi, S. Yamanaka, and A. Budhiono, "Bacterial cellulose- a masterpiece of nature's arts," Journal of Materials Science, vol. 35, no. 2, pp. 261-270, 2000.

[64] E. E. Brown and M. P. G. Laborie, "Bioengineering bacterial cellulose/poly(ethylene oxide) nanocomposites," Biomacromolecules, vol. 8, no. 10, pp. 3074-3081, 2007.

[65] A. N. Nakagaito and H. Yano, "Novel high-strength biocomposites based on microfibrillated cellulose having nanoorder-unit web-like network structure," Applied Physics A, vol. 80, no. 1, pp. 155-159, 2005.

[66] D. J. Gardner, G. S. Oporto, R. Mills, and M. Samir, "Adhesion and surface issues in cellulose and nanocellulose," Journal of Adhesion Science and Technology, vol. 22, pp. 545$545,2008$.

[67] S. Kalia and R. Sheoran, "Modification of ramie fibers using microwave-assisted grafting and cellulase enzyme-assisted biopolishing: a comparative study of morphology, thermal stability, and crystallinity," International Journal of Polymer Analysis and Characterization, vol. 16, no. 5, pp. 307-318, 2011.

[68] J. Njuguna, P. Wambua, K. Pielichowski, and K. Kayvantash, "Natural Fiber-reinforced polymer composites and nanocomposites for automotive applications," in Cellulose Fibers: Bio- and Nano-Polymer Composites, S. Kalia, B. S. Kaith, and I. Kaur, Eds., Springer, Heidelberg, Germany, 2011.

[69] S. Mishra, A. K. Mohanty, L. T. Drzal, M. Misra, and G. Hinrichsen, "A review on pineapple leaf fibers, sisal fibers and their biocomposites," Macromolecular Materials and Engineering, vol. 289, no. 11, pp. 955-974, 2004.

[70] P. Wambua, J. Ivens, and I. Verpoest, "Natural fibres: can they replace glass in fibre reinforced plastics?" Composites Science and Technology, vol. 63, no. 9, pp. 1259-1264, 2003.

[71] J. Summerscales, N. Dissanayake, A. Virk, and W. Hall, "A review of bast fibres and their composites. Part 2composites," Composites Part A, vol. 41, no. 10, pp. 13361344, 2010.

[72] A. K. Bledzki and J. Gassan, "Composites reinforced with cellulose based fibres," Progress in Polymer Science, vol. 24, no. 2, pp. 221-274, 1999.

[73] R. Gauthier, C. Joly, A. C. Coupas, H. Gauthier, and M. Escoubes, "Interfaces in polyolefin/cellulosic fiber composites: chemical coupling, morphology, correlation with adhesion and aging in moisture," Polymer Composites, vol. 19, no. 3, pp. 287-300, 1998.

[74] J. George, M. S. Sreekala, and S. Thomas, "A review on interface modification and characterization of natural fiber reinforced plastic composites," Polymer Engineering \& Science, vol. 41, no. 9, pp. 1471-1485, 2001.

[75] Y. Xie, C. A. S. Hill, Z. Xiao, H. Militz, and C. Mai, "Silane coupling agents used for natural fiber/polymer composites: a review," Composites Part A, vol. 41, no. 7, pp. 806-819, 2010.

[76] J. Gassan and A. K. Bledzki, "Effect of cyclic moisture absorption desorption on the mechanical properties of silanized jute-epoxy composites," Polymer Composites, vol. 20, no. 4, pp. 604-611, 1999.

[77] A. K. Mohanty, M. Misra, and L. T. Drzal, Eds., Natural Fibers, Biopolymers, and Biocomposites, CRC Press, Boca Raton, Fla, USA, 2005.
[78] H. L. Bos, J. Müssig, and M. J. A. van den Oever, "Mechanical properties of short-flax-fibre reinforced compounds," Composites Part A, vol. 37, no. 10, pp. 1591-1604, 2006.

[79] H. L. Bos, The potential of flax fibers as reinforcement for composite materials, Ph.D. thesis, Technische Universiteit Eindhoven, Eindhoven, The Netherlands, 2004.

[80] S. K. Garkhail, R. W. H. Heijenrath, and T. Peijs, "Mechanical properties of natural-fibre-mat-reinforced thermoplastics based on flax fibres and polypropylene," Applied Composite Materials, vol. 7, no. 5-6, pp. 351-372, 2000.

[81] T. Nishino, "Natural fiber sources," in Green Composites: Polymer Composites and the Environment, CRC Press, Boca Raton, Fla, USA, 2004.

[82] A. Espert, F. Vilaplana, and S. Karlsson, "Comparison of water absorption in natural cellulosic fibres from wood and one-year crops in polypropylene composites and its influence on their mechanical properties," Composites Part A, vol. 35, no. 11, pp. 1267-1276, 2004.

[83] M. M. Thwe and K. Liao, "Durability of bamboo-glass fiber reinforced polymer matrix hybrid composites," Composites Science and Technology, vol. 63, no. 3-4, pp. 375-387, 2003.

[84] C. Pavithran, P. S. Mukherjee, and M. Brahmakumar, "Coir-glass intermingled fibre hybrid composites," Journal of Reinforced Plastics and Composites, vol. 10, no. 1, pp. 91-101, 1991.

[85] B. C. Tobias, "Tensile and Impact behaviour of natural fiber-reinforced composite materials," in Proceedings of the International Conference on Advanced Composite Materials, $\mathrm{T}$. D. A. K. Chandra, Ed., The Minerals, Metals and Materials Society, 1993.

[86] H. D. Mueller, "Improving the impact strength of natural fiber reinforced composites by specifically designed material and process parameters," IJN Winter, 2004.

[87] J. C. M. De Bruijn, "Natural fibre mat thermoplastic products from a processor's point of view," Applied Composite Materials, vol. 7, no. 5-6, pp. 415-420, 2000.

[88] J. Gassan, "A study of fibre and interface parameters affecting the fatigue behaviour of natural fibre composites," Composites Part A, vol. 33, no. 3, pp. 369-374, 2002.

[89] H. Savastano Jr., S. F. Santos, M. Radonjic, and W. O. Soboyejo, "Fracture and fatigue of natural fiber-reinforced cementitious composites," Cement and Concrete Composites, vol. 31, no. 4, pp. 232-243, 2009.

[90] A. N. Towo and M. P. Ansell, "Fatigue of sisal fibre reinforced composites: constant-life diagrams and hysteresis loop capture," Composites Science and Technology, vol. 68, no. 3-4, pp. 915-924, 2008.

[91] A. N. Towo and M. P. Ansell, "Fatigue evaluation and dynamic mechanical thermal analysis of sisal fibre-thermosetting resin composites," Composites Science and Technology, vol. 68, no. 3-4, pp. 925-932, 2008.

[92] T. Yuanjian and D. H. Isaac, "Impact and fatigue behaviour of hemp fibre composites," Composites Science and Technology, vol. 67, no. 15-16, pp. 3300-3307, 2007.

[93] M. Henriksson, G. Henriksson, L. A. Berglund, and T. Lindström, "An environmentally friendly method for enzymeassisted preparation of microfibrillated cellulose (MFC) nanofibers," European Polymer Journal, vol. 43, no. 8, pp. 3434-3441, 2007.

[94] T. Saito, S. Kimura, Y. Nishiyama, and A. Isogai, "Cellulose nanofibers prepared by TEMPO-mediated oxidation of native cellulose," Biomacromolecules, vol. 8, no. 8, pp. 24852491, 2007. 
[95] L. Wågberg, G. Decher, M. Norgren, T. Lindström, M. Ankerfors, and K. Axnäs, "The build-up of polyelectrolyte multilayers of microfibrillated cellulose and cationic polyelectrolytes," Langmuir, vol. 24, no. 3, pp. 784-795, 2008.

[96] M. E. Malainine, M. Mahrouz, and A. Dufresne, "Thermoplastic nanocomposites based on cellulose microfibrils from opuntia ficus-indica parenchyma cell," Composites Science and Technology, vol. 65, no. 10, pp. 1520-1526, 2005.

[97] Y. Habibi, A. L. Goffin, N. Schiltz, E. Duquesne, P. Dubois, and A. Dufresne, "Bionanocomposites based on $\operatorname{poly}(\varepsilon$ caprolactone)-grafted cellulose nanocrystals by ring-opening polymerization," Journal of Materials Chemistry, vol. 18, no. 41, pp. 5002-5010, 2008.

[98] M. Grunert and W. T. Winter, "Nanocomposites of cellulose acetate butyrate reinforced with cellulose nanocrystals," Journal of Polymers and the Environment, vol. 10, no. 1-2, pp. 27-30, 2002.

[99] N. L. Garcia de Rodriguez, W. Thielemans, and A. Dufresne, "Sisal cellulose whiskers reinforced polyvinyl acetate nanocomposites," Cellulose, vol. 13, no. 3, pp. 261270, 2006.

[100] I. Kvien, B. S. Tanem, and K. Oksman, "Characterization of cellulose whiskers and their nanocomposites by atomic force and electron microscopy," Biomacromolecules, vol. 6, no. 6, pp. 3160-3165, 2005.

[101] M. A. S. A. Samir, F. Alloin, M. Paillet, and A. Dufresne, "Tangling effect in fibrillated cellulose reinforced nanocomposites," Macromolecules, vol. 37, no. 11, pp. 4313-4316, 2004.

[102] M. N. Anglès and A. Dufresne, "Plasticized starch/tuniein whiskers nanocomposites. 1. Structural analysis," Macromolecules, vol. 33, no. 22, pp. 8344-8353, 2000.

[103] W. Helbert, J. Y. Cavaillé, and A. Dufresne, "Thermoplastic nanocomposites filled with wheat straw cellulose whiskers. Part I: processing and mechanical behavior," Polymer Composites, vol. 17, no. 4, pp. 604-611, 1996.

[104] K. Fleming, D. Gray, S. Prasannan, and S. Matthews, "Cellulose crystallites: a new and robust liquid crystalline medium for the measurement of residual dipolar couplings," Journal of the American Chemical Society, vol. 122, no. 21, pp. 5224-5225, 2000.

[105] Y. Pu, J. Zhang, T. Elder, Y. Deng, P. Gatenholm, and A. J. Ragauskas, "Investigation into nanocellulosics versus acacia reinforced acrylic films," Composites Part B, vol. 38, no. 3, pp. 360-366, 2007.

[106] A. B. Elmabrouk, T. Wim, A. Dufresne, and S. Boufi, "Preparation of poly(styrene-co-hexylacrylate)/cellulose whiskers nanocomposites via miniemulsion polymerization," Journal of Applied Polymer Science, vol. 114, no. 5, pp. 2946-2955, 2009.

[107] J. F. Revol, "On the cross-sectional shape of cellulose crystallites in valonia ventricosa," Carbohydrate Polymers, vol. 2, no. 2, pp. 123-134, 1982.

[108] S. J. Hanley, J. Giasson, J. F. Revol, and D. G. Gray, "Atomic force microscopy of cellulose microfibrils: comparison with transmission electron microscopy," Polymer, vol. 33, no. 21, pp. 4639-4642, 1992.

[109] C. Tokoh, K. Takabe, M. Fujita, and H. Saiki, "Cellulose synthesized by acetobacter xylinum in the presence of acetyl glucomannan," Cellulose, vol. 5, no. 4, pp. 249-261, 1998.

[110] M. Roman and W. T. Winter, "Effect of sulfate groups from sulfuric acid hydrolysis on the thermal degradation behavior of bacterial cellulose," Biomacromolecules, vol. 5, no. 5, pp. 1671-1677, 2004.
[111] R. Zuluaga, J. L. Putaux, A. Restrepo, I. Mondragón, and P. Ganan, "Cellulose microfibrils from banana farming residues: isolation and characterization," Cellulose, vol. 14, no. 6, pp. 585-592, 2007.

[112] K. Oksman, J. A. Etang, A. P. Mathew, and M. Jonoobi, "Cellulose nanowhiskers separated from a bio-residue from wood bioethanol production," Biomass \& Bioenergy, vol. 35, no. 1, pp. 146-152, 2011.

[113] G. Siqueira, H. Abdillahi, J. Bras, and A. Dufresne, "High reinforcing capability cellulose nanocrystals extracted from Syngonanthus nitens (Capim Dourado)," Cellulose, vol. 17, no. 2, pp. 289-298, 2010.

[114] E. D. M. Teixeira, D. Pasquini, A. A. S. Curvelo, E. Corradini, M. N. Belgacem, and A. Dufresne, "Cassava bagasse cellulose nanofibrils reinforced thermoplastic cassava starch," Carbohydrate Polymers, vol. 78, no. 3, pp. 422-431, 2009.

[115] U. J. Kim, S. Kuga, M. Wada, T. Okano, and T. Kondo, "Periodate oxidation of crystalline cellulose," Biomacromolecules, vol. 1, no. 3, pp. 488-492, 2000.

[116] M. F. Rosa, E. S. Medeiros, J. A. Malmonge et al., "Cellulose nanowhiskers from coconut husk fibers: effect of preparation conditions on their thermal and morphological behavior," Carbohydrate Polymers, vol. 81, no. 1, pp. 83-92, 2010.

[117] X. M. Dong, J. F. Revol, and D. G. Gray, "Effect of microcrystallite preparation conditions on the formation of colloid crystals of cellulose," Cellulose, vol. 5, no. 1, pp. 19-32, 1998.

[118] T. Ebeling, M. Paillet, R. Borsali et al., "Shear-induced orientation phenomena in suspensions of cellulose microcrystals, revealed by small angle X-ray scattering," Langmuir, vol. 15, no. 19, pp. 6123-6126, 1999.

[119] J. Araki, M. Wada, and S. Kuga, "Steric Stabilization of a Cellulose Microcrystal Suspension by Poly(ethylene glycol) Grafting," Langmuir, vol. 17, no. 1, pp. 21-27, 2001.

[120] Y. Lu, L. Weng, and X. Cao, "Biocomposites of plasticized starch reinforced with cellulose crystallites from cottonseed linter," Macromolecular Bioscience, vol. 5, no. 11, pp. 11011107, 2005.

[121] A. C. Corrêa, E. M. Teixeira, L. A. Pessan, and L. H. C. Mattoso, "Cellulose nanofibers from curaua fibers," Cellulose, vol. 17, no. 6, pp. 1183-1192, 2010.

[122] A. Bendahou, Y. Habibi, H. Kaddami, and A. Dufresne, "Physico-chemical characterization of palm from Phoenix Dactylifera-L, preparation of cellulose whiskers and natural rubber-based nanocomposites," Journal of Biobased Materials and Bioenergy, vol. 3, no. 1, pp. 81-90, 2009.

[123] J. P. De Mesquita, C. L. Donnici, and F. V. Pereira, "Biobased nanocomposites from layer-by-layer assembly of cellulose nanowhiskers with chitosan," Biomacromolecules, vol. 11, no. 2, pp. 473-480, 2010.

[124] X. Cao, H. Dong, and C. M. Li, "New nanocomposite materials reinforced with flax cellulose nanocrystals in waterborne polyurethane," Biomacromolecules, vol. 8, no. 3, pp. 899-904, 2007.

[125] J. K. Pandey, J. W. Lee, W. S. Chu, C. S. Kim, C. S. Lee, and S. H. Ahn, "Cellulose nanowhiskers from grass of Korea," Macromolecular Research, vol. 16, no. 5, pp. 396-498, 2008.

[126] J. K. Pandey, W. S. Chu, C. S. Kim, C. S. Lee, and S. H. Ahn, "Bio-nano reinforcement of environmentally degradable polymer matrix by cellulose whiskers from grass," Composites Part B, vol. 40, no. 7, pp. 676-680, 2009.

[127] B. Wang, M. Sain, and K. Oksman, "Study of structural morphology of hemp fiber from the micro to the nanoscale," Applied Composite Materials, vol. 14, no. 2, pp. 89-103, 2007. 
[128] G. Siqueira, J. Bras, and A. Dufresne, "Luffa cylindrica as a lignocellulosic source of fiber, microfibrillated cellulose, and cellulose nanocrystals," BioResources, vol. 5, no. 2, pp. 727740, 2010.

[129] R. Li, J. Fei, Y. Cai, Y. Li, J. Feng, and J. Yao, "Cellulose whiskers extracted from mulberry: a novel biomass production," Carbohydrate Polymers, vol. 76, no. 1, pp. 94-99, 2009.

[130] G. Chen, A. Dufresne, J. Huang, and P. R. Chang, "A novel thermoformable bionanocomposite based on cellulose nanocrystal-graft-poly(E-caprolactone)," Macromolecular Materials and Engineering, vol. 294, pp. 59-67, 2009.

[131] Y. Lu, L. Weng, and X. Cao, "Morphological, thermal and mechanical properties of ramie crystallites-reinforced plasticized starch biocomposites," Carbohydrate Polymers, vol. 63, no. 2, pp. 198-204, 2006.

[132] Y. Habibi and A. Dufresne, "Highly filled bionanocomposites from functionalized polysaccharide nanocrystals," Biomacromolecules, vol. 9, no. 7, pp. 1974-1980, 2008.

[133] P. B. Filson, B. E. Dawson-Andoh, and D. Schwegler-Berry, "Enzymatic-mediated production of cellulose nanocrystals from recycled pulp," Green Chemistry, vol. 11, no. 11, pp. 1808-1814, 2009.

[134] G. Siaueira, J. Bras, and A. Dufresne, "Cellulose whiskers versus microfibrils: influence of the nature of the nanoparticle and its surface functionalization on the thermal and mechanical properties of nanocomposites," Biomacromolecules, vol. 10, no. 2, pp. 425-432, 2009.

[135] G. Siqueira, J. Bras, and A. Dufresne, "New process of chemical grafting of cellulose nanoparticles with a long chain isocyanate," Langmuir, vol. 26, no. 1, pp. 402-411, 2010.

[136] E. M. Teixeira, T. J. Bondancia, K. B. R. Teodoro, A. C. Corrêa, J. M. Marconcini, and L. H. C. Mattoso, "Sugarcane bagasse whiskers: extraction and characterizations," Industrial Crops and Products, vol. 33, no. 1, pp. 63-66, 2011.

[137] V. Favier, G. R. Canova, J. Y. Cavaillé, H. Chanzy, A. Dufresne, and C. Gauthier, "Nanocomposite materials from latex and cellulose whiskers," Polymers for Advanced Technologies, vol. 6, no. 5, pp. 351-355, 1995.

[138] J. Araki, M. Wada, S. Kuga, and T. Okano, "Influence of surface charge on viscosity behavior of cellulose microcrystal suspension," Journal of Wood Science, vol. 45, no. 3, pp. 258261, 1999.

[139] S. Beck-Candanedo, M. Roman, and D. G. Gray, "Effect of reaction conditions on the properties and behavior of wood cellulose nanocrystal suspensions," Biomacromolecules, vol. 6, no. 2, pp. 1048-1054, 2005.

[140] M. A. S. A. Samir, F. Alloin, and A. Dufresne, "Review of recent research into cellulosic whiskers, their properties and their application in nanocomposite field," Biomacromolecules, vol. 6, no. 2, pp. 612-626, 2005.

[141] A. Dufresne, "Comparing the mechanical properties of high performances polymer nanocomposites from biological sources," Journal of Nanoscience and Nanotechnology, vol. 6, no. 2, pp. 322-330, 2006.

[142] A. Dufresne, "Polysaccharide nanocrystals reinforced nanocomposites," Canadian Journal of Chemistry, vol. 86, pp. 484-494, 2008.

[143] M. A. Hubbe, O. J. Rojas, L. A. Lucia, and M. Sain, "Cellulosic nanocomposites: a review," Bioresources, vol. 3, pp. 929-980, 2008.

[144] A. Šturcova, G. R. Davies, and S. J. Eichhorn, "Elastic modulus and stress-transfer properties of tunicate cellulose whiskers," Biomacromolecules, vol. 6, no. 2, pp. 1055-1061, 2005.
[145] Liu Dagang, Zhong Tuhua, R. Chang Peter, Li Kaifu, and Wu Qinglin, "Starch composites reinforced by bamboo cellulosic crystals," Bioresource Technology, vol. 101, no. 7, pp. 25292536, 2010.

[146] M. N. Anglès and A. Dufresne, "Plasticized starch/tunicin whiskers nanocomposite materials. 2. Mechanical behavior," Macromolecules, vol. 34, no. 9, pp. 2921-2931, 2001.

[147] A. P. Mathew and A. Dufresne, "Morphological investigation of nanocomposites from sorbitol plasticized starch and tunicin whiskers," Biomacromolecules, vol. 3, no. 3, pp. 609617, 2002.

[148] W. J. Orts, J. Shey, S. H. Imam, G. M. Glenn, M. E. Guttman, and J. F. Revol, "Application of cellulose microfibrils in polymer nanocomposites," Journal of Polymers and the Environment, vol. 13, no. 4, pp. 301-306, 2005.

[149] A. P. Mathew, W. Thielemans, and A. Dufresne, "Mechanical properties of nanocomposites from sorbitol plasticized starch and tunicin whiskers," Journal of Applied Polymer Science, vol. 109, no. 6, pp. 4065-4074, 2008.

[150] A. J. Svagan, M. S. Hedenqvist, and L. Berglund, "Reduced water vapour sorption in cellulose nanocomposites with starch matrix," Composites Science and Technology, vol. 69, no. 3-4, Article ID 10.1016/j.compscitech.2008.11.016, pp. 500-506, 2009.

[151] Y. Noishiki, Y. Nishiyama, M. Wada, S. Kuga, and J. Magoshi, "Mechanical properties of silk fibroin-microcrystalline cellulose composite films," Journal of Applied Polymer Science, vol. 86, no. 13, pp. 3425-3429, 2002.

[152] M. A. S. A. Samir, F. Alloin, J. Y. Sanchez, and A. Dufresne, "Cellulose nanocrystals reinforced poly(oxyethylene)," Polymer, vol. 45, no. 12, pp. 4149-4157, 2004.

[153] M. A. S. A. Samir, F. Alloin, W. Gorecki, J. Y. Sanchez, and A. Dufresne, "Nanocomposite polymer electrolytes based on poly(oxyethylene) and cellulose nanocrystals," The Journal of Physical Chemistry B, vol. 108, no. 30, pp. 10845-10852, 2004.

[154] M. A. S. A. Samir, A. M. Mateos, F. Alloin, J. Y. Sanchez, and A. Dufresne, "Plasticized nanocomposite polymer electrolytes based on poly(oxyethylene) and cellulose whiskers," Electrochimica Acta, vol. 49, no. 26, pp. 4667-4677, 2004.

[155] M. A. S. A. Samir, L. Chazeau, F. Alloin, J. Y. Cavaillé, A. Dufresne, and J. Y. Sanchez, "POE-based nanocomposite polymer electrolytes reinforced with cellulose whiskers," Electrochimica Acta, vol. 50, no. 19, pp. 3897-3903, 2005.

[156] M. A. S. A. Samir, F. Alloin, and A. Dufresne, "High performance nanocomposite polymer electrolytes," Composite Interfaces, vol. 13, no. 4-6, pp. 545-559, 2006.

[157] T. Zimmermann, E. Pöhler, and T. Geiger, "Cellulose fibrils for polymer reinforcement," Advanced Engineering Materials, vol. 6, no. 9, pp. 754-761, 2004.

[158] T. Zimmermann, E. Pöhler, and P. Schwaller, "Mechanical and morphological properties of cellulose fibril reinforced nanocomposites," Advanced Engineering Materials, vol. 7, no. 12, pp. 1156-1161, 2005.

[159] M. Roohani, Y. Habibi, N. M. Belgacem, G. Ebrahim, A. N. Karimi, and A. Dufresne, "Cellulose whiskers reinforced polyvinyl alcohol copolymers nanocomposites," European Polymer Journal, vol. 44, no. 8, pp. 2489-2498, 2008.

[160] S. A. Paralikar, J. Simonsen, and J. Lombardi, "Poly(vinyl alcohol)/cellulose nanocrystal barrier membranes," Journal of Membrane Science, vol. 320, no. 1-2, pp. 248-258, 2008.

[161] J. Lu, T. Wang, and L. T. Drzal, "Preparation and properties of microfibrillated cellulose polyvinyl alcohol composite materials," Composites Part A, vol. 39, no. 5, pp. 738-746, 2008. 
[162] Y. Choi and J. Simonsen, "Cellulose nanocrystal-filled carboxymethyl cellulose nanocomposites," Journal of Nanoscience and Nanotechnology, vol. 6, no. 3, pp. 633-639, 2006.

[163] Y. Wang, X. Cao, and L. Zhang, "Effects of cellulose whiskers on properties of soy protein thermoplastics," Macromolecular Bioscience, vol. 6, no. 7, pp. 524-531, 2006.

[164] A. Dufresne, J. Y. Cavaillé, and W. Helbert, “Thermoplastic nanocomposites filled with wheat straw cellulose whiskers. Part II: effect of processing and modeling," Polymer Composites, vol. 18, no. 2, pp. 198-210, 1997.

[165] D. Dubief, E. Samain, and A. Dufresne, "Polysaccharide microcrystals keinforced amorphous poly(/3-hydroxyoctanoate) nanocomposite materials," Macromolecules, vol. 32, no. 18, pp. 5765-5771, 1999.

[166] A. Dufresne, M. B. Kellerhals, and B. Witholt, "Transcrystallization in Mcl-PHAs/cellulose whiskers composites," Macromolecules, vol. 32, no. 22, pp. 7396-7401, 1999.

[167] A. Dufresne, "Dynamic mechanical analysis of the interphase in bacterial polyester/cellulose whiskers natural composites," Composite Interfaces, vol. 7, no. 1, pp. 53-67, 2000.

[168] L. Chazeau, J. Y. Cavaillé, G. Canova, R. Dendievel, and B. Boutherin, "Viscoelastic properties of plasticized PVC reinforced with cellulose whiskers," Journal of Applied Polymer Science, vol. 71, no. 11, pp. 1797-1808, 1999.

[169] L. Chazeau, J. Y. Cavaillé, and P. Terech, "Mechanical behaviour above $\mathrm{T}(\mathrm{g})$ of a plasticised PVC reinforced with cellulose whiskers; a SANS structural study," Polymer, vol. 40, no. 19 , pp. 5333-5344, 1999.

[170] L. Chazeau, M. Paillet, and J. Y. Cavaillé, "Plasticized PVC reinforced with cellulose whiskers. I. Linear viscoelastic behavior analyzed through the quasi-point defect theory," Journal of Polymer Science Part B, vol. 37, no. 16, pp. 21512164, 1999.

[171] L. Chazeau, J. Y. Cavaillé, and J. Perez, "Plasticized PVC reinforced with cellulose whiskers. II. Plastic behavior," Journal of Polymer Science Part B, vol. 38, no. 3, pp. 383-392, 2000.

[172] M. M. Ruiz, J. Y. Cavaillé, A. Dufresne, C. Graillat, and J. F. Gérard, "New waterborne epoxy coatings based on cellulose nanofillers," Macromolecular Symposia, vol. 169, pp. 211-222, 2001.

[173] A. Bendahou, H. Kaddami, and A. Dufresne, "Investigation on the effect of cellulosic nanoparticles' morphology on the properties of natural rubber based nanocomposites," European Polymer Journal, vol. 46, no. 4, pp. 609-620, 2010.

[174] M. F. Rosa, E. S. Medeiros, J. A. Malmonge et al., "Nanocomposites based on natural rubber and cellulose nanocrystals from coconut fibers," in Proceedings of the 11th International Conference on Advanced Materials (ICAM '09), Rio de Janeiro, Brazil, September 2009.

[175] K. Oksman, A. P. Mathew, D. Bondeson, and I. Kvien, "Manufacturing process of cellulose whiskers/polylactic acid nanocomposites," Composites Science and Technology, vol. 66, no. 15 , pp. 2776-2784, 2006.

[176] D. Bondeson and K. Oksman, "Polylactic acid/cellulose whisker nanocomposites modified by polyvinyl alcohol," Composites Part A, vol. 38, no. 12, pp. 2486-2492, 2007.

[177] A. J. de Menezes, G. Siqueira, A. A. S. Curvelo, and A. Dufresne, "Extrusion and characterization of functionalized cellulose whiskers reinforced polyethylene nanocomposites," Polymer, vol. 50, no. 19, pp. 4552-4563, 2009.

[178] A. L. Goffin, J. M. Raquez, E. Duquesne, Y. Habibi, A. Dufresne, and P. Dubois, "Poly( $\varepsilon$-caprolactone) based nanocomposites reinforced by surface-grafted cellulose nano- whiskers via extrusion processing: morphology, rheology, and thermo-mechanical properties," Polymer, vol. 52, no. 7, Article ID 10.1016/j.polymer.2011.02.004, pp. 1532-1538, 2011.

[179] L. Lemahieu, L. Bras, P. Tiquet, S. Augier, and A. Dufresne, "Extrusion of nanocellulose-reinforced nanocomposites using the dispersed nano-objects protective encapsulation (DOPE) process ," Macromolecular Materials and Engineerinjournal name. In press.

[180] G. Chauve, L. Heux, R. Arouini, and K. Mazeau, "Cellulose poly(ethylene-co-vinyl acetate) nanocomposites studied by molecular modelling and mechanical spectroscopy," Biomacromolecules, vol. 6, no. 4, pp. 2025-2031, 2005.

[181] N. Ljungberg, C. Bonini, F. Bortolussi, C. Boisson, L. Heux, and J. Y. Cavaillé, "New nanocomposite materials reinforced with cellulose whiskers in atactic polypropylene: Effect of surface and dispersion characteristics," Biomacromolecules, vol. 6, no. 5, pp. 2732-2739, 2005.

[182] R. N. Rowell, "A new generationof composite materials from agro-based fibers," in Polymers and Other Advanced Materials: Emerging Technologies and Business Opportunity, P. N. Prasas, M. E. James, and T. F. Joo, Eds., pp. 66-69, Plenum Press, New York, NY, USA, 1995.

[183] R. N. Rowell, "A new generation of composite materials from agro-based fibers," in Proceedings of the Third International Conference on Frontiers of Polymers and Advanced Materials, Kuala Lumpur, Malaysia, January 1995.

[184] M. A. Dweib, B. Hu, H. W. Shenton, and R. P. Wool, "Bio-based composite roof structure: manufacturing and processing issues," Composite Structures, vol. 74, no. 4, pp. 379-388, 2006.

[185] V. M. H. Govindarao, "Utilization of rice husk-a preliminary analysis," Journal of Scientific \& Industrial Research, vol. 39, no. 9, pp. 495-515, 1980.

[186] R. Burgueño, M. J. Quagliata, G. M. Mehta, A. K. Mohanty, M. Misra, and L. T. Drzal, "Sustainable cellular biocomposites from natural fibers and unsaturated polyester resin for housing panel applications," Journal of Polymers and the Environment, vol. 13, no. 2, pp. 139-149, 2005.

[187] R. M. Brown, "Microbial Cellulose: a new resource for wood, paper, textiles, food and specialty products," Position Paper, 1998, http://www.botany.utexas.edu/facstaff/facpages/mbrown/position1.htm.

[188] R. Jonas and L. F. Farah, "Production and application of microbial cellulose," Polymer Degradation and Stability, vol. 59, no. 1-3, pp. 101-106, 1998.

[189] J. Shah and R. M. Brown Jr., "Towards electronic paper displays made from microbial cellulose," Applied Microbiology and Biotechnology, vol. 66, no. 4, pp. 352-355, 2005.

[190] H. Yano, J. Sugiyama, A. N. Nakagaito et al., "Optically transparent composites reinforced with networks of bacterial nanofibers," Advanced Materials, vol. 17, no. 2, pp. 153-155, 2005.

[191] C. Legnani, H. S. Barud, W. G. Quirino et al., "Transparent nanocomposite bacterial cellulose used as flexible substrate for OLED," in Proceedings of the 11th International Conference on Advanced Materials, Rio de Janeiro, Brazil, September 2009.

[192] B. R. Evans, H. M. O’Neill, V. P. Malyvanh, I. Lee, and J. Woodward, "Palladium-bacterial cellulose membranes for fuel cells," Biosensors and Bioelectronics, vol. 18, no. 7, pp. 917-923, 2003.

[193] D. G. Olson, S. A. Tripathi, R. J. Giannone et al., "Deletion of the Cel48S cellulase from Clostridium thermocellum," 
Proceedings of the National Academy of Sciences of the United States of America, vol. 107, no. 41, pp. 17727-17732, 2010.

[194] D. A. A. Alderman, "A review of cellulose ethers in hydrophilic matrices for oral controlled-release dosage forms," International Journal of Pharmaceutical Technology and Product Manufacture, vol. 5, no. 3, pp. 1-9, 1984.

[195] J. Heller, "Use of polymers in controlled release of active agents in controlled drug delivery," in Fundamentals and Applications, J. R. Robinson and V. H. L. Lee, Eds., pp. 210180, Marcel Dekker, New York, NY, USA, 2nd edition, 1987.

[196] M. A. Longer and J. R. Robinson, "Sustained-release drug delivery systems," in Remington's Pharmaceutical Sciences, J. P. Remington, Ed., pp. 1676-1693, Mack Publishing, Easton, $\mathrm{Pa}, \mathrm{USA}, 18$ th edition, 1990.

[197] M. D. Baumann, C. E. Kang, J. C. Stanwick et al., "An injectable drug delivery platform for sustained combination therapy," Journal of Controlled Release, vol. 138, no. 3, pp. 205-213, 2009.

[198] Y. Watanabe, B. Mukai, K. I. Kawamura et al., "Preparation and evaluation of press-coated aminophylline tablet using crystalline cellulose and polyethylene glycol in the outer shell for timed-release dosage forms," Yakugaku Zasshi, vol. 122, no. 2, pp. 157-162, 2002.

[199] S. Shaikh, A. Birdi, S. Qutubuddin, E. Lakatosh, and H. Baskaran, "Controlled release in transdermal pressure sensitive adhesives using organosilicate nanocomposites," Annals of Biomedical Engineering, vol. 35, no. 12, pp. 2130-2137, 2007.

[200] H. Lönnberg, L. Fogelström, M. A. S. A. Samir, L. Berglund, E. Malmström, and A. Hult, "Surface grafting of microfibrillated cellulose with poly( $\varepsilon$-caprolactone $)$ - synthesis and characterization," European Polymer Journal, vol. 44, no. 9, pp. 2991-2997, 2008.

[201] J. D. Fontana, A. M. de Souza, C. K. Fontana et al., "Acetobacter cellulose pellicle as a temporary skin substitute," Applied Biochemistry and Biotechnology, vol. 24-25, pp. 253264, 1990.

[202] L. R. Mello, Y. Feltrin, R. Selbach, G. Macedo Jr., C. Spautz, and L. J. Haas, "Use of lyophilized cellulose in peripheral nerve lesions with loss of substance," Arquivos de NeuroPsiquiatria, vol. 59, no. 2, pp. 372-379, 2001.

[203] W. K. Czaja, D. J. Young, M. Kawecki, and R. M. Brown Jr., "The future prospects of microbial cellulose in biomedical applications," Biomacromolecules, vol. 8, no. 1, pp. 1-12, 2007.

[204] S. W. Negrão, R. R. L. Bueno, E. E. Guérios et al., "A Eficácia do stent recoberto com celulose biossintética comparado ao stent convencional em angioplastia em coelhos," Revista Brasileira de Cardiologia Invasiva, vol. 14, no. 1, pp. 10-19, 2006.

[205] D. Klemm, D. Schumann, U. Udhardt, and S. Marsch, "Bacterial synthesized cellulose-artificial blood vessels for microsurgery," Progress in Polymer Science, vol. 26, no. 9, pp. 1561-1603, 2001.

[206] M. A. Croce, C. Silvestri, D. Guerra et al., "Adhesion and proliferation of human dermal fibroblasts on collagen matrix," Journal of Biomaterials Applications, vol. 18, no. 3, pp. 209-222, 2004.

[207] S. V. Madihally and H. W. T. Matthew, "Porous chitosan scaffolds for tissue engineering," Biomaterials, vol. 20, no. 12, pp. 1133-1142, 1999.

[208] S. Nehrer, H. A. Breinan, A. Ramappa et al., "Canine chondrocytes seeded in type I and type II collagen implants inves- tigated in vitro," Journal of Biomedical Materials Research, vol. 38, no. 2, pp. 95-104, 1997.

[209] T. V. Kumari, U. Vasudev, A. Kumar, and B. Menon, "Cell surface interactions in the study of biocompatibility," Trends in Biomaterials and Artificial Organs, vol. 15, no. 2, pp. 37-41, 2001.

[210] Y. Ikada, "Challenges in tissue engineering," Journal of the Royal Society Interface, vol. 3, no. 10, pp. 589-601, 2006.

[211] G. Q. Chen and Q. Wu, "The application of polyhydroxyalkanoates as tissue engineering materials," Biomaterials, vol. 26, no. 33, pp. 6565-6578, 2005.

[212] K. Anselme, "Osteoblast adhesion on biomaterials," Biomaterials, vol. 21, no. 7, pp. 667-681, 2000.

[213] H. S. Barud, "Development and evaluation of Biocure obtained from bacterial cellulose and standardized extract of propolis (EPP-AF) for the treatment of burns and / or skin lesions," São Paulo Research Foundation-FAPESP, Brazil, 2009.

[214] W. Czaja, A. Krystynowicz, S. Bielecki, and R. M. Brown Jr., "Microbial cellulose - the natural power to heal wounds," Biomaterials, vol. 27, no. 2, pp. 145-151, 2006.

[215] L. E. Millon and W. K. Wan, "The polyvinyl alcohol-bacterial cellulose system as a new nanocomposite for biomedical applications," Journal of Biomedical Materials Research Part $B$, vol. 79, no. 2, pp. 245-253, 2006.

[216] Z. Cai and J. Kim, "Bacterial cellulose/poly(ethylene glycol) composite: characterization and first evaluation of biocompatibility," Cellulose, vol. 17, no. 1, pp. 83-91, 2010.

[217] A. Seves, G. Testa, A. M. Bonfatti, E. D. Paglia, E. Selli, and B. Marcandalli, "Characterization of native cellulose/poly(ethylene glycol) films," Macromolecular Materials and Engineering, vol. 286, no. 9, pp. 524-528, 2001.

[218] Y. Z. Wan, L. Hong, S. R. Jia et al., "Synthesis and characterization of hydroxyapatite-bacterial cellulose nanocomposites," Composites Science and Technology, vol. 66, no. 11-12, pp. 1825-1832, 2006.

[219] K. Yasuda, J. P. Gong, Y. Katsuyama et al., "Biomechanical properties of high-toughness double network hydrogels," Biomaterials, vol. 26, no. 21, pp. 4468-4475, 2005.

[220] S. B. Lin, C. P. Hsu, L. C. Chen, and H. H. Chen, "Adding enzymatically modified gelatin to enhance the rehydration abilities and mechanical properties of bacterial cellulose," Food Hydrocolloids, vol. 23, no. 8, pp. 2195-2203, 2009.

[221] J. Huia, J. Yuanyuan, W. Jiao, H. Yuan, Z. Yuan, and J. Shiru, "Potentiality of bacterial cellulose as the scaffold of tissue engineering of cornea," in Proceedings of the 2nd International Conference on Biomedical Engineering and Informatics, (BMEI '09), China, October 2009.

[222] D. A. Schumann, J. Wippermann, D. O. Klemm et al., "Artificial vascular implants from bacterial cellulose: preliminary results of small arterial substitutes," Cellulose, vol. 16, no. 5, pp. 877-885, 2009.

[223] W. L. Amorim, H. O. Costa, F. C. Souza, M. G. Castro, and L. Silva, "Experimental study of the tissue reaction caused by the presence of cellulose produced," Brazilian Journal of Otorhinolaryngology, vol. 75, no. 2, pp. 200-207, 2009.

[224] J. Hart, D. Silcock, S. Gunnigle, B. Cullen, N. D. Light, and P. W. Watt, "The role of oxidised regenerated cellulose/collagen in wound repair: effects in vitro on fibroblast biology and in vivo in a model of compromised healing," International Journal of Biochemistry and Cell Biology, vol. 34, no. 12, pp. 1557-1570, 2002.

[225] G. Helenius, H. Backdahl, A. Bodin, U. Nannmark, P. Gatenholm, and B. Risberg, "In vivo biocompatibility of 
bacterial cellulose," Journal of Biomedical Materials Research Part A, vol. 76, no. 2, pp. 431-438, 2006.

[226] E. C. Silva, Hidroxiapatita Sintética em alvéolo dentário após exodontia em Felis catus: estudo clínico, radiológico e histomorfométrico, M.S. Dissertation, Universidade Federal de Viçosa, Viçosa, Brazil, 2009.

[227] H. O. Costa and F. C. de Souza, "Evaluation of the tissue regeneration of the burned pigś skin followed by Biotissue ${ }^{T M}$ grafting," Acta ORL/Técnicas em Otorrinolaringologia, vol. 23, no. 4, pp. 192-196, 2005.

[228] A. P. Nemetz, D. R. R. Loures, J. C. U. Coelho et al., "Efeito estrutural da utilização de celulose biossintética e politetrafluoroetileno expandido como substitutos do peritônio em cães," Arquivos Brasileiros De Cirugia Digestiva, vol. 14, no. 2, pp. 139-142, 2001.

[229] A. B. Novaes Jr. and A. B. Novaes, "Soft tissue management for primary closure in guided bone regeneration: sugical technique and case report," The International Journal of Oral and Maxillofacial Implants, vol. 12, no. 1, pp. 84-87, 1997.

[230] A. B. Novaes Jr. and A. B. Novaes, "IMZ implants placed into extraction sockets in association with membrane therapy (Gengiflex) and porous hydroxyapatite: a case report," The International Journal of Oral and Maxillofacial Implants, vol. 7, no. 4, pp. 536-540, 1992.

[231] L. A. Salata, G. T. Craig, and I. M. Brook, "In vivo evaluation of a new memnbrane (Gengiflex) for guided bone regeneratien (GBR)," Journal of Dental Research, vol. 74, no. 3, p. 825, 1995.

[232] C. Dahlin, A. Linde, J. Gottlow, and S. Nyman, "Healing of bone defects by guided tissue regeneration," Plastic and Reconstructive Surgery, vol. 81, no. 5, pp. 672-676, 1988.

[233] N. L. Macedo, F. S. Matuda, L. G. S. Macedo, A. S. F. Monteiro, M. C. Valera, and Y. R. Carvalho, "Evaluation of two membranes in guided bone tissue regeneration: histological study in rabbits," Brazilian Journal of Oral Sciences, vol. 3, no. 8, pp. 395-400, 2004. 

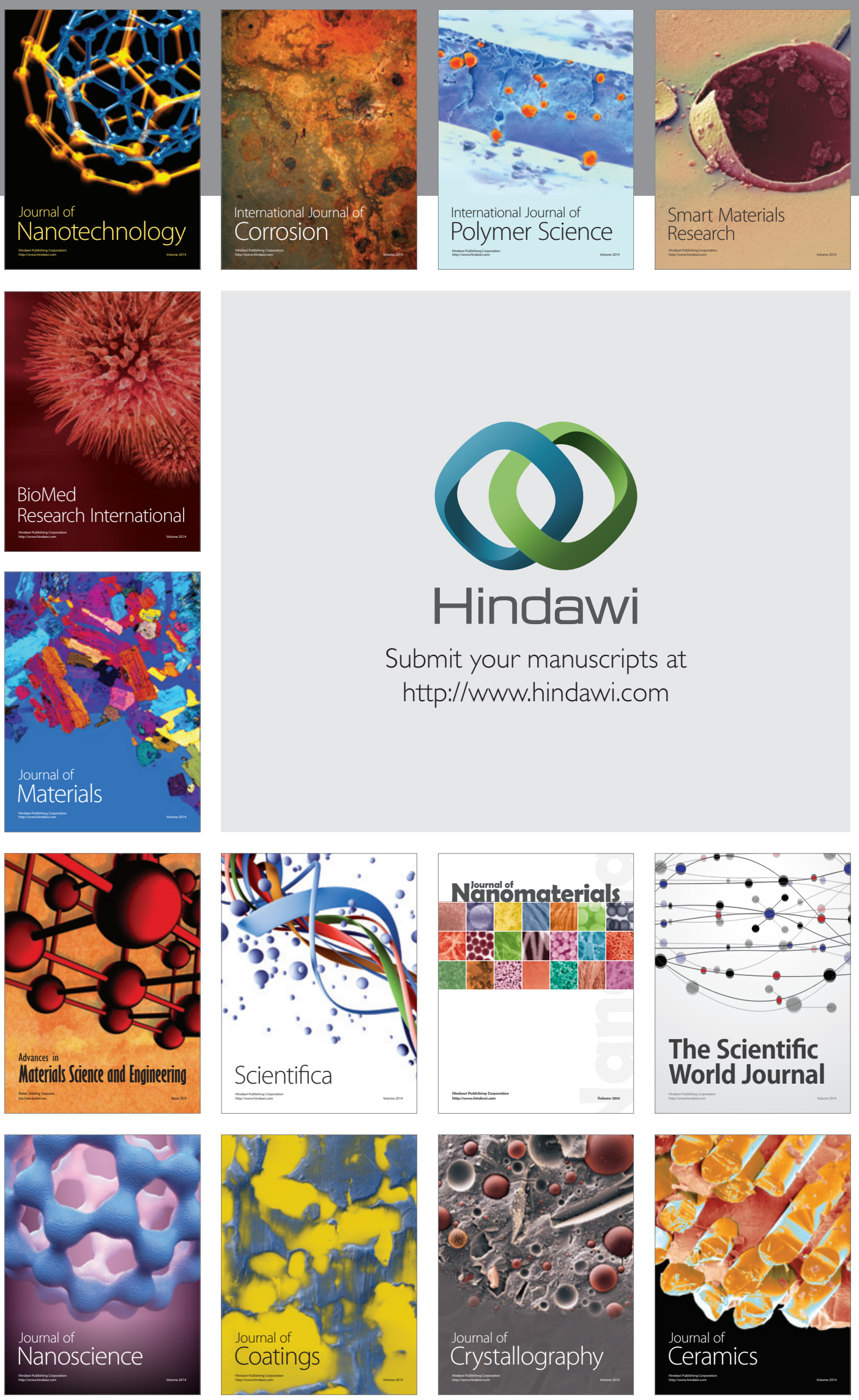

The Scientific World Journal

Submit your manuscripts at

http://www.hindawi.com

\section{World Journal}

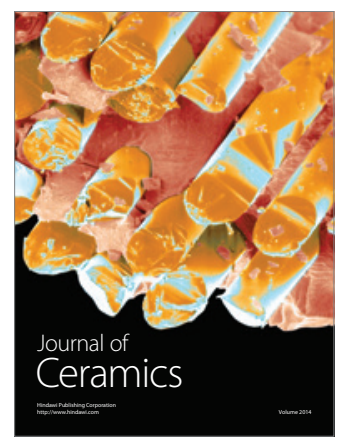

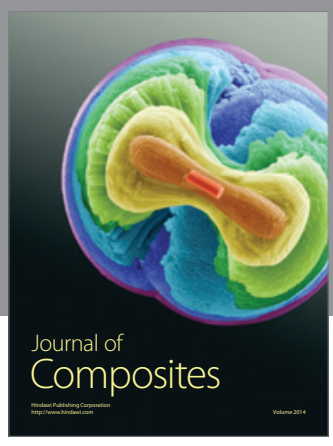
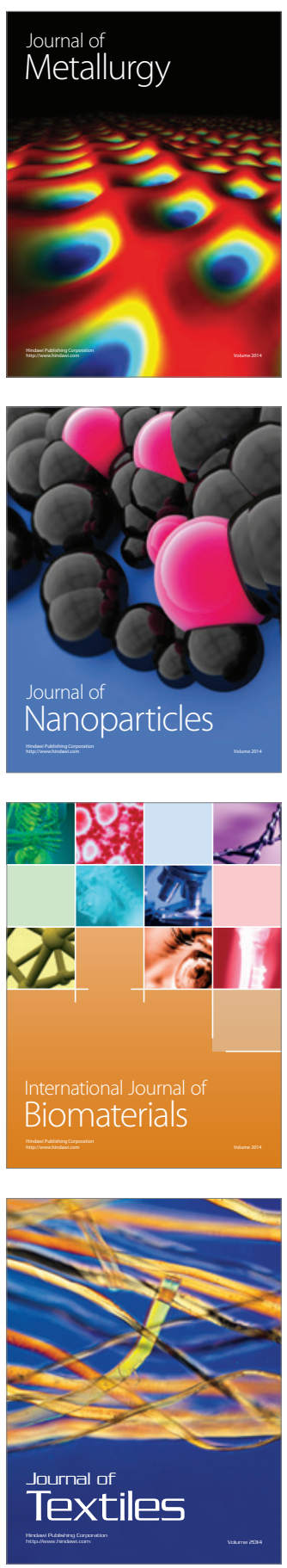